\title{
Gut
}

\section{Deciphering the complex interplay between pancreatic cancer, diabetes mellitus subtypes, and obesity/BMI through causal inference and mediation analyses}

\begin{tabular}{|c|c|}
\hline Journal: & Gut \\
\hline Manuscript ID & Draft \\
\hline Article Type: & Original Article \\
\hline $\begin{array}{r}\text { Date Submitted by the } \\
\text { Author: }\end{array}$ & $\mathrm{n} / \mathrm{a}$ \\
\hline Complete List of Authors: & $\begin{array}{l}\text { Molina-Montes, Esther; Spanish National Cancer Research Centre, } \\
\text { Genetic and Molecular Epidemiology; CIBERONC } \\
\text { Coscia, Claudia; Spanish National Cancer Research Centre, Genetic and } \\
\text { Molecular Epidemiology; CIBERONC } \\
\text { Gomez-Rubio, Paulina; Spanish National Cancer Research Centre } \\
\text { (CNIO), Genetic and Molecular Epidemiology; CIBERONC } \\
\text { Fernández, Alba; Spanish National Cancer Research Centre, Genetic and } \\
\text { Molecular Epidemiology } \\
\text { Boenink, Rianne; Spanish National Cancer Research Centre, Genetic and } \\
\text { Molecular Epidemiology } \\
\text { Rava, Marta; Spanish National Cancer Research Centre, Genetic and } \\
\text { Molecular Epidemiology } \\
\text { Márquez, Mirari; Spanish National Cancer Research Centre; CIBERONC } \\
\text { Molero, Xavier; Hospital Universitari Vall d'Hebron, Institut de Recerca } \\
\text { (VHIR), ; Universitat Autònoma de Barcelona, CIBEREHD, } \\
\text { L९hr, Matthias; Karolinska Institutet and University Hospital, } \\
\text { Gastrocentrum } \\
\text { Sharp, Linda; National Cancer Registry Ireland; University College Cork } \\
\text { Michalski, Christoph; TU Munich, Surgery; Martin-Luther-Universitat } \\
\text { Halle-Wittenberg, Department of Visceral, Vascular and Endocrine } \\
\text { Surgery } \\
\text { Farre, Antoni; Hospital de la Santa Creu i Sant Pau, Gastroenterology } \\
\text { and Clinical Biochemistry } \\
\text { Perea, Jose; Hospital 12 de Octubre, Surgery; Research Institute } \\
\text { Fundación Jiménez Díaz, Surgery } \\
\text { O'Rorke, Michael; Queen's University Belfast, Centre for Public Health; } \\
\text { University of Iowa, College of Public Health } \\
\text { Greenhalf, William; Liverpool Cancer Research-UK Centre, University of } \\
\text { Liverpool, Department of Molecular and Clinical Cancer Medicine } \\
\text { Iglesias, Mar; Hospital del Mar, Parc de Salut Mar; CIBERONC } \\
\text { Tardón, Adonina; Instituto Universitario de Oncología del Principado de } \\
\text { Asturias,; IBER Epidemiología y Salud Pública (CIBERESP), } \\
\text { Gress, Thomas; University of Marburg, Gastroenterology } \\
\text { Barberá, Victor M; University General Hospital of Elche, Molecular } \\
\text { Genetics Laboratory } \\
\text { Crnogorac-Jurcevic, Tatjana; Barts Cancer Institute, } \\
\text { Muñoz-Bellvís, Luis; Hospital Universitario de Salamanca, Surgery } \\
\text { Dominguez-Munoz, J.Enrique; University Hospital of Santiago de }\end{array}$ \\
\hline
\end{tabular}




\begin{tabular}{|c|l|}
\hline Compostela, Spain, Gastroenterology \\
Renz, Harald; Phillips University of Marburg, Institute of Laboratory \\
Medicine and Pathobiochemistry \\
Balcells, Joaquim; Exocrine Pancreas Research Unit, Hospital Universitari \\
Vall d'Hebron, Institut de Recerca (VHIR), ; Universitat Autònoma de \\
Barcelona, CIBEREHD, \\
Costello, Eithne; University of Liverpool, Molecular and Clinical Cancer \\
Medicine \\
Ilzarbe, Lucas; Hospital del Mar - Parc de Salut Mar, Department of \\
Gastroenterology \\
Kleeff, Joerg; Martin-Luther-Universitat Halle-Wittenberg, Department of \\
Visceral, Vascular and Endocrine Surgery; Technical University of \\
Munich, Surgery \\
Kong, Bo; TU Munich, Surgery \\
Mora, Josefina; Hospital de la Santa Creu i Sant Pau, Department of \\
Gastroenterology and Clinical Biochemistry \\
O'Driscoll, Damian; HRB Clinical Research Facility at University College \\
Cork, Clinical Research Facility; National Cancer Registry Ireland \\
Poves, Ignasi; Hospital del Mar - Parc de Salut Mar, \\
SCARPA, ALDO; UNIVERSITY OF VERONA, ARC-Net Research Centre and \\
Department of Diagnostics and Public Health-Section of Pathology \\
Yu, Jingru; Karolinska Institutet and University Hospital, Medical \\
Epidemiology and Biostatistics \\
Hidalgo, Manuel; Beth Israel Deaconess Medical Center, Medical \\
Oncology; Hospital Universitario Madrid Sanchinarro \\
Lawlor, Rita; ARC-Net, Applied Research on Cancer Centre,, Department \\
of Pathology and Diagnostics, University of Verona \\
Ye, Weimin; Karolinska Institutet, Medical Epidemiology and Biostatistics \\
Carrato, Alfredo; Hospital Ramón y Cajal, Medical Oncology; CIBERONC \\
Real, Francisco X.; Spanish National Cancer Research Centre, Epithelial \\
Carcinogenesis; CIBERONC \\
Malats, Noria; Spanish National Cancer Research Centre, \\
\hline Keywords: \\
PANCREATIC CANCER, DIABETES MELLITUS, OBESITY, CANCER \\
EPIDEMIOLOGY \\
\hline \\
\hline
\end{tabular}

\section{SCHOLARONE ${ }^{\text {m }}$ Manuscripts}


1 Title: Deciphering the complex interplay between pancreatic cancer, diabetes mellitus subtypes,

2

3

4

5

6

7

8

9

10

11

12

13

14

15

16

17

18

19

20

21

22 and obesity/BMI through causal inference and mediation analyses

Authors: $\quad$ Esther Molina-Montes (1), Claudia Coscia (1), Paulina Gómez-Rubio (1), Alba Fernández (1), Rianne Boenink (1), Marta Rava (1), Mirari Márquez (1), Xavier Molero (2), Matthias Löhr (3), Linda Sharp (4), Christoph W. Michalski (5), Antoni Farré (6), José Perea (7), Michael O’Rorke (8), William Greenhalf (9), Mar Iglesias (10), Adonina Tardón (11), Thomas Gress (12), Victor M. Barberà (13), Tatjana Crnogorac-Jurcevic(14), Luis MuñozBellvís (15), Enrique Domínguez-Muñoz (16), Harald Renz (17), Joaquim Balsells (2) , Eithne Costello (9), Lucas Ilzarbe (10), Jörg Kleeff (5), Bo Kong (18), Josefina Mora (6), Damian O'Driscoll (19), Ignasi Poves (10), Aldo Scarpa (20), Jingru Yu (21), Manuel Hidalgo (22), Rita T. Lawlor (20), Weimin Ye (21), Alfredo Carrato (23), Francisco X. Real (24), Núria Malats (1) on behalf of the PanGenEU Study Investigators (25).

\section{Authors' affiliations:}

(1) Genetic and Molecular Epidemiology Group, Spanish National Cancer Research Center (CNIO), Madrid, and CIBERONC, Spain.

(2) Hospital Universitari Vall d'Hebron, Vall d'Hebron Research Institute (VHIR), Barcelona, Universitat Autònoma de Barcelona, and CIBEREHD, Spain.

(3) Gastrocentrum, Karolinska Institutet and University Hospital, Stockholm, Sweden.

(4) National Cancer Registry Ireland and HRB Clinical Research Facility, University College Cork, Cork, Ireland; and Newcastle University, Institute of Health \& Society, Newcastle, UK.

(5) Department of Surgery, Technical University of Munich, Munich; and g, Department of Visceral, Vascular and Endocrine Surgery, Martin-Luther-University Halle-WittenberHalle (Saale), Germany.

(6) Department of Gastroenterology and Clinical Biochemistry, Hospital de la Santa Creu i Sant Pau, Barcelona, Spain. 
(7) Department of Surgery, Hospital 12 de Octubre; and Department of Surgery and Health Research Institute, Fundación Jiménez Díaz, Madrid, Spain.

(8) Centre for Public Health, Belfast, Queen's University Belfast, UK; and College of Public Health, The University of lowa, lowa City, IA, USA.

(9) Department of Molecular and Clinical Cancer Medicine, University of Liverpool, Liverpool, UK.

(10) Hospital del Mar-Parc de Salut Mar, Barcelona, and CIBERONC, Spain.

(11) Department of Medicine, Instituto Universitario de Oncología del Principado de Asturias, Oviedo, and CIBERESP, Spain.

(12) Department of Gastroenterology, University Hospital of Giessen and Marburg, Marburg, Germany.

(13) Molecular Genetics Laboratory, General University Hospital of Elche, Spain.

(14) Barts Cancer Institute, Centre for Molecular Oncology, Queen Mary University of London, London, UK.

(15) Department of Surgery, Hospital Universitario de Salamanca - IBSAL. Universidad de Salamanca and CIBERONC, Spain.

(16) Department of Gastroenterology, University Clinical Hospital of Santiago de Compostela, Spain.

(17) Institute of Laboratory Medicine and Pathobiochemistry, Philipps University of Marburg, Marburg, Germany, Member of the German Center for Lung Research (DZL) and the Universities of Giessen and Marburg Lung School (UGMLC).

(18) Department of Surgery, Technical University of Munich, Munich, Germany.

(19) National Cancer Registry Ireland and HRB Clinical Research Facility, University College Cork, Cork, Ireland.

(20) ARC-Net centre for Applied Research on Cancer and Department of Pathology and Diagnostics, University and Hospital trust of Verona, Verona, Italy.

(21) Department of Medical Epidemiology and Biostatistics, Karolinska Institutet, Stokholm, Sweden.

(22) Madrid-Norte-Sanchinarro Hospital, Madrid, Spain; and Weill Cornell Medicine, New York, USA.

(23) Department of Oncology, Ramón y Cajal University Hospital, IRYCIS, Alcala University, Madrid, and CIBERONC, Spain. 
60

61

62

63

64

65

66

67

68

69

70

71

(24) Epithelial Carcinogenesis Group, Madrid, Spanish National Cancer Research Centre (CNIO), Madrid, Universitat Pompeu Fabra, Departament de Ciències Experimentals i de la Salut, Barcelona, and CIBERONC, Spain.

(25) PanGenEU Study Investigators (Supplementary Annex).

Correspondence to: Dr. Esther Molina and Dr. Núria Malats, Genetic and Molecular Epidemiology Group, Spanish National Cancer Research Center (CNIO), C/Melchor Fernandez Almagro, 3, 28029 Madrid, Spain.

E-mail: memolina@cnio.es and nmalats@cnio.es. Phone: +34 917328000

Word count - Abstract: 248

Word count - Text (excluding references): 4,005

Number of References: 55

Number of Tables: 4

Number of Figures: 2

Number of supplementary tables: 17

Number of supplementary figures: $\mathbf{3}$ 


\section{Abstract}

73 OBJECTIVES: To characterize the association between type 2 diabetes mellitus (T2DM) subtypes (newonset-NODM or long-standing-LSDM) and pancreatic cancer (PC) risk, to explore the direction of causation through Mendelian randomization (MR) analysis, and to assess the mediation role of BMI.

DESIGN: Information about T2DM and related factors was collected from 2,018 PC cases and 1,540 controls

77 from the PanGenEU study. A subset of PC cases and controls had glycated haemoglobin (Hb1Ac), CPeptide, and genotype data. Multivariate logistic regression models were applied to derive odds ratios (ORs) and 95\% confidence intervals (Cls). T2DM and PC-related SNPs were used as instrumental variables (IV) in bidirectional MR analysis to test for two-way causal associations between PC, NODM, and LSDM. Indirect and direct effects of the BMI-T2DM-PC association were further explored using multivariable and mediation analysis.

RESULTS: T2DM was associated with an increased PC risk when compared to non-T2DM (OR=2.50, $95 \% \mathrm{Cl}: 2.05-3.05)$, the risk being greater for NODM (OR=6.39, 95\% Cl: $4.18-9.78)$ and among insulin users (OR=3.69, 95\% Cl: 2.80-4.86). The causal association between T2DM (57-SNP IV) and PC was not statistically significant. On the contrary, there was a strong causal association between PC (40-SNP IV) and NODM (OR=2.85, 95\% Cl: 2.04-3.98), although genetic pleiotropy was present. Potential mediating effects of T2DM and obesity (125 SNPs as IV) on both associations were evidenced. is the cause of NODM. The interplay between obesity and T2DM is complex.

92 Keywords: Pancreatic cancer risk; Diabetes mellitus type 2; Obesity; Case-control; Causal inference; 93 Mendelian randomization analysis. 
97

98

99

100

101

102

103

104

105

106

107

108

109

110

111

114

115

116

117

118

119

120

121

\section{SUMMARY BOX}

\section{What is already known about this subject?}

- The association between type 2 diabetes mellitus (T2DM) and risk of pancreatic cancer (PC) has been evidenced in numerous studies.

- Few studies have suggested the distinct role of T2DM subtypes, new-onset T2DM (NODM) and long-standing (LSDM), in PC aetiology; while both were associated with PC risk, they may exhibit a different causal relationship with PC.

- Uncertainties surrounding the association between T2DM and PC risk also concern confounding or mediation by obesity, T2DM medication effects, and the causal pathway linking both diseases.

\section{What are the new findings?}

- This study underlines the importance of a timely and accurate T2DM diagnosis in relation to PC cancer risk; it confirms the time-dependent association between T2DM and PC risk, and sheds new light on some of the existing knowledge gaps about the causal relationship between the two.

- Causal inference methods revealed different types of association: a non-existent causal link between LSDM and PC risk and an effect of PC on NODM, suggesting a reverse causal sequence, and possibly influenced by weight loss preceding PC.

- The interplay of obesity in the association between LSDM and PC risk is crucial according to causal pathways connecting the diseases, with LSDM likely being an intermediate step in the obesity and $\mathrm{PC}$ risk association.

\section{How might it impact on clinical practice in the foreseeable future?}

- Differences in PC risk by T2DM subtypes and mediating effects by obesity point to a complex multi-pathway mechanism underlying pancreatic carcinogenesis. These mechanisms need to be fully explored to pursue PC prevention efforts in the population. 
122

126

127

- Preventing obesity and related risk factors yield to valuable prevention interventions to reduce the burden of PC associated with LSDM.

- Recently diagnosed T2DM patients, i.e., NODM, can be a target group for routine PC screening and surveillance if early signs of PC disease (i.e., weight loss) is present. 
128

129

130

131

132

133

134

135

136

137

138

139

140

141

142

143

144

145

146

147

148

149

150

151

152

153

\section{Introduction}

Pancreatic cancer (PC) has a high case-fatality rate in Western countries,[1] expected to rise in coming years if no immediate actions are taken.[2,3] Many unknowns in PC aetiology remain even regarding some of the well-established risk factors of this disease.[4] This also applies to type 2 diabetes mellitus (T2DM), despite representing an important hallmark for PC prevention given the relatively high PC incidence among T2DM patients.[5] One possible explanation is that observational epidemiological studies are prone to confounding and reverse causality bias, which makes inference about causal factors of PC impossible. Mendelian randomization (MR) overcomes this problem by using genetic variants as instrumental variable (IV) of the risk factor to estimate its causal effect on the outcome.[6,7]

Thus, while a large number of observational studies evidenced that T2DM increases PC risk,[8-10] the actual role of T2MD in pancreas carcinogenesis remains unsolved. These earlier studies have shown that the excess risk increases within the first years since the diagnosis of T2DM, decreasing thereafter and keeping the association with PC risk in the long-term. $[9,11]$ Given this temporal relationship, it is believed that new-onset and long-standing T2DM (NODM and LSDM, respectively) could play a different role in PC aetiology.[8] In the former case, the tumour in the pancreas might induce T2DM development through tissue destruction or paracrine mechanisms. This form of diabetes has been described as pancreatogenic or type 3c.[12] The fact that up to $60-85 \%$ of newly diagnosed PC patients present T2DM or hyperglycemia,[12,13] and that T2DM frequently abates after tumour resection,[14] supports that this mechanism underpins PCrelated T2DM. In the case of LSDM, however, chronic hyperinsulinemia could trigger PC development.[15] Experimental studies support this hypothesis.[16,17]

Common risk factors such as obesity could explain the association between LSDM and PC risk, but this has not yet been fully explored. Similarly, a common genetic susceptibility between both diseases also needs to be established.[18] Use of antidiabetic medication is another relevant aspect in the association between T2DM and PC risk. Insulin-users, relative to non-users, have a higher PC risk,[11] whereas PC risk lowers among metformin-users. $[11,19]$ It remains to be determined whether this association differs between NODM and LSDM. 
154 While a MR study on the association between T2DM and PC has been published, it only partially addressed

155 the questions posed above.[20] Even though this study supported that T2DM and PC are not causally linked,

156 it did not assess such a relation according to T2DM subgroups.[20] Interestingly, obesity was found to be a

157 causal factor of PC in this study, but whether obesity interacts with T2DM or mediates the association

158 between T2DM and PC risk was also not accounted for.[20] Therefore, whether NODM or LSDM, or both,

159 promote the development of PC, with or without the interplay of obesity, continues to be uncertain. In fact,

160 there have been few attempts to characterize both T2DM subtypes in PC pathogenesis given the likely

161 under-ascertainment of NODM at PC diagnosis.[13] Studies reliably profiling characteristics of both T2DM

162 subtypes are still missing.

163 The aim of this study was to explore the association between LSDM and NODM and PC risk, based on self-

164 reported data and biomarker measures. To disentangle the causal link behind these associations, we 165 explored through MR the unbiased effect of T2DM-related genetic variants as IV on PC risk and, vice versa, 166 the effect of PC-related genetic variants as IV on T2DM risk. Potential mediating and modifying effects 167 between T2DM and BMI on the associations were also explored.

Methods

170 Study Population: PanGenEU study information is provided in Supplementary Methods and in previous 171 publications.[21] This study was conducted with ethical approvals of all the participating centres and the 172 subject's written consent to participate.

173 Data collection: Information about study protocols to collect data on PC risk factors is provided in 174 Supplementary Methods. Nearly all PC cases and controls provided biological samples, among them blood, 175 at enrolment.

176 Assessment of diabetes status: Participants who responded affirmatively to the question "has a doctor ever 177 told you to have diabetes or elevated glucose levels" were regarded as having diabetes. They were asked 178 further about the age at which they were first informed they had diabetes and about the use of antidiabetic 179 medication: oral medication, insulin, or no-medication but diet. This information was used to derive variables 
180 on diabetes status by time since diagnosis of T2DM ( $\leq 2$ years, and $>2$ years since diagnosis to distinguish

181 between NODM and LSDM, respectively), age at diagnosis ( $<55,55-65$, and $\geq 65$ years) and by use of 182 medication (use of oral medication, insulin, diet). T2DM biomarkers, glycated haemoglobin ( $\mathrm{Hb} 1 \mathrm{Ac}$ ) and C183 peptide, were determined in 509 PC cases and 413 controls with available non-fasting erythrocyte and 184 serum samples as described in Supplementary Methods. These data allowed to refine the assessment of diabetes status.

186 SNP selection and genotyping: Details on the genotyping of the DNA samples in the PanGenEU study are 187 provided in Supplementary Methods. A GWAS database review in the GWAS catalog [22] was performed 188 to identify SNPs associated with T2DM in at least two independent GWAS studies and with a p-value of $\leq 5 \times 10-5$. SNPs with a minor allele frequency (MAF) $\geq 0.05$ in our study population were selected. In addition, SNPs of previous T2DM-PC association studies were also included.[23-25] A total of 57 T2DM-related

191 SNPs were considered. Using the same approach, we selected 40 PC-related SNPs and 125 obesity-related 192 SNPs for the analyses (Supplementary Table 1).

Statistical analysis for the observational association study: There were 2,018 PC cases and 1,540 controls available for assessing the observational association between T2DM and PC risk (Supplementary Figure 1A). Missing data were imputed as described in Supplementary Methods, whereby a high imputation yield was reached (Supplementary Table 2). Multivariate unconditional logistic regression was applied to evaluate

197 the association between T2DM and PC risk by Odds Ratios (ORs) and 95\% Confidence Intervals (Cl). 198 Models were adjusted for age, sex and country (Model 1), and subsequently for smoking and body mass 199 index (BMI) 2 years before recruitment (Model 2). Effect modification was evaluated by adding interaction 200 terms in the models and comparing them with models lacking this interaction via the likelihood ratio test 201 (LRT). Effect measure modification was further evaluated in stratified analyses by strata of these variables. 202 Dose-response and trend analysis was conducted by fitting a T2DM ordinal score in the logistic models. The 203 dose-response curve was evaluated by applying restricted cubic splines.[26] Interaction by centre but not 204 by country was apparent; therefore, random centre effects in mixed models when appropriate were 205 applied.[27] Further details are provided in Supplementary Methods. 
206 Mediation analysis: As outlined in Supplementary Methods, the counterfactual mediation model for binary

207 mediators and outcomes was used to explore mediation by estimating the natural indirect and direct effect 208 of the associations (NIE and NDE, respectively).[28] We explored whether obesity leading to T2DM, and 209 subsequently to PC, could explain the observational association between T2DM and PC. Similarly, potential 210 mediating effects of body fat measures on the association between T2DM and PC risk were explored.

211 Mendelian Randomisation Analysis (MR): The causal effect of T2DM subtypes on PC (Supplementary 212 Figure 1 B) was estimated using several MR tests (Wald ratio, 2-stage least squares -TSLS, inverse 213 variance weighted method-IVW, and simple median),[29,30] adjusting estimates for potential confounders. 214 Supplementary Methods detail how the genetic IV for T2DM was built. In addition, the weighted median 215 estimation and the MR-Egger approach were applied to detect and correct bias due to pleiotropy.[29,31,32] 216 Bidirectional MR: The same procedure was used to explore the causal effect of PC on T2DM 217 (Supplementary Figure $1 \mathrm{C}$ ). We kept 33 PC-related SNPs for the analyses after removing SNPs in LD and 218 those associated with other traits (Supplementary Tables 1 and 3). The association of the IV with PC was 219 estimated in non-T2DM individuals, followed by its association with T2DM in all subjects.

220 MR using pleiotropic genetic variants: Causal assessment of obesity (at two time points: age 50 and 2 years 221 before the interview) and PC was explored considering an IV of 85 obesity-related SNPs (41 SNPs were 222 removed due to LD and pleiotropy: Supplementary Tables 1 and 3). Multivariable MR was used to 223 disentangle further the causal effect of T2DM and obesity on PC using T2DM-SNPs as IV, or PC-SNPs as 224 IV in the opposite direction (Supplementary Figure $1 \mathrm{D}$ and E). The IVW, TSLS, and Egger methods were 225 applied in these analyses.[33,34] To extend the aforementioned mediation analyses, potential mediating 226 effects of obesity or T2DM (mediators) were explored considering separate IVs for the exposure and 227 mediator variables (Supplementary Figure $1 \mathrm{~F}$ and G).[35] NIE and NDE were likewise estimated using the 228 counterfactual method.[28]

229 Sensitivity analyses regarding imputation and other issues are detailed in Supplementary Methods. For 230 instance, we evaluated pleiotropy and unmeasured confounding using several approaches, $[31,36,37,38]$ 231 Results are presented as $\mathrm{OR}$ and $95 \% \mathrm{Cl}$, considering $\mathrm{p}$-values $<0.05$ as statistically significant. Statistical 
232 analyses were conducted using software R-project (version 3.3.0).[39] Mediation models were fitted with the

233 paramed module in Stata version 14.[40]

234

235 Results

236 Baseline characteristics of cases and controls are displayed in Supplementary Table 4. Cases and controls

237 with genetic or biomarker data had similar baseline characteristics (data not shown). By T2DM subtypes,

238 subjects with LSDM were diagnosed with T2DM at younger ages, and were more frequent users of 239 antidiabetic oral medication than subjects with NODM (Supplementary Table 5).

240 Observational association study: The association between T2DM and PC risk is shown in Table 1. T2DM 241 (vs non-T2DM) was associated with a 2.5 -fold higher risk of PC $(95 \% \mathrm{Cl}: 2.05 ; 3.05)$. PC risk was higher for 242 NODM (OR=6.39; 95\%Cl:4.18;9.78) and notably lower for LSDM (OR=1.86; 95\%Cl:1.49;2.32). A significant 243 positive trend of the association by time since diagnosis and age at T2DM diagnosis was observed ( $p$ 244 trend=6.3E-07). The PC risk nonlinear curve of time since T2DM showed a peak at two years following a 245 gradual decrease of the risk (Supplementary Figure 2). Statistical significance persisted until nearly 30 years 246 since T2DM diagnosis. Regarding T2DM control measure, the insulin use or non-use of oral medication, 247 were both significantly associated with a higher PC risk among diabetic patients $(O R=3.69$ and 2.94, 248 respectively) compared to non-T2DM. Adjustment for insulin use led to an attenuation of the risk estimates 249 compared to that observed for age, sex and country-adjusted models (Supplementary Table 6). When 250 adjusting for time since T2DM diagnosis, intriguingly, risk estimates turned non-significant, except for NODM 251 (OR=2.64; 95\% Cl:1.40;4.97) and diabetic patients using insulin ( $\mathrm{OR}=1.61 ; 95 \% \mathrm{Cl}: 1.01 ; 2.58)$. Family history 252 (FH) of T2DM (vs no $\mathrm{FH}$ ) was also associated with a significantly increased PC risk (OR=1.22; $25395 \% \mathrm{Cl}: 1.03 ; 1.48)$.

254 When T2DM status was established upon self-reported and Hb1Ac data (Table 2), the prevalence of T2DM 255 increased by $15 \%$ among PC cases at the expenses of NODM (from $13 \%$ to $26 \%$ ). Accordingly, the PC risk 256 estimates when considering reclassified T2DM subtypes with biomarker data were OR=4.63 and 1.97 for 257 NODM and LSDM, respectively (Supplementary Table 7). Assessment of T2DM status based on both data 258 was associated with a 3 -fold $(95 \% \mathrm{Cl}: 2.21 ; 4.07)$ higher PC risk, with this risk being mainly driven by 
259 uncontrolled and undiagnosed T2DM (OR=3.58;95\% Cl:2.53;5.11). Increasing levels of $\mathrm{Hb} 1 \mathrm{Ac}$ were also 260 associated with increased PC risk (per 1-unit increase $\mathrm{OR}=1.49 ; 95 \% \mathrm{Cl}: 1.30 ; 1.70$ and $\geq 6.5$ vs $<5.5 \mathrm{Hb} 1 \mathrm{Ac}$ levels OR=3.99; 95\% $\mathrm{Cl}: 2.64 ; 6.01, p$-trend=2E-16), whereas C-Peptide levels were inversely associated with PC risk. Indeed, a remarkable PC risk (OR=8.38; 95\%Cl:4.71;16.11) was seen for Type 3c-like diabetes (vs non-T2DM) when both markers were considered.

264 Several factors appeared to modify the association between T2DM and PC risk (Table 3). PC risk was considerably higher in diabetic patients with a higher educational degree than in those with lower education attainment ( $p$-het by education=0.004), for either T2DM subtype and irrespective of the type of control measure used. There was evidence for effect modification by smoking status, with former smokers with T2DM exhibiting the highest PC risk ( $p$-het by smoking=0.03). By gender, there was a significantly increased $\mathrm{PC}$ risk in males with $\mathrm{FH}$ of T2DM, though not in females ( $p$-het by gender $=0.007)$. Estimates were similar across obese and non-obese subjects. Obesity was not associated with PC risk, except in subgroups of men ( $p$-het by gender=0.03) (data not shown). There was no indication of effect modification by selected covariates on the association between $\mathrm{Hb} 1 \mathrm{Ac}$ and C-Peptide levels and PC risk (data not shown).

By T2DM subtypes, there were differences in risk estimates across the strata of gender, smoking status, educational level and post-50s weight-loss compared to non-T2DM (Table 4). For NODM, PC risk appeared to be higher in men $(\mathrm{OR}=10.42)$ than in women $(\mathrm{OR}=3.73$; $p$-het by gender=0.02); in former smokers

$276(\mathrm{OR}=11.51)$ than in never $(\mathrm{OR}=6.21)$, or current smokers $(\mathrm{OR}=3.09$; $p$-het by smoking=0.04); and among 277 those who lost weight $(O R=13.06)$ compared to those who did not $(O R=4.76, p$-het by weight loss $=0.04)$. By contrast, in LSDM, a slightly increased PC risk was seen with higher $(\mathrm{OR}=2.88)$ vs lower educational level $(\mathrm{OR}=1.49 ; p$-het by educational level $=0.006)$. While an interaction could not be established for other diabetes-related variables, risk of PC tended to be higher in NODM treated with insulin or if oral medication was not taken. This trend was less apparent for LSDM. Also, there was a borderline significant interaction effect with BMI in LSDM (Supplementary Table 8). The significance of some of these associations were lost

283 (e.g., weight loss and gender) when the biomarker data were used to reclassify NODM (data not shown). A closer evaluation of the association between T2DM subtypes with PC risk revealed that certain subgroups with NODM (males, insulin users or non-users of oral medication) were more likely to develop PC, whereas 
286 for LSDM this risk pattern differed (e.g., FH of PC, former alcohol drinkers, and insulin users were at higher

287 PC risk) (Supplementary Table 9). There were no significant gender, smoking, body fat measures, or

288 treatment differences between type-3 like NODM, NODM, and LSDM (data not shown).

289 Mendelian Randomization Analyses: Estimates for the causal association between T2DM and PC risk are 290 shown in Figure 1 and Supplementary Table 10. The genetic score (IV) for T2DM was significantly 291 associated with both NODM ( $p$-value=1.7E-04) and LSDM ( $p$-value=1.2E-05). However, the causal 292 association between the IV and PC was not statistically significant for any T2DM subtypes and this finding 293 was consistent when causal estimates were obtained with the MR-Egger regression. In the opposite 294 direction, the PC genetic IV score was associated with PC (p-value=9.3E-09) as well as with NODM (p295 value $=2 E-04$ ), though not with LSDM ( $p$-value=0.121). This resulted in a statistically significant causal association between PC and NODM (OR $\left.\mathrm{OR}_{\mathrm{TSS}}=2.52 ; 95 \% \mathrm{Cl}: 2.18 ; 2.88\right)$. However, pleiotropy was present in

297 MR-Egger (Intercept=0.09, $p$-value $=0.03$ ) and weighted median regression; these methods did not reach 298 the level of statistical significance. Similar results were observed for the association between PC and Type $2993 \mathrm{c}\left(\mathrm{OR}_{\mathrm{TSLS}}=2.29, \mathrm{p}\right.$-value $\left.=0.02\right)$ (data not shown). In multivariable MR, using the T2DM-IV to assess causal 300 effects on PC risk, comparable results were observed (Supplementary Table 11). Conversely, estimates 301 were largely affected in the opposite direction, suggesting that PC has causal effects on T2DM risk 302 independent of the potential pleiotropic effects of obesity $\left(\mathrm{OR}_{\mathrm{TSLS}}=1.58 ; 95 \% \mathrm{Cl}: 1.15 ; 2.17\right)$, though still not supported by MR-Egger regression. Thus, obesity was likely to drive the observed pleiotropy, despite a causal association with PC risk not being observed (Supplementary Table 12).

Mediation analyses results are shown in Figure 2 and Supplementary Table 13. There was an indication for mediation by overweight/obesity 2 years before recruitment in the T2DM and PC risk association for both NODM and LSDM though in opposite directions. The association between NODM and PC risk was mediated by recent weight loss ( $\mathrm{NIE}=0.55)$, whereas indirect effects by overweight/obesity were less noticeable in the

309 LSDM-PC risk association. When exploring mediator effects of T2DM, a significant association between 310 several obesity measures and either NODM or LSDM was seen, but the total effect did not reach the 311 statistical significance except for overweight/obesity at age 50. Interestingly, NODM was not an intermediate 312 step in the association between overweight/obesity at age 50 and PC risk, whereas LSDM seemed to be a 
313 potential mediator in this association $(\mathrm{NIE}=1.04)$. These causal pathways were confirmed when 314 implementing the use of IVs.

315 Sensitivity analyses: The overall results were not altered in sensitivity analyses (Supplementary Tables 14 316 and 15). Asymmetry in the funnel plots confirmed the presence of pleiotropy in the PC-NODM association 317 (Supplementary Table 16; Figure 3), but unmeasured confounding was unlikely (Supplementary Table 17).

\section{Discussion}

In this large and standardized case-control study, T2DM was associated with an increased PC risk, with NODM being associated with a higher risk than LSDM. About $34 \%$ of PC patients presented with diabetogenic levels of $\mathrm{Hb} 1 \mathrm{Ac}(>6.5 \%)$ at diagnosis, which entails a 3.3-fold increase in PC risk in comparison with normal blood levels. The proportion of undiagnosed T2DM in PC patients was notable (15\%), showing the importance of assessing T2DM status with biomarkers at PC diagnosis. This study also showed that PC risk gradually increased from pre-diabetes range levels. A causal association between LSDM and PC risk was not observed in MR, whereas estimates derived from bidirectional analyses suggested a causal effect of PC on NODM risk, though affected by potential pleiotropy. A complex biological interplay between obesity and LSDM or NODM in PC aetiology was confirmed in mediation analyses.

Pre-existing studies based the assessment of T2DM on self-reports, which is prone to misclassification bias given that under-diagnosis of T2DM is likely. In case-control studies on PC, this bias is aggravated in view of the fact that around $30 \%$ of PC patients can present undiagnosed T2DM at diagnosis.[41] Moreover, prediabetes $\mathrm{Hb} 1 \mathrm{Ac}$ levels can represent an important warning sign of subclinical $\mathrm{PC}$, as evidenced in risk prediction models of PC for diabetic patients.[42] In our study, we used information on $\mathrm{Hb} 1 \mathrm{Ac}$ and C-Peptide levels to reclassify T2DM status and to explore PC risk from pre-diabetes range levels. By doing so, we assessed more appropriately PC risk associated with T2DM status and Hb1Ac and C-Peptide levels. Only one previous study within the European Prospective Investigation into Cancer and Nutrition cohort (466 PC cases and matched controls) assessed PC risk by Hb1Ac levels.[43] Like us, this study also found that prediabetes was associated with an increased PC risk. Chari et al., also showed that elevated T2DM biomarker 
339 levels (e.g., fasting glucose) 2-3 months prior to PC diagnosis were associated with a higher PC risk in a

340 cohort of $848 \mathrm{PC}$ patients.[44]

341 Our findings on the observational association between T2DM and PC risk are concordant with previous 342 studies. Various meta-analyses have shown that T2DM is associated with an approximately two-fold 343 increased risk of PC (summary RRs ranged from 1.82 to 1.94$)$ ). $[8,10]$ Also consistent with previous studies, 344 e.g., the Pancreatic Cancer Case Control Consortium (PanC4) including 8,305 cases and 13,987 controls, 345 PC risk differs upon timing of T2DM diagnosis, with T2DM lasting less than 2 years (NODM) posing a greater 346 PC risk than LSDM.[45] Cohort studies using incident T2DM data also support that NODM and LSDM are 347 two distinct entities in PC aetiology.[9,46,47] As reported within the PanC4 study, our study also evidenced 348 differing PC risks in men and women with NODM, with men being at a greater PC risk.[45] However, in our 349 study, this difference turned non-significant when considering reclassified NODM using biomarker data, 350 probably because of lack of statistical power. By type of medication used to control T2DM, we also observed 351 that among diabetic patients, non-use of oral antidiabetic agents or use of insulin conferred a higher PC 352 risk.[45] Nonetheless, our study provides a more thorough assessment of PC risk by T2DM subtypes and 353 reveals remarkable differences between them. For instance, NODM remained positively associated with PC 354 risk irrespective of time since T2DM diagnosis (within a 2-year period) and was related to a more frequent 355 use of insulin. This type of T2DM, if type $3 c$ diabetes, has been previously associated with an earlier insulin 356 treatment initiation due to a faster or more aggressive disease progression by inducing beta-cell dysfunction 357 and insulin resistance, as well as by impairing proinsulin processing.[14,48]

358 A genetic link between T2DM and PC risk has been explored in three case-control studies, without finding 359 any significantly associated T2DM-related variant with PC risk.[18,23,49] The causal link between both 360 diseases has been previously investigated using MR.[20] Our findings on the absence of a causal 361 association between T2DM and PC risk are in agreement with this study. In contrast, and as a new finding, 362 in our study we performed a bidirectional MR in both T2DM subtypes and established their causal 363 association with PC risk. This approach enabled a more appropriate dissection of the directional association 364 between T2DM and PC. Thereby, we have elucidated that LSDM is not causally linked to PC, whereas PC 365 may cause NODM, if the influencing effects of body weight are ruled out. However, our study does not 
support the causal or observational association between BMI and PC risk, possibly due to reverse causation, a common bias in case-control studies, survival-selection bias, or misclassification of obesity.[50,51] Indeed, obesity measures were self-reported by the participants at recruitment. Adipose tissue loss in the early development of PC may explain this lack of association and support reverse causation.[52] In fact, the presence of coexisting PC and NODM has been related to weight loss prior to PC diagnosis. [53] This is also supported by a recent study in mouse models showing that adipose wasting is related to altered exocrine function in early PC.[54] In mediation analyses we could confirm that there is a 'cross-talk' between obesity and T2DM in relation to PC risk. Our findings suggest that weight loss related to NODM are related to the development of PC, whereas LSDM may mediate the association between obesity and PC risk.

Among the limitations of our study there is pleiotropic effects, i.e. genetic confounding, in the association study between PC and NODM, despite we accounted for potential pleiotropic associations in multivariable

377 MR.[33] Thus, pleotropic effects may still have an influence effect on this association. Also, our study may be prone to confounding bias, although the likelihood of unmeasured confounder effects was low according to Evalue estimates. We used one-sample data rather than summarized data due to lack of information on summary statistics for NODM and LSDM in public GWAS databases. Therefore, when MR approaches for summarized data were applied, we accounted for the correlation between the variants associated with the exposure and the outcome. In addition, we provided causal estimates using the T2LS method, which is more convenient for one-sample MR.[32] We considered bidirectional MRA, but this approach also assumes that the causal association occurs in one direction, such that the impact of feedback loops between the exposure and outcome cannot be addressed.[29] Our study only included subjects with European ancestry, which

387 The strengths of our study include a relatively large sample size, inclusion of a large number of standardized T2DM-related variables, accounting for biomarker data on Hb1Ac and C-Peptide levels to establish T2DM status, and the use of MR approaches to assess causal effects between T2DM and PC in both potential causal directions. We considered two T2DM subtypes and explored their role in PC aetiology, which was not done before. However, NODM definition was time-based (from self-reports) and misclassification is likely. Indeed, whether all NODM comprise type $3 c$ diabetes cannot be established due to lack of dynamic 
393 biomarkers. ${ }^{40}$ However, using C-Peptide data we could better define this subtype and conduct a more proper

394 assessment of PC risk. In addition, there might be other T2DM subtypes involved in this disease. Indeed,

395 one study using medical claims data have identified relevant T2DM subtypes,[55] with possibly different

396 effect measures in PC disease.

397 In conclusion, while this study confirms the association between T2DM and PC risk, it does not support a 398 causal effect of T2DM on PC development. Our findings suggest that T2DM is likely to be either a 399 consequence of an adverse milieu created during the progressive growth of pancreatic cancer cells in the 400 case of NODM, or a mediator in the causal pathway between obesity and PC in the case of LSDM, rather 401 than a cause of PC. This study also highlights the importance of diabetogenic levels of $\mathrm{Hb} 1 \mathrm{Ac}$ not only for 402 a proper classification of T2DM status in PC, but also as a predictor of PC risk. These findings, if confirmed 403 in future studies, may have implications to achieve a breakthrough towards PC prevention.

404

405 Acknowledgements:

406 The authors are thankful to the coordinators, field and administrative workers, technicians and study 407 participants of the European Study into Digestive Illnesses and Genetics (PanGenEU) study.

409 Funding:

410 The work was partially supported by Fondo de Investigaciones Sanitarias (FIS), Instituto de Salud Carlos 411 III, Spain (\#PI11/01542, \#PI0902102, \#PI12/01635, \#PI12/00815, \#PI15/01573); Red Temática de 412 Investigación Cooperativa en Cáncer, Spain (\#RD12/0036/0034, \#RD12/0036/0050, \#RD12/0036/0073); 413 WCR (15-0391); European Cooperation in Science and Technology - COST Action \#BM1204: EUPancreas. 414 EU-6FP Integrated Project (\#018771-MOLDIAG-PACA), EU-FP7-HEALTH (\#259737-CANCERALIA, 415 \#256974-EPC-TM-Net); Associazione Italiana Ricerca sul Cancro (12182); Cancer Focus Northern Ireland 416 and Department for Employment and Learning; and ALF (\#SLL20130022), Sweden. 


\section{References}

4201 Allemani C, Matsuda T, Di Carlo V, et al. Global surveillance of trends in cancer survival 2000-14

421 (CONCORD-3): analysis of individual records for 37513025 patients diagnosed with one of 18 422 cancers from 322 population-based registries in 71 countries. Lancet (London, England) $423 \quad$ 2018;391:1023-75.

4242 Rahib L, Smith BD, Aizenberg R, et al. Projecting cancer incidence and deaths to 2030: The 425 unexpected burden of thyroid, liver, and pancreas cancers in the united states. Cancer Res $426 \quad 2014 ; 74: 2913-21$.

4273 Ferlay J, Partensky C, Bray F. More deaths from pancreatic cancer than breast cancer in the EU by 428 2017. Acta Oncol (Madr) 2016;55:1158-60.

4294 Maisonneuve P LA. Risk factors for pancreatic cancer: a summary review of meta-analytical studies. $430 \quad$ Int J Epidemiol J Epidemiol 2015;44:186-98.

4315 Chari ST, Leibson CL, Rabe KG et al. Probability of Pancreatic Cancer Following Diabetes: a 432 population-based study. Gastroenterology 2005;192:504-11.

4336 Sheehan N a., Didelez V, Burton PR, et al. Mendelian randomisation and causal inference in $434 \quad$ observational epidemiology. PLoS Med 2008;5:1205-10.

4357 Burgess S, Butterworth A, Thompson SG. Mendelian randomization analysis with multiple genetic $436 \quad$ variants using summarized data. Genet Epidemiol 2013;37:658-65.

4378 Batabyal P, Vander Hoorn S, Christophi C, et al. Association of diabetes mellitus and pancreatic 438 adenocarcinoma: a meta-analysis of 88 studies. Ann Surg Oncol 2014;21:2453-62.

4399 Song $S$, Wang B, Zhang $X$, et al. Long-term diabetes mellitus is associated with an increased risk $440 \quad$ of pancreatic cancer: A meta-analysis. PLoS One 2015;10:1-27.

44110 Ben $Q, X u M$, Ning X, et al. Diabetes mellitus and risk of pancreatic cancer: A meta-analysis of $442 \quad$ cohort studies. Eur J Cancer 2011;47:1928-37.

44311 Bosetti C, Rosato V, Li D, et al. Diabetes, antidiabetic medications, and pancreatic cancer risk: an 444 analysis from the International Pancreatic Cancer Case-Control Consortium. Ann Oncol $445 \quad 2014 ; 25: 2065-72$.

44612 Sah RP, Nagpal SJS, Mukhopadhyay D, et al. New insights into pancreatic cancer-induced 447 paraneoplastic diabetes. Nat Rev Gastroenterol Hepatol 2013;10:423-33.

44813 Aggarwal G, Kamada P, Chari ST. Prevalence of Diabetes Mellitus in Pancreatic Cancer Compared 449 to Common Cancers. Pancreas 2013;42:198-201.

45014 Balzano G, Dugnani E, Pasquale V, et al. Clinical signature and pathogenetic factors of diabetes 
451

452

$453 \quad 15$

454

455

456

457

458

459

460

461

462

463

464

465

$466 \quad 20$

467

468

469

470

471

472

473

474

475

476

477

478

479

$480 \quad 26$

$481 \quad 27$

482

associated with pancreas disease ( $\mathrm{T} 3 \mathrm{cDM})$ : a prospective observational study in surgical patients. Acta Diabetol 2014;51:801-11.

15

Zhang AM, Magrill J, Winter TJJ de, et al. Endogenous insulin contributes to pancreatic cancer development. Cell Metab 2019;::pii: S1550-4131(19)30376-6.

Rahn S, Zimmermann V, Viol F, et al. Diabetes as risk factor for pancreatic cancer : Hyperglycemia promotes epithelial-mesenchymal-transition and stem cell properties in pancreatic ductal epithelial cells. Cancer Lett 2018;415:129-50.

Sciacca, L; Vigneri, R; Tumminia, A; Frasca, F; Squatrio, S; Frittitta, L; Vigneri P. Clinical and molecular mechanisms favoring cancer initiation and progression in diabetic patients. Nutr Metab Cardiovasc Dis 2013;23:808-15.

18

Wu L, Rabe KG, Petersen GM. Do variants associated with susceptibility to pancreatic cancer and type 2 diabetes reciprocally affect risk? PLoS One 2015;10:1-13.

Wang Z, Lai S, Xie L, et al. Metformin is associated with reduced risk of pancreatic cancer in patients with type 2 diabetes mellitus: A systematic review and meta-analysis. Diabetes Res Clin Pract 2014;106:19-26.

Carreras-Torres R, Johansson M, Gaborieau V, et al. The role of obesity and metabolic factors in pancreatic cancer: A Mendelian randomization study. J Natl Cancer Inst 2017;109(9).

21 Gomez-Rubio P, Zock J-P, Rava M, et al. Reduced risk of pancreatic cancer associated with asthma and nasal allergies. Gut 2017;66:314-22.

22 Buniello A, Macarthur JAL, Cerezo M, et al. The NHGRI-EBI GWAS Catalog of published genomewide association studies, targeted arrays and summary statistics 2019. Nucleic Acids Res 2019;47:D1005-12.

23 Pierce BL, Austin MA AH. Association study of type 2 diabetes genetic susceptibility variants and risk of pancreatic cancer: an analysis of PanScan-I data. Cancer Causes $\{\&\}$ Control 2011;22:87783.

Kuruma S, Egawa N, Kurata M, et al. Case-control study of diabetes-related genetic variants and pancreatic cancer risk in Japan. World J Gastroenterol 2014;20:17456-62.

Tang H, Wei P, Duell EJ, et al. Genes-environment interactions in obesity- and diabetes-associated pancreatic cancer: A GWAS data analysis. Cancer Epidemiol Biomarkers Prev 2014;23:98-106.

Durrleman S, Simon R. Flexible regression models with cubic splines. Stat Med 1989;8:551-61.

Neuhaus JM, McCulloch CE BR. Estimation of covariate effects in generalized linear mixed models with a misspecified distribution of random intercepts and slopes. Stat Med 2013;32:2419-29. 
48328 VanderWeele T. Mediation Analysis: A Practitioner's Guide. Annu Rev Public Health 2016;17-32.

48429 Haycock PC, Burgess S, Wade KH, et al. Best (but oft-forgotten) practices: The design, analysis, 485 and interpretation of Mendelian randomization studies. Am J Clin Nutr 2016;103:965-78.

48630 Yavorska 00, Burgess S. MendelianRandomization: an R package for performing Mendelian 487 randomization analyses using summarized data. Int J Epidemiol 2017;46:1734-9.

48831 Burgess S, Burgess S. Interpreting findings from Mendelian randomization using the MR-Egger $489 \quad$ method. Eur J Epidemiol 2017;32:377-89.

49032 Bowden J, Davey Smith G, Haycock PC, et al. Consistent Estimation in Mendelian Randomization 491 with Some Invalid Instruments Using a Weighted Median Estimator. Genet Epidemiol 2016;40:30449214.

$493 \quad 33$ Burgess S, Thompson SG. Multivariable Mendelian randomization: The use of pleiotropic genetic $494 \quad$ variants to estimate causal effects. Am J Epidemiol 2015;181:251-60.

49534 Rees JMB, Wood AM, Burgess S. Extending the MR-Egger method for multivariable Mendelian 496 497 randomization to correct for both measured and unmeasured pleiotropy. Stat Med 2017;36:470518.

Burgess S, Daniel RM, Butterworth AS, et al. Network Mendelian randomization: Using genetic variants as instrumental variables to investigate mediation in causal pathways. Int $\mathrm{J}$ Epidemiol 2015;44:484-95.

503

Staley JR, Blackshaw J, Kamat MA, et al. PhenoScanner: A database of human genotypephenotype associations. Bioinformatics 2016;32:3207-9.

504

Hemani G, Zheng J, Elsworth B, et al. The MR-base platform supports systematic causal inference across the human phenome. Elife 2018;7:e34408.

50538 Vanderweele TJ, Ding P. Sensitivity Analysis in Observational Research: Introducing the E-Value. 506 Ann Intern Med 2017;167:268-74.

50739 R Core Team. R: a language and environment for statistical computing. R Found. Stat. Comput. 508 2014. http://www.r-project.org/.

$50940 \quad$ StataCorp.2011. Stata Statistical Software: Release 12. 2011.

51041 Roeyen $\mathrm{G}$, Jansen $\mathrm{M}$, Chapelle $\mathrm{T}$, et al. Diabetes mellitus and pre-diabetes are frequently 511 undiagnosed and underreported in patients referred for pancreatic surgery. A prospective $512 \quad$ observational study. Pancreatology 2016;16:671-6.

51342 Boursi B, Finkelman B, Giantonio BJ, et al. A Clinical Prediction Model to Assess Risk for Pancreatic 514 Cancer Among Patients With New-Onset Diabetes. Gastroenterology 2017;152:840--850.e3. 
51543 Grote VA, Rohrmann S, Nieters A, et al. Diabetes mellitus, glycated haemoglobin and C-peptide 516 levels in relation to pancreatic cancer risk: A study within the European Prospective Investigation into Cancer and Nutrition (EPIC) cohort. Diabetologia 2011;54:3037-46.

51844 Sharma A, Smyrk TC, Levy MJ, et al. Fasting Blood Glucose Levels Provide Estimate of Duration 519 and Progression of Pancreatic Cancer Before Diagnosis. Gastroenterology 2018;155:490-500.e2.

52045 Bosetti C, Rosato V, Li D, et al. Diabetes, antidiabetic medications, and pancreatic cancer risk: an 521 analysis from the International Pancreatic Cancer Case-Control Consortium. Ann Oncol Off J Eur Soc Med Oncol 2014;25:2065-72.

52346 Pang Y, Kartsonaki C, Guo Y, et al. Diabetes, plasma glucose and incidence of pancreatic cancer: 524 A prospective study of 0.5 million Chinese adults and a meta-analysis of 22 cohort studies. Int $J$ Cancer 2017;140:1781-8.

Setiawan VW, Stram DO, Porcel J, et al. Pancreatic Cancer Following Incident Diabetes in African Americans and Latinos: The Multiethnic Cohort. JNCI J Natl Cancer Inst 2018;111:27-33.

Mizuno S, Nakai Y, Isayama H, et al. Risk factors and early signs of pancreatic cancer in diabetes: screening strategy based on diabetes onset age. J Gastroenterol 2013;48:238-46.

Tang H, Dong X, Hassan M, et al. Body mass index and obesity- and diabetes-associated genotypes and risk for pancreatic cancer. Cancer Epidemiol Biomarkers Prev 2011;20:779-92.

Hu Z-H, Connett JE, Yuan J-M, et al. Role of survivor bias in pancreatic cancer case-control studies. Ann Epidemiol 2016;26:50-6.

Sperrin M, Candlish J, Badrick E, et al. Collider bias is only a partial explanation for the obesity paradox. Epidemiology 2016;27:525-30.

53652 Sah RP, Sharma A, Nagpal S, et al. Phases of Metabolic and Soft Tissue Changes in Months 537 Preceding a Diagnosis of Pancreatic Ductal Adenocarcinoma. Gastroenterology 2019;156:1742$538 \quad 52$.

53953 Hart PA, Kamada P, Rabe KG, et al. Weight loss precedes cancer-specific symptoms in pancreatic cancer-associated diabetes mellitus. Pancreas 2011;40:768-72.

54154 Danai L V., Babic A, Rosenthal MH, et al. Altered exocrine function can drive adipose wasting in early pancreatic cancer. Nature 2018;558:600-4.

54355 Li L, Cheng W-Y, Glicksberg BS, et al. Identification of type 2 diabetes subgroups through topological analysis of patient similarity. Sci Transl Med 2015;7:311ra174 LP-311ra174. 


\section{Tables}

548 Table 1: Association between diabetes-related variables and PC risk in the PanGenEU study $(2,018$ cases 549 and 1,540 controls).

550 Table 2: Association between diabetes status based on biomarker levels and PC risk in the Spanish 551 PanGenEU biomarker study (509 cases and 413 controls).

552 Table 3: Association between diabetes-related variables and PC risk by gender, educational level, obesity 553 and smoking status in the PanGenEU study (2,018 cases and 1,540 controls).

554 Table 4: Association between diabetes and PC risk according to T2DM subtypes among different subgroups 555 in the PanGenEU study (2,018 cases and 1,540 controls).

556

557 Figures

558 Figure 1: Forest plot of estimated results (OR and $95 \% \mathrm{Cl})$ from the observational study and Mendelian 559 randomisation (MR) analysis, conducted among 1,162 cases and 752 controls with epidemiological and 560 genetic data.

561 The point estimates are represented by a bullet along with the $95 \%$ confidence intervals. LSDM and NODM 562 were evaluated in comparison to T2DM-free individuals (1,489 subjects: 851 PC cases and 638 controls), 563 with subjects classified as either NODM $(\mathrm{N}=136)$ or LSDM $(\mathrm{N}=289)$ being removed, respectively. All 564 estimates were adjusted for age $(<55,55-65,65-75, \geq 75$ years), gender, BMl $(<25,25-30, \geq 30 \mathrm{~kg} / \mathrm{m} 2)$, 565 smoking (never-smokers and tertiles of pack-years), country and the first five principal components for 566 population ancestries. A and B refer to the directional association between T2DM and PC risk. The allele 567 score (IV) included 35 T2DM-SNPs. Mr-Egger Intercept: 0.006 ( $p$-value=0.964) and -0.022 (p-value=0.468), 568 for NODM and LSDM, respectively. $\mathbf{C}$ and $\mathbf{D}$ refer to the directional association between PC and T2DM risk. 569 The allele score (IV) included 33 PC-SNPs. Mr-Egger Intercept: 0.090 (p-value=0.027) and 0.07 ( $p$ 570 value=0.807), for NODM and LSDM, respectively. 
572 Figure 2: Directed acyclic graphs showing results of causal mediation analyses evaluating mediator effects

573 of obesity or T2DM on the PC risk associations by T2DM subtypes. Results are shown for overweight/obesity

574 assessed 2 years before recruitment for NODM or at age 50 for LSDM. The natural indirect (NIE), direct

575 (NDE) and total effect (TE) of the associations are shown with corresponding ORs [95\% Cls]. Estimates are

576 derived from counterfactual models (2,018 cases and 1,540 controls) and IV mediation analyses (1,162

577 cases and 752 controls with epidemiological and genetic data). $\mathbf{A}$ and $\mathbf{B}$ for LSDM or obesity (mediators) in

578 association analyses between obesity or NODM and PC risk, respectively. C and D for LSDM or

579 overweight/obesity (mediators) in association analyses between overweight/obesity or NODM and PC risk,

580 respectively. 
581 Table 1: Association between diabetes-related variables and PC risk in the PanGenEU study (2,018 cases

582 and 1,540 controls).

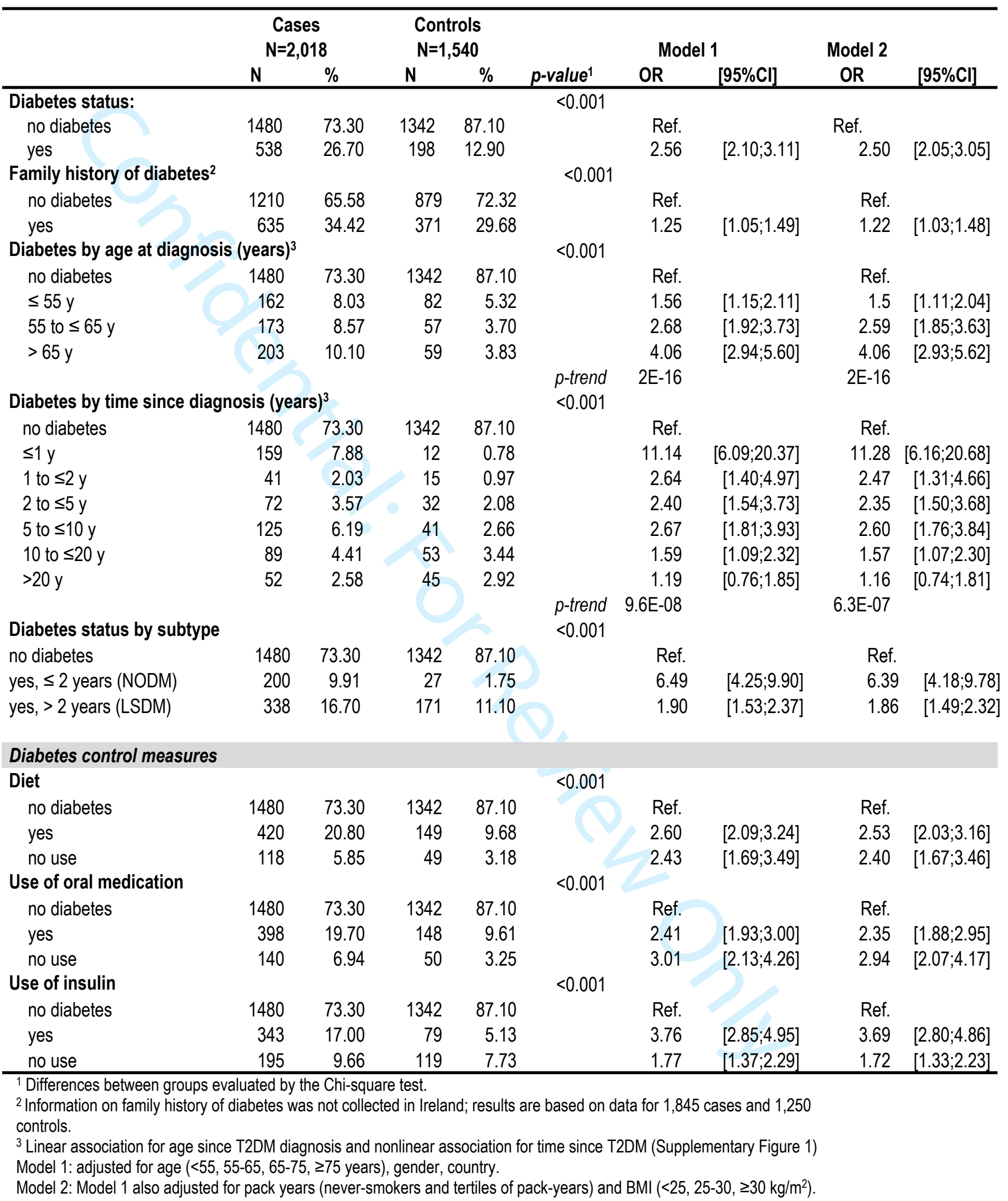


Table 2: Association between diabetes status based on biomarker levels and PC risk in the Spanish PanGenEU biomarker study (509 cases and 413 controls).

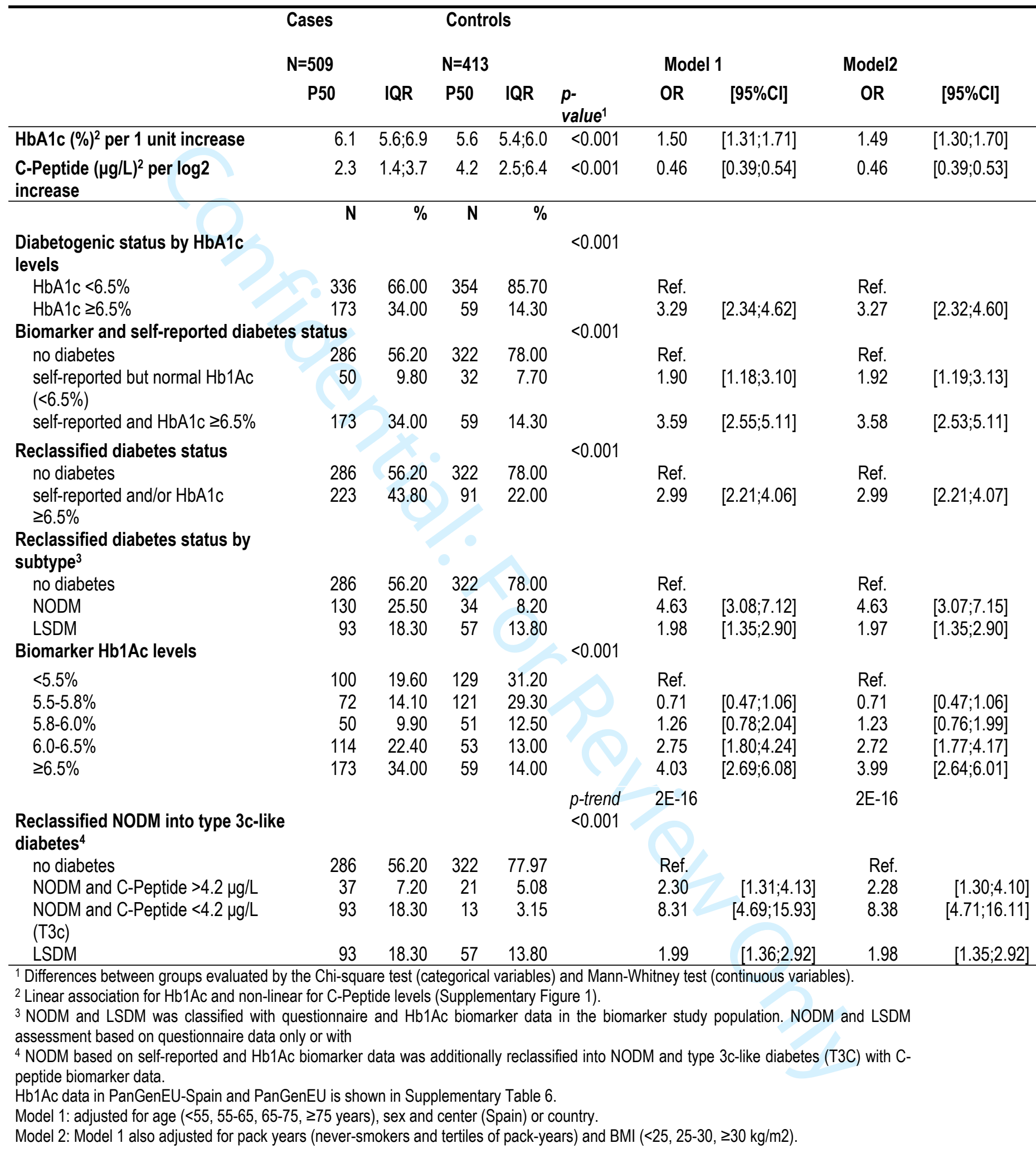


Table 3: Association between diabetes-related variables and PC risk by gender, educational level, obesity and smoking status in the PanGenEU study (2,018 cases and 1,540 controls).

\begin{tabular}{|c|c|c|c|c|c|c|c|c|c|c|c|c|c|c|c|c|c|c|}
\hline & \multicolumn{4}{|c|}{ Gender $^{1}$} & \multicolumn{4}{|c|}{ Educational level } & \multicolumn{4}{|c|}{ Obese $^{1,2}$} & \multicolumn{6}{|c|}{ Smoking status ${ }^{1}$} \\
\hline & \multicolumn{2}{|c|}{ Females $(\mathrm{N}=1,578)$} & \multicolumn{2}{|c|}{ Males $(\mathrm{N}=1,980)$} & \multicolumn{2}{|c|}{$<5-9$ years $(\mathrm{N}=1,405)$} & \multirow{2}{*}{\multicolumn{2}{|c|}{$\begin{array}{c}\geq 10 \text { years }(\mathrm{N}=2,153) \\
\text { OR } \quad[95 \% \mathrm{Cl}]\end{array}$}} & \multicolumn{2}{|c|}{ No $(\mathrm{N}=2,872)$} & \multicolumn{2}{|c|}{ Yes $(\mathrm{N}=686)$} & \multicolumn{2}{|c|}{ Never $(\mathrm{N}=1,451)$} & \multicolumn{2}{|c|}{ Former $(\mathrm{N}=1,246)$} & \multicolumn{2}{|c|}{ Current $(\mathrm{N}=861)$} \\
\hline & OR & {$[95 \% \mathrm{Cl}]$} & OR & {$[95 \% \mathrm{Cl}]$} & $O R$ & {$[95 \% \mathrm{Cl}]$} & & & OR & {$[95 \% \mathrm{Cl}]$} & OR & {$[95 \% \mathrm{Cl}]$} & OR & {$[95 \% \mathrm{Cl}]$} & OR & {$[95 \% \mathrm{Cl}]$} & & {$[95 \% \mathrm{Cl}]$} \\
\hline abetes status by subtype & & & & & & & & & & & & & & & & & & \\
\hline no diabetes & ef. & & Ref. & & Ref. & & Ref. & & Ref. & & Ref. & & Ref. & & Ref. & & Ref. & \\
\hline yes, $\leq 2$ years (NODM) & 3.67 & {$[2.05 ; 6.58]$} & 10.35 & {$[5.44 ; 19.67]$} & 4.22 & {$[2.38 ; 7.49]$} & 9.54 & {$[5.01 ; 18.16]$} & 6.84 & {$[4.14 ; 11.3]$} & 5.12 & {$[2.28 ; 11.49]$} & 6.07 & {$[3.17 ; 11.89]$} & 11.66 & {$[5.21 ; 26.08]$} & 3.08 & {$[1.44 ; 6.61]$} \\
\hline yes, > 2 years (LSDM) & 1.71 & {$[1.19 ; 2.46]$} & 2.03 & {$[1.54 ; 2.67]$} & 1.39 & {$[1.02 ; 1.89]$} & 2.64 & {$[1.92 ; 3.62]$} & 1.66 & {$[1.29 ; 2.15]$} & 2.36 & {$[1.52 ; 3.67]$} & 1.58 & {$[1.12 ; 2.21]$} & 2.58 & {$[1.80 ; 3.70]$} & 1.49 & {$[0.90 ; 2.45]$} \\
\hline$p$-value for interaction & & & & 0.078 & & & & 0.004 & & & & 0.310 & & & & 0.028 & & \\
\hline \multicolumn{19}{|l|}{$\mathrm{FH}$ of diabetes ${ }^{3}$} \\
\hline no & Ref. & & Ref. & & Ref. & & Ref. & & Ref. & & Ref. & & Ref. & & Ref. & & Ref. & \\
\hline & 0.93 & {$[0.72 ; 1.21]$} & 1.50 & {$[1.19 ; 1.89]$} & 1.22 & {$[0.95 ; 1.58]$} & 1.23 & {$[0.97 ; 1.56]$} & 1.31 & {$[1.08 ; 1.59]$} & 0.95 & {$[0.64 ; 1.39]$} & 1.03 & {$[0.78 ; 1.34]$} & 1.59 & {$[1.19 ; 2.15]$} & 1.19 & {$[0.83 ; 1.70]$} \\
\hline$p$-value for in & & & & 0.007 & & & & 0.971 & & & & 0.263 & & & & 0.070 & & \\
\hline abetes by age at di & & & & & & & & & & & & & & & & & & \\
\hline no diabetes & Ref. & & Ref. & & Ref. & & Ref. & & Ref. & & Ref. & & Ref. & & Ref. & & Ref. & \\
\hline$\leq 55 \mathrm{y}$ & 1.53 & {$[0.88 ; 2.62]$} & 1.53 & {$[1.06 ; 2.21]$} & 1.03 & {$[0.65 ; 1.63]$} & 2.06 & {$[1.37 ; 3.11]$} & 1.35 & {$[0.95 ; 1.92]$} & 1.97 & {$[1.05 ; 3.65]$} & 1.29 & {$[0.75 ; 2.20]$} & 2.23 & {$[1.35 ; 3.67]$} & 1.22 & {$[0.88 ; 1.68]$} \\
\hline 55 to $\leq 65 y$ & 2.14 & {$[1.24 ; 3.83]$} & 2.99 & {$[1.98 ; 4.50]$} & 1.42 & {$[0.88 ; 2.28]$} & 4.55 & {$[2.80 ; 7.39]$} & 2.47 & {$[1.66 ; 3.69]$} & 2.72 & 12] & 1.69 & .87] & 4.01 & {$[2.30 ; 7.01]$} & 2.78 & {$[1.32 ; 5.85]$} \\
\hline$>65 \mathrm{y}$ & 2.62 & {$[1.69 ; 4.06]$} & 6.57 & {$[4.00 ; 10.81]$} & 3.05 & {$[2.02 ; 4.60]$} & 6.27 & {$[3.62 ; 10.86]$} & 3.93 & {$[2.71 ; 5.71]$} & 4.25 & {$[2.17 ; 8.32]$} & 3.43 & {$[2.20 ; 5.36]$} & 5.11 & {$[3.00 ; 8.70]$} & 4.92 & {$[1.59 ; 15.23]$} \\
\hline$p$-value for interaction & & & & 0.073 & & & & $4.7 E-4$ & & & & 0.682 & & & & 0.115 & & \\
\hline Diabetes cont & & & & & & & & & & & & & & & & & & \\
\hline no diabetes & Ref. & & Ref. & & Ref. & & Ref. & & Ref. & & Ref. & & Ref. & & Ref. & & Ref. & \\
\hline yes & 2.13 & {$[1.51 ; 2.92]$} & 2.91 & {$[2.18 ; 3.89]$} & 1.86 & {$[1.38 ; 2.55]$} & 3.48 & {$[2.55 ; 4.76]$} & 2.38 & {$[1.85 ; 3.07]$} & 2.87 & {$[1.81 ; 4.52]$} & 2.05 & {$[1.46 ; 2.82]$} & 3.76 & [2.62;5.39] & 2.00 & {$[1.21 ; 3.3]$} \\
\hline & 2.37 & {$[1.24 ; 4.39]$} & 2.52 & {$[1.61 ; 3.94]$} & 1.61 & {$[1.01 ; 2.59]$} & 4.08 & {$[2.27 ; 7.35]$} & 2.27 & {$[1.47 ; 3.49]$} & 2.7 & {$[1.35 ; 5.38]$} & 2.52 & {$[1.43 ; 4.44]$} & 2.85 & {$[1.51 ; 5.39]$} & 1.62 & {$[0.8 ; 3.28]$} \\
\hline \multirow{2}{*}{\multicolumn{19}{|c|}{ Diabetes and oral medication }} \\
\hline & & & & & & & & & & & & & & & & & & \\
\hline no diabetes & Ref. & & Ref. & & Ref. & & Ref. & & Ref. & & Ref. & & Ref. & & Ref. & & Ref. & \\
\hline yes & 2.14 & {$[1.5 ; 3.01]$} & 2.54 & {$[1.96 ; 3.40]$} & 1.64 & {$[1.23 ; 2.23]$} & 3.51 & {$[2.52$} & 2.27 & {$[1.75 ; 2.96]$} & 2.47 & {$[1.6 ; 3.81]$} & 1.72 & 42] & 3.69 & ;5.42] & 2.06 & {$[1.25 ; 3.42]$} \\
\hline & 2.25 & {$[1.25 ; 3.87]$} & 3.60 & {$[2.31 ; 5.63]$} & 2.31 & {$[1.40 ; 3.80]$} & 3.82 & {$[2.34 ; 6.23]$} & 2.56 & {$[1.74 ; 3.77]$} & 4.7 & {$[2.04 ; 10.82]$} & 4.36 & {$[2.33 ; 8.16]$} & 3.27 & {$[1.93 ; 5.55]$} & 1.51 & {$[0.75 ; 3.05]$} \\
\hline$p$-value for interaction & & & & 0.496 & & & & 0.003 & & & & 0.354 & & & & 0.005 & & \\
\hline \multicolumn{19}{|l|}{ Diabetes and insulin } \\
\hline no diabetes & Ref. & & Ref. & & Ref. & & Ref. & & Ref. & & Ref. & & Ref. & & Ref. & & Ref. & \\
\hline yes & 3.24 & {$[2.05 ; 5.14]$} & 3.95 & {$[2.79 ; 5.60]$} & 2.92 & {$[1.97 ; 4.34]$} & 4.56 & {$[3.1 ; 6.71]$} & 3.42 & {$[2.5 ; 4.67]$} & 4.62 & {$[2.51 ; 8.49]$} & 3.42 & {$[2.24 ; 5.33]$} & 4.66 & {$[3 ; 7.25]$} & 2.64 & [1.45;4.81] \\
\hline $\begin{array}{r}\text { no } \\
p \text {-value for interaction }\end{array}$ & 1.51 & {$[1.01 ; 2.25]$} & 1.99 & $\begin{array}{r}{[1.42 ; 2.78]} \\
0.723\end{array}$ & 1.17 & {$[0.82 ; 1.67]$} & 2.78 & $\begin{array}{c}{[1.89 ; 4.08]} \\
0.003\end{array}$ & 1.58 & {$[1.16 ; 2.15]$} & 1.98 & $\begin{array}{l}{[1.21 ; 3.23]} \\
0.498\end{array}$ & 1.45 & {$[0.98 ; 2.14]$} & 2.64 & $\begin{array}{r}{[1.7 ; 4.09]} \\
0.094\end{array}$ & 1.34 & {$[0.77 ; 2.35]$} \\
\hline
\end{tabular}

${ }_{1}^{1}$ Odds ratios (ORs) adjusted for age ( $<55,55-65,65-75, \geq 75$ years), gender, country, pack years (never-smokers and tertiles of pack-years) and BMI (<25, 25-30, $\left.\geq 30 \mathrm{~kg} / \mathrm{m}^{2}\right)$ (Model 2), except: sex in analyses stratified by sex, BMl in analyses stratified by obesity and pack-years in analyses stratified by smoking status.

2 Obesity status defined based on BMI 2 years before recruitment.

${ }^{3}$ Information on family history $(F H)$ of diabetes was not collected in Ireland; results based on data for 1,845 cases and 1,250 controls.

Molina-Montes E, PanGenEU: Diabetes and PC risk (29 09 2019) 
Table 4: Association between diabetes and PC risk according to T2DM subtypes among different subgroups in the PanGenEU study (2,018 cases and 1,540 controls).

\begin{tabular}{|c|c|c|c|c|c|}
\hline & No diabetes (Ref.) & NODM & & LSDM & \\
\hline & Cases;Controls & Cases; Controls & $\mathrm{OR}^{1}[95 \% \mathrm{Cl}]$ & Cases;Controls & $\mathrm{OR}^{1}[95 \% \mathrm{Cl}]$ \\
\hline \multicolumn{6}{|l|}{ Gender } \\
\hline females & $691 ; 624$ & $67 ; 16$ & $3.73[2.13 ; 6.86]$ & $115 ; 65$ & $1.75[1.22 ; 2.51]$ \\
\hline males & $789 ; 718$ & $133 ; 11$ & $10.42[5.74 ; 20.89]$ & $223 ; 106$ & $2.03[1.54 ; 2.68]$ \\
\hline & $p$-value for interaction & 0.0213 & & 0.5704 & \\
\hline \multicolumn{6}{|l|}{ Obese $^{2}$} \\
\hline$\geq 30 \mathrm{~kg} / \mathrm{m}^{2}$ & $\begin{array}{r}252 ; 248 \\
\text { p-value for interaction }\end{array}$ & $\begin{array}{r}46 ; 8 \\
0.5862\end{array}$ & $5.01[2.34 ; 12.04]$ & $\begin{array}{r}94 ; 42 \\
0.2048\end{array}$ & $2.37[1.53 ; 3.71]$ \\
\hline \multicolumn{6}{|l|}{ Smoking status } \\
\hline never & $573 ; 601$ & $67 ; 11$ & $6.21[3.3 ; 12.79]$ & $120 ; 79$ & $1.58[1.13 ; 2.23]$ \\
\hline former & $457 ; 494$ & $87 ; 7$ & $11.51[5.5 ; 28.17]$ & $139 ; 62$ & $2.55[1.79 ; 3.67]$ \\
\hline current & $\begin{array}{r}450 ; 247 \\
p \text {-value for interaction }\end{array}$ & $\begin{array}{r}46 ; 9 \\
0.0418\end{array}$ & $3.09[1.49 ; 7.04]$ & $\begin{array}{r}79 ; 30 \\
0.0699\end{array}$ & $1.52[0.93 ; 2.53]$ \\
\hline \multicolumn{6}{|c|}{ Family history diabetes $^{3}$} \\
\hline no & $1063 ; 1009$ & $105 ; 12$ & $6.66[3.68 ; 13.10]$ & $162 ; 90$ & $1.61[1.19 ; 2.19]$ \\
\hline yes & $\begin{array}{r}417 ; 333 \\
p \text {-value for interaction }\end{array}$ & $\begin{array}{r}95 ; 15 \\
0.8253\end{array}$ & $6.07[3.49 ; 11.26]$ & $\begin{array}{l}176 ; 81 \\
0.1825\end{array}$ & $2.12[1.52 ; 2.96]$ \\
\hline \multicolumn{6}{|c|}{ Diabetes controlled with diet } \\
\hline yes & 0 & $156 ; 18$ & $7.31[4.51 ; 12.55]$ & $264 ; 131$ & $1.89[1.49 ; 2.42]$ \\
\hline no & $\begin{array}{r}0 \\
p \text {-value for interaction }\end{array}$ & $\begin{array}{r}44 ; 9 \\
\text { NA }\end{array}$ & $4.61[2.28 ; 10.32]$ & $\begin{array}{r}74 ; 40 \\
\text { NA }\end{array}$ & $1.89[1.25 ; 2.88]$ \\
\hline \multicolumn{6}{|c|}{ Diabetes with oral medication } \\
\hline yes & 0 & $120 ; 19$ & $4.63[2.83 ; 7.94]$ & $278 ; 129$ & $2.03[1.59 ; 2.59]$ \\
\hline no & 0 & $80 ; 8$ & $10.71[5.42 ; 24.37]$ & $60 ; 42$ & $1.48[0.97 ; 2.27]$ \\
\hline & $p$-value for interaction & NA & & NA & \\
\hline \multicolumn{6}{|c|}{ Diabetes with insulin } \\
\hline yes & 0 & $123 ; 6$ & $16.97[7.98 ; 43.91]$ & $220 ; 73$ & $2.60[1.93 ; 3.52]$ \\
\hline no & $\begin{array}{r}0 \\
p \text {-value for interaction }\end{array}$ & $\begin{array}{r}77 ; 21 \\
\text { NA }\end{array}$ & $3.45[2.12 ; 5.85]$ & $\begin{array}{r}118 ; 98 \\
\text { NA }\end{array}$ & $1.36[1.01 ; 1.83]$ \\
\hline \multicolumn{6}{|c|}{ Diabetes by age at diagnosis } \\
\hline$\leq 55 y$ & 0 & $32 ; 5$ & $4.47[1.78 ; 13.65]$ & $128 ; 75$ & $1.39[1.01 ; 1.91]$ \\
\hline 55 to $\leq 65$ & 0 & $56 ; 7$ & $6.47[3.03 ; 16.01]$ & $121 ; 52$ & $2.13[1.47 ; 3.11]$ \\
\hline$>65 y$ & $\begin{array}{r}0 \\
p \text {-value for interaction }\end{array}$ & $\begin{array}{r}112 ; 15 \\
\text { NA }\end{array}$ & $7.02[4.11 ; 12.82]$ & $\begin{array}{r}89 ; 44 \\
\text { NA }\end{array}$ & $2.60[1.76 ; 3.80]$ \\
\hline \multicolumn{6}{|l|}{ Educational level } \\
\hline$<5 y$ & $230 ; 132$ & $39 ; 5$ & $5.54[2.21 ; 16.87]$ & $74 ; 40$ & $1.49[0.92 ; 2.44]$ \\
\hline 6 to $9 y$ & $353 ; 328$ & $55 ; 11$ & $3.82[1.94 ; 8.11]$ & $78 ; 60$ & $1.35[0.89 ; 2.04]$ \\
\hline 10 to $13 y$ & $517 ; 456$ & $61 ; 8$ & $6.9[3.35 ; 16.14]$ & $120 ; 44$ & $2.56[1.70 ; 3.90]$ \\
\hline$\geq 14$ y & $380 ; 426$ & $45 ; 3$ & $16.34[5.75 ; 68.71]$ & $66 ; 27$ & $2.88[1.76 ; 4.79]$ \\
\hline \multicolumn{6}{|c|}{ Weight loss since age 50} \\
\hline yes & $486 ; 390$ & $65 ; 6$ & $13.06[6.05 ; 34.11]$ & $121 ; 55$ & $2.23[1.61 ; 3.11]$ \\
\hline no & 994;952 & $135 ; 21$ & $4.76[2.59 ; 9.37]$ & $217 ; 116$ & $1.67[1.15 ; 2.45]$ \\
\hline & $p$-value for interaction & 0.0441 & & 0.2868 & \\
\hline
\end{tabular}

${ }^{1}$ Odds ratios (ORs) adjusted for age ( $<55,55-65,65-75, \geq 75$ years), gender, country, pack years (never-smokers and tertiles of pack-years) and $\mathrm{BMI}\left(<25,25-30, \geq 30 \mathrm{~kg} / \mathrm{m}^{2}\right)$, except: sex in analyses stratified by sex, BMl in analyses stratified by obesity and pack-years in analyses stratified by smoking status.

2 Obesity status defined based on BMI 2 years before recruitment.

${ }^{3}$ Information on family history (FH) of diabetes was not collected in Ireland; results based on data for 1,845 cases and 1,250 controls. 
6द्धु ${ }_{3}^{2}$ Figure 1

$\begin{array}{lr}\text { A: NODM->PC } & \\ \text { Observational association } & \text { OR } \\ \text { T2DM and PC } & 6.10 \\ \text { T2DM-allele score and T2DM } & 1.31 \\ \text { T2DM-allele score and PC } & 1.02 \\ \text { Causal estimates (MRA) } & \text { OR } \\ \text { MRA Wald } & 1.06 \\ \text { T2LS } & 1.07 \\ \text { IVW } & 0.98 \\ \text { MR-Egger } & 0.98 \\ \text { Weighted median } & 1.03 \\ \text { Simple median } & 1.01\end{array}$

\section{C: PC->NODM}

Observational association

$\mathrm{PC}$ and T2DM

$\mathrm{PC}$-allele score and $\mathrm{PC}$

$\mathrm{PC}$-allele score and T2DM

Causal estimates (MRA)

MRA Wald

T2LS

IVW

MR-Egger

Weighted median

Simple median
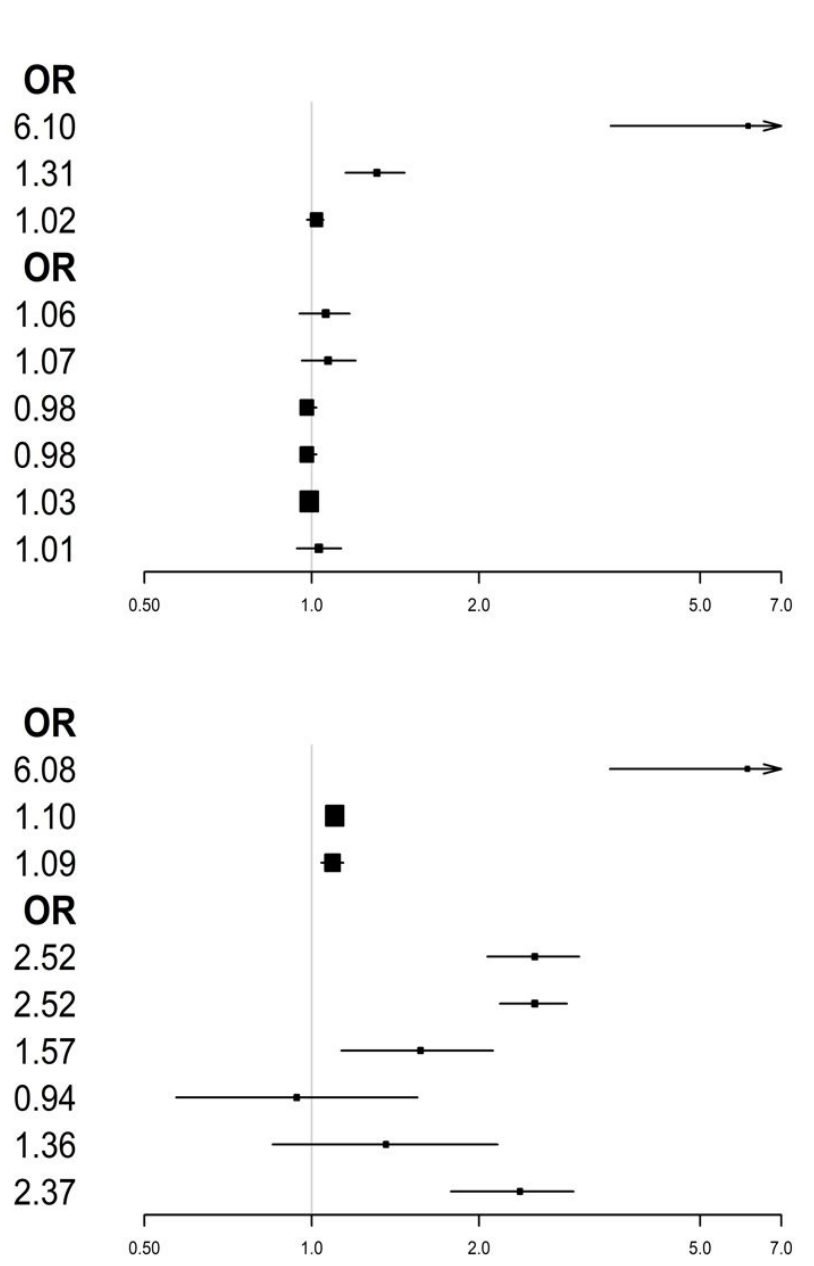

\section{B: LSDM->PC}

Observational association

T2DM and PC

T2DM-allele score and T2DM

T2DM-allele score and PC

\section{Causal estimates (MRA)}

MRA Wald

T2LS

IVW

MR-Egger

Weighted median

Simple median

\section{D: PC->LSDM}

\section{Observational association}

$\mathrm{PC}$ and T2DM

$\mathrm{PC}$-allele score and $\mathrm{PC}$

PC-allele score and T2DM

Causal estimates (MRA)

\section{MRA Wald}

T2LS

IVW

MR-Egger

Weighted median

Simple median

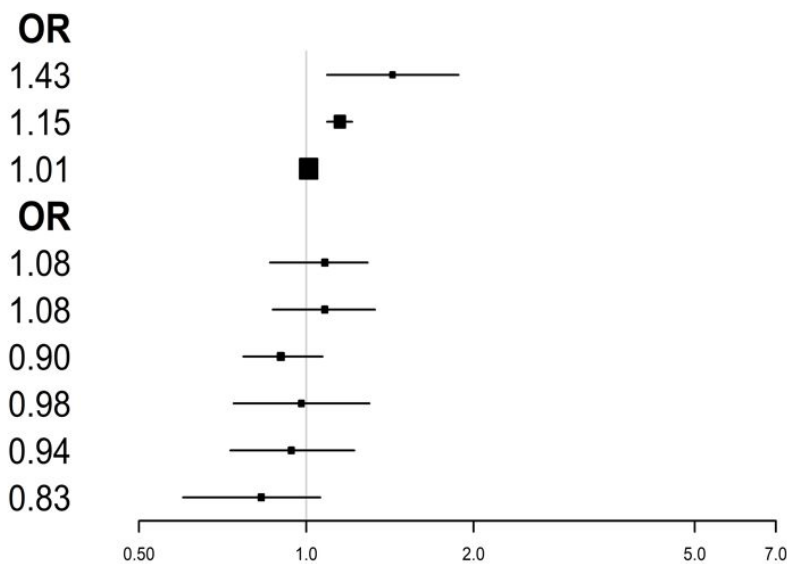

\section{OR}

1.44

1.10
1.03

OR

1.32

1.32

1.12

1.09

1.18

1.50

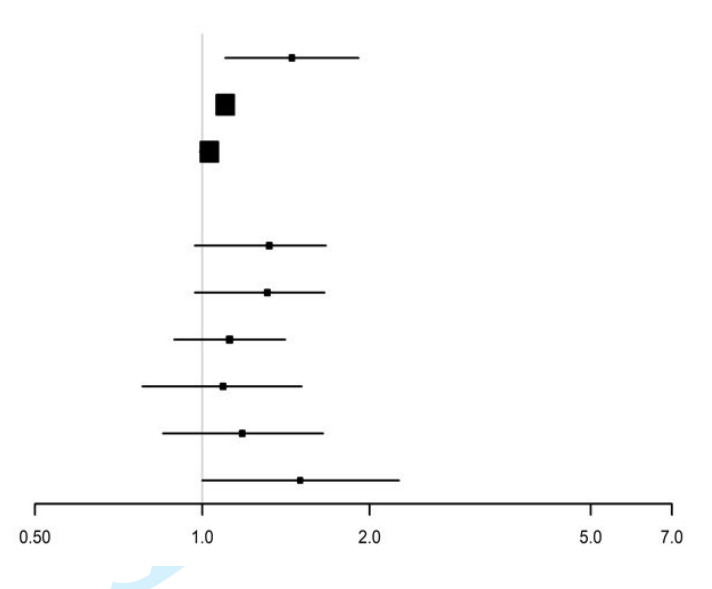


Figure 2

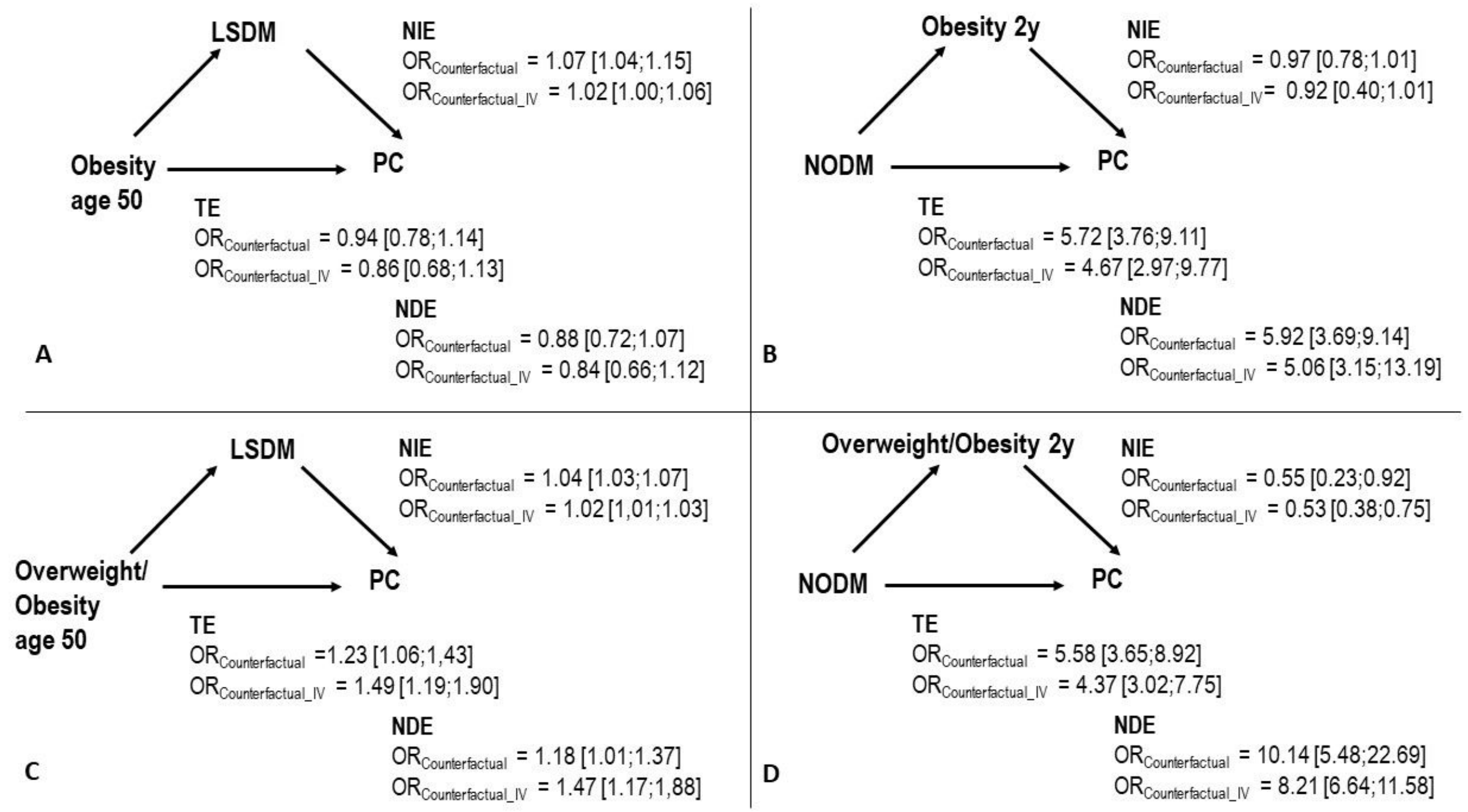


Deciphering the complex interplay between pancreatic cancer, diabetes mellitus subtypes, and obesity/BMI through causal inference and mediation analyses. Molina-Montes E et al.

\section{Supplementary material}

Supplementary Annex. PanGenEU centres and investigators

Supplementary Methods.

Supplemental Table 1: Selected genetic variants of T2DM, PC, and obesity .....................................

Supplemental Table 2: Evaluation of the performance of the missing data imputation...........................10

Supplemental Table 3: Genetic variants associated individually at $p$-value level $<0.05$ with T2DM and PC, as well as with selected covariates in the study population (752 controls).

Supplemental Table 4: General characteristics of the study population. PanGenEU study (2,018 cases and 1,540 controls). Imputed data.

Supplemental Table 5: Baseline characteristics of NODM and LSDM in the PanGenEU study (538 cases and 198 controls). Imputed data.

Supplemental Table 6: Association between diabetes-related variables and PC risk in the PanGenEU study (2,018 cases and 1,540 controls) when adjusting for T2DM treatment and duration of the disease. .16

Supplemental Table 7: Association between T2DM status based on $\mathrm{Hb} 1 \mathrm{Ac}$ levels and questionnaire data and PC risk in the PanGenEU study.

Supplemental Table 8: Association between T2DM and PC risk by T2MD subtypes and other covariates in the PanGenEU study (2,018 cases and 1,540 controls). .19

Supplemental Table 9: Factors associated with PC risk among patients with NODM and LSDM in the PanGenEU study (2,018 cases and 1,540 controls). .21

Supplemental Table 10: Estimates for the observational and causal association between T2DM and PC and viceversa, applying different MRA methods, conducted among 1,162 cases and 752 controls with epidemiological and genetic data. T2DM status based on self-reported (SR) data. .23

Supplemental Table 11: Estimates for the causal association between T2DM and PC and viceversa, applying different Multivariable MRA methods, conducted among 1,162 cases and 752 controls with epidemiological and genetic data. T2DM status based on self-reported (SR) data. .24

Supplemental Table 12: Estimates for the observational and causal association between obesity measures and PC, applying different MRA methods, conducted among 1,162 cases and 752 controls with epidemiological and genetic data.

Supplemental Table 13: Results of causal mediation analyses evaluating mediator effects of T2DM on the obesity and PC association considering different obesity measures, and mediator effects of obesity on the T2DM and PC association. Estimates are derived from counterfactual models (2,018 cases and 1,540 controls) and MRA (1,162 cases and 752 controls with epidemiological and genetic data).

Supplemental Table 14: Association between diabetes-related variables and PC risk in the PanGenEU study (2,018 cases and 1,540 controls). Unimputed data. 
Supplemental Table 15: Estimates for the observational and causal association between T2DM and PC and vice versa, applying different MRA methods, conducted among 1,162 cases and 752 controls with epidemiological and genetic data. T2DM status based on self-reported (SR) and biomarker data. .28

Supplemental Table 16: Estimates for the observational and causal association between T2DM and PC and vice versa, after removing other potential pleiotropic variants and outliers (based on Cook's distances) and applying different MRA methods, conducted among 1,162 cases and 752 controls with epidemiological and genetic data. T2DM status based on self-reported (SR) data.

Supplemental Table 17: Magnitudes of the E-value for different combinations of the Exposure-Confounder Association RREU and the Confounder-Outcome Association RRUD for the estimation of the causal effect of NODM on PC (OR=6.39 (4.18;9.78)) and of LSDM on PC (OR=1.86 (1.49;2.32)). .30

Supplemental Figure 1: Directed acyclic graphs illustrating the single MR and multivariable and network MR approaches used to explore causal associations and mediation in the causal pathways between T2DM, obesity and PC.

Supplemental Figure 2: Linear and Non-linear association between T2DM-related continuous variables and pancreatic cancer risk, with non-diabetics as a reference group: (A) time since T2DM diagnosis; $(B)$ age at T2DM diagnosis; (C) Hb1Ac levels and (D) C-Peptide levels with the minimum value (Hb1Ac=4; $\mathrm{C}$ Peptide $=0.05$ ) as the reference group. .33

Supplemental Figure 3: Pleiotropy visualization plots regarding the directional association between PC and NODM risk.

A: funnel plot for IV made up of SNPs without SNPs in LD and SNPs associated with obesity and smoking. B: funnel plot for IV excluding further SNPs that were outliers (based on Cooks distances). Y-axes represent SNP to outcome effect corrected by SNP to exposure standard error of the effect. X-axes (SNP to exposure effect) are in logarithmic scale. C: Correlation plot of per-allele associations (genetic score of the IV) with the outcome and exposure. D: Forest plot of per-allele MR effect size for exposure on outcome and E: leaveone-out analyses. .34 


\section{Supplementary Annex. PanGenEU centres and investigators}

Spanish National Cancer Research Centre (CNIO), Madrid, Spain: Núria Malats ${ }^{1}$, Francisco X Real ${ }^{1}$, Evangelina López de Maturana, Paulina Gómez-Rubio, Esther Molina-Montes, Lola Alonso, Mirari Márquez, Roger Milne, Ana Alfaro, Tania Lobato, Lidia Estudillo.

Verona University, Italy: Rita Lawlor ${ }^{1}$, Aldo Scarpa, Stefania Beghelli.

National Cancer Registry Ireland, Cork, Ireland: Linda Sharp ${ }^{1}$, Damian O'Driscoll.

Hospital Madrid-Norte-Sanchinarro, Madrid, Spain: Manuel Hidalgo ${ }^{1}$, Jesús Rodríguez Pascual.

Hospital Ramon y Cajal, Madrid, Spain: Alfredo Carrato ${ }^{1}$, Carmen Guillén-Ponce, Mercedes Rodríguez-

Garrote, Federico Longo-Muñoz, Reyes Ferreiro, Vanessa Pachón, M Ángeles Vaz.

Hospital del Mar, Barcelona, Spain: Mar Iglesias¹, Cristina Álvarez-Urturi, Xavier Bessa, Felipe Bory, Lucas Ilzarbe, Lucía Márquez, Ignasi Povest, Fernando Burdío, Luis Grande, Javier Gimeno.

Hospital Vall d'Hebron, Barcelona, Spain: Xavier Molero', Luisa Guarnert, Joaquin Balcells.

Technical University of Munich, Germany: Christoph Michalski ${ }^{1}$, Jörg Kleeff, Bo Kong.

Karolinska Institute, Stockholm, Sweden: Matthias Löhr' ${ }^{1}$, Jiaqui Huang, Weimin Ye, Jingru Yu.

Hospital 12 de Octubre, Madrid, Spain: José Perea1', Pablo Peláez.

Hospital de la Santa Creu i Sant Pau, Barcelona, Spain: Antoni Farré1, Josefina Mora, Marta Martín, Vicenç Artigas, Carlos Guarner, Francesc J Sancho, Mar Concepción, Teresa Ramón y Cajal.

The Royal Liverpool University Hospital, UK: William Greenhalf' ${ }^{1}$, Eithne Costello.

Queen's University Belfast, UK: Michael O'Rorke ${ }^{1}$, Liam Murray+, Marie Cantwell.

Laboratorio de Genética Molecular, Hospital General Universitario de Elche, Spain: Víctor M Barberá1, Javier Gallego.

Instituto Universitario de Oncología del Principado de Asturias, Oviedo, Spain: Adonina Tardón", Luis Barneo.

Hospital Clínico Universitario de Santiago de Compostela, Spain: Enrique Domínguez Muñoz¹, Antonio Lozano, Maria Luaces.

Hospital Clínico Universitario de Salamanca, Spain: Luís Muñoz-Bellvís ${ }^{1}$, J.M. Sayagués, M.L.

Gutíerrrez Troncoso, A. Orfao de Matos.

University of Marburg, Department of Gastroenterology, Phillips University of Marburg, Germany: Thomas Gress $^{1}$, Malte Buchholz, Albrecht Neesse.

Queen Mary University of London, UK: Tatjana Crnogorac-Jurcevic ${ }^{1}$, Hemant M Kocher, Satyajit Bhattacharya, Ajit T Abraham, Darren Ennis, Thomas Dowe, Tomasz Radon

Scientific advisors of the PanGenEU Study: Debra T Silverman (NCl, USA) and Douglas Easton (U. of Cambridge, UK)

${ }_{1}^{1}$ Principal Investigator in each centre 


\section{Supplementary Methods}

Study population: PanGenEU (the European Study into Digestive Illnesses and Genetics) is a mostly hospital-based casecontrol study of PC conducted in six European countries (Spain, Germany, Ireland, United Kingdom, Italy and Sweden) and 28 centers, designed to evaluate environmental and genetic factors associated with PC. Recruitment of PC cases and corresponding controls matched by region, sex and age ( \pm 10 years) took place from 2007 to 2014 in all participating centers, except in those from Italy were only cases were ascertained. Inclusion criteria were cases diagnosed or suspected of having PC, who had lived in one of the study areas and aged older than 18 years. All medical records were reviewed to ensure the PC diagnosis for study entry. Participants incapable of participating in the study due to impairment of physical ability were excluded. Response rates varied by center and were on average $76 \%$ among cases and $85 \%$ among controls.

Data collection: A standardized epidemiological questionnaire including self-reported socio-demographic and anthropometric data (location of body fat, height and weight at different ages: age 20 and 50 years, 2 years before recruitment and at PC diagnosis), the likely fat accumulation zone (abdominal, hips, all equally, no extra weight gain), family history of cancer including PC, medical history (e.g., chronic pancreatitis, diabetes and others) including regular use of specific medication, and lifestyle behaviors (e.g., smoking and alcohol habits) was administered by trained personnel in a face-to-face interview. This information was used as input to generate other variables such as body mass index (BMl: weight in $\mathrm{kg} /$ height in $\left.\mathrm{m}^{2}:<25,25-30, \geq 30 \mathrm{~kg} / \mathrm{m}^{2}\right)$ at different ages (20,50 and two years before recruitment). Weight gain ( $>5$ or $10 \mathrm{~kg}$ ) between young and old adulthood (20 and 50 years, respectively), and weight loss since age 50 until two years before recruitment, was also derived (younger than 50 years, yes weight gain/loss, no weight gain/loss).

T2DM biomarker assays: Non-fasting erythrocyte and serum samples collected at subject recruitment and stored at $-80^{\circ} \mathrm{C}$ from 509 PC cases and 413 controls of the Spanish PanGenEU study were analysed blinded to the disease status. All individuals had epidemiological information; 356 cases and 298 controls also participated in the genetic study. Glycated haemoglobin or $\mathrm{Hb} 1 \mathrm{Ac}$ (as percentage of haemoglobin and $\mathrm{mmol} / \mathrm{mol}$ ) was measured with an automated HPLC analyzer (Menarini Diagnostics, Spain) at the Hospital 12 de Octubre, Madrid (Spain). Mean intra-batch and inter-batch coefficients of variations were $0.42 \%$ and $8.46 \%$, respectively. Diabetes status based on $\mathrm{Hb} 1 \mathrm{Ac}$ data was established for values above $6.5 \%$. Undiagnosed T2DM, most likely NODM, was identified on this basis. Other predefined levels of Hb1Ac were considered to distinguish between prediabetes $(\geq 6 \%$ and $<6.5 \%)$ and non-diabetes $(<6 \%)$. Furthermore, undiagnosed or uncontrolled T2DM ( $\mathrm{Hb} 1 \mathrm{Ac} \geq 6.5 \%$ ), or HbA1c levels $<6.5 \%$ but self-reported T2DM diagnosis, i.e., controlled T2DM patients, were considered in separate categories. C-peptide was measured at University Hospital Giessen and Marburg using a Cobas e411 (Roche Diagnostics, Mannheim, Germany) by means of Electro-chemiluminescence immune assay. Coefficients of variations were $<5 \%$. Type $3 c$-like diabetes was defined as NODM with C-peptide levels below the median $(4.2 \mu \mathrm{g} / \mathrm{L}$ in controls).

SNP selection and genotyping: Consistent quality SNP data was available for 1,162 cases and 540 controls who provided blood samples. DNA samples were genotyped on the Infinium OncoArray-500K at the CEGEN (Spanish National Cancer Research Centre, CNIO). The genotype data was filtered for call rate, relatedness, European ancestry $<80 \%$ and sex chromosome abnormalities. Overall, 451,883 SNPs passed these quality filters and underwent imputation of missing genotypes using IMPUTE v2. The control group was enlarged with 212 controls participating in two Spanish bladder cancer case-control studies (EPICURO and ISBlaC), with analogous characteristics to the source population (Spanish PC cases; $44 \%$ females and mean age $=64.7$ years) and with genotype and epidemiological data available. Similar protocols for data collection and genotyping were used in all studies. Genotype distributions of each SNP and deviation from Hardy-Weinberg equilibrium were assessed separately in each of the geographical areas. Principal components to control for population stratification were calculated with the prcomp function in $R$.

Imputation: Missing data $(9.8 \%$ in the dataset containing 63 variables with predictors to improve the imputation performance), assumed to be at random, was substituted by the random forest (RF) imputation algorithm. RF tress ( $n=100)$ trained on the observed values of the data set predicted the missing values of the data. The out-of-bag error (OOB) was considered as a measure of the imputation error. A further test of imputation performance consisted of comparing observed imputed values versus the expected values (\% of concordance) in a test set resembling the pattern of missingness of the original data. Mean OOB error (0.05) and concordance estimates (92.5\%) demonstrated good imputation performance (Supplementary Table 2). 
Statistical analysis for the observational association study: There were 2,018 PC cases and 1,540 controls available for assessing the observational association between T2DM and PC risk (Supplementary Figure 1A). Descriptive statistics by case-control status were performed, evaluating differences between the groups via Pearson chi-square and Student's t-test or Mann-Whitney test, where appropriate. Multivariate unconditional logistic regression was applied to evaluate the association between T2DM and PC risk by Odds Ratios (ORs) and 95\% Confidence Intervals (Cls). The influence of smoking, obesity (BMI variables), alcohol status, asthma and/or allergies, educational level, and family history of PC, was evaluated in age, sex and country-adjusted models (Model 1), whereby only smoking (non-smokers and smokers in tertiles of pack-years) proved to be a confounder ( $>10 \%$ change of the risk estimators). The lowest Akaike's Information Criterion value was reached by further including BMI 2 years before recruitment (normal weight/overweight/obese) (Model 2).

Effect modification by country, center, age, gender, smoking and alcohol status, and BMI variables was evaluated by adding interaction terms in the models, and comparing them with models lacking this interaction (likelihood ratio test, LHR). Effect measure modification was further evaluated in stratified analyses by subgroups of these variables.

Dose-response and trend analysis was conducted by fitting the categorized variables (time since T2DM, age at T2DM diagnosis and $\mathrm{Hb} 1 \mathrm{Ac}$ levels) as an ordinal score in the logistic models. The dose-response curve was evaluated by applying restricted cubic splines ( 3 knots at the $10 \%, 50 \%$ and $90 \%$ percentile). ${ }^{24}$ Linearity tests were performed by comparing via the LHR test the continuous variable models as nonlinear or as linear. Interaction by centre but not by country was apparent; therefore, random centre effects in mixed models when appropriate were applied. ${ }^{25}$

Mediation analysis: The counterfactual mediation model for binary mediators and outcomes was used to explore mediation effects on the associations. ${ }^{26}$ We explored whether obesity leading to T2DM, and subsequently to PC, could explain the observational association between T2DM and PC. With this method, we estimated the total effect (TE) of obesity on PC by determining a natural direct effect (NDE) of obesity on PC and a natural indirect effect (NIE) of obesity on T2DM accounting by the influence of confounders. Standard errors were generated using Monte Carlo bootstrapping with 1,000 replications. Similarly, potential mediating effects of obesity on the association between T2DM and PC risk were explored.

Mendelian Randomization Analysis (MRA): The causal effect of T2DM subtypes on PC (Supplementary Figure 1 B) was estimated using several MRA approaches (Wald ratio, 2-stage least squares -TSLS, inverse variance weighted methodIVW, and simple median), ${ }^{27}$ adjusting estimates for the aforementioned potential confounders. Some of these methods were applied via the MendelianRandomization $R$ package. ${ }^{28} \mathrm{~A}$ total of 16 variants in high $L D\left(R^{2}>0.8\right)$ were removed for these analyses (Supplementary Table 1). Since genetic variants for T2DM can be confounded by BMl effects due to sharing of variants (i.e., pleiotropy), we tested for the association between the variants and BMI, as well as other confounders, and removed those variants showing an association with other traits (Supplementary Table 3). After removing them, 35 T2DMSNPs remained to build the IV. The genetic association of this IV with T2DM was estimated in controls only, and subsequently with PC in the case-control setting. Logistic regression models adjusted for age, sex and five principal components to control for population stratification were used to assess the per allele effect of each SNP and of the genetic score. In addition, the weighted median estimation and the MR-Egger approach were applied to detect and correct bias due to pleiotropy. $27,29,30$ The weighted median estimator reflects the median of the distribution of weighted Wald ratio estimates. This test is less sensitive to the influence of pleiotropic variants since less weight is given to outlying estimates. ${ }^{29,30}$ The MREgger approach performs a weighted linear regression of the genetic associations with the outcome on the genetic associations with the exposure, while keeping the intercept unconstrained. This test provides evidence for directional pleiotropy when the intercept differs from zero. ${ }^{29}$

Bidirectional MRA: The same procedure was used to explore the causal effect of PC on T2DM (Supplementary Figure 1 C). We kept 33 PC-related SNPs for the analyses after removing SNPs in LD and those associated with other traits (Supplementary Tables 1 and 3). The association of the IV with PC was estimated in non-T2DM, followed by its association with T2DM in all subjects.

MRA using pleiotropic genetic variants: Causal assessment of obesity (at age 50 and 2 years before the interview) and PC was explored considering 85 obesity-related SNPs (41 SNPs were removed due to LD and associations with other traits: Supplementary Tables 1 and 3). Multivariable MRA was used to disentangle further the causal effect of T2DM and obesity on PC using T2DM-SNPs as IV (Supplementary Figure 1 D), or PC-SNPs as IV in the opposite direction (Supplementary Figure $1 \mathrm{E}$ ). The IVW, TSLS and Egger methods were applied in these analyses. ${ }^{31,32}$ In line with the aforementioned mediation analyses, we explored potential mediating effects of obesity or T2DM (mediators) using separate IVs (Supplementary Figure $1 \mathrm{~F}$ and G). ${ }^{33}$ Direct and indirect effects were estimated using the counterfactual method. ${ }^{26}$ 
Sensitivity analyses: We compared estimates from the unimputed and imputed data to assess the robustness of the results. Although heterogeneity by country was absent, we evaluated the consistency of the results across countries by removing each country at a time from the analyses. This was particularly relevant for PC cases from Italy due to the lack of matched controls. Sensitivity analyses also comprised the assessment of T2DM status based on questionnaire, i.e. self-reported (SR) data, or biomarker data in different study settings. In MRA, to further detect potential pleiotropic variants, we also removed SNPs that were outliers based on Cook's distances and removed additional variants potentially associated with other phenotypes..$^{29}$ The latter were identified in publicly available data from GWAS studies (PhenoScanner database). ${ }^{34}$ The MR-base platform was also used to inspect the presence of pleiotropy. For instance, scatter plots of the gene-outcome and gene-exposure associations and for the SNP risk increase against the strength of instrumental SNPs were constructed, along with leave-one out analyses funnel plots for visual assessment of pleitropy. ${ }^{35} \mathrm{In}$ addition, since unmeasured confounding is a major concern of causal inference in observational studies, we tested by estimating the E-Value how strong such confounders would have to be related to the exposure and the outcome to explain away the observed association. ${ }^{36}$ High E-Values reflect less impact of these confounders on the observed associations.

Results were comparable to those seen in analyses of the original data, regarding the use of unimputed missing data (Supplementary Tables 14), country-specific data (data not shown), reclassified T2DM status with biomarker data (e.g., Supplementary Table 15), and in analyses of the influence of pleiotropic effects in MRA (Supplementary Table 16 and Supplementary Figure 3). The E-value for the causal effect between NODM or LSDM with PC risk (E-value $=12.29$ and 3.12, respectively) suggested that unmeasured confounders are unlikely to explain away the effect of the observed association, especially with regard to NODM (Supplementary Table 17). 
Supplemental Table 1: Selected genetic variants of T2DM, PC, and obesity.

\begin{tabular}{|c|c|c|c|c|c|c|c|c|c|}
\hline \multirow[b]{2}{*}{ ID } & \multicolumn{3}{|l|}{ T2DM } & \multicolumn{3}{|l|}{ PC } & \multicolumn{3}{|l|}{ Obesity } \\
\hline & SNP & $\mathrm{Chr}$ & Position & SNP & $\mathrm{Chr}$ & Position & SNP & $\mathrm{Chr}$ & Position \\
\hline 1 & rs2641348 & 1 & 120437884 & rs13303010 & 1 & 894573 & rs11208659 & 1 & 65979280 \\
\hline 2 & rs340874 & 1 & 214159256 & rs1747924 & 1 & 64538961 & rs3101336 & 1 & 72751185 \\
\hline 3 & rs13414140 & 2 & 43671176 & rs351365 & 1 & 113046395 & rs2568958 & 1 & 72765116 \\
\hline 4 & rs243021 & 2 & 60584819 & rs10919791 & 1 & 199965168 & rs7531118 & 1 & 72837239 \\
\hline 5 & rs2943641 & 2 & 227093745 & rs2816938 & 1 & 199985368 & rs 1993709 & 1 & 72838529 \\
\hline 6 & rs780094 & 2 & 27741237 & rs3790844 & 1 & 200007432 & rs 1514177 & 1 & 74991402 \\
\hline 7 & rs1801282 & 3 & 12393125 & rs962856 & 2 & 67593803 & rs1514174 & 1 & 74993063 \\
\hline 8 & rs1470579 & 3 & 185529080 & rs1486134 & 2 & 67639769 & rs17381664 & 1 & 78048331 \\
\hline 9 & rs 4402960 & 3 & 185511687 & rs12478462 & 2 & 153654720 & rs12408810 & 1 & 106640943 \\
\hline 10 & rs11708067 & 3 & 123065778 & rs9854771 & 3 & 189508471 & rs17024258 & 1 & 110147321 \\
\hline 11 & rs2877716 & 3 & 123094451 & rs6537481 & 4 & 148396094 & rs633715 & 1 & 177852580 \\
\hline 12 & rs4411878 & 3 & 64703665 & rs2736098 & 5 & 1294086 & rs12130212 & 1 & 209727257 \\
\hline 13 & rs6802898 & 3 & 12391207 & rs35226131 & 5 & 1295373 & rs 2605100 & 1 & 219644224 \\
\hline 14 & rs10012946 & 4 & 6293350 & rs401681 & 5 & 1322087 & rs6429082 & 1 & 235600129 \\
\hline 15 & rs7708285 & 5 & 76425867 & rs 31490 & 5 & 1344458 & rs12145833 & 1 & 243483754 \\
\hline 16 & rs9472138 & 6 & 43811762 & rs17688601 & 7 & 40866663 & rs6711012 & 2 & 624034 \\
\hline 17 & rs 1535500 & 6 & 39284050 & rs73328514 & 7 & 47488569 & rs12463617 & 2 & 629244 \\
\hline 18 & rs 4712523 & 6 & 20657564 & rs6971499 & 7 & 130680521 & rs11127485 & 2 & 632028 \\
\hline 19 & rs10946398 & 6 & 20661034 & rs2941471 & 8 & 76470404 & rs10189761 & 2 & 646364 \\
\hline 20 & rs7754840 & 6 & 20661250 & rs10094872 & 8 & 128719884 & rs10182181 & 2 & 25150296 \\
\hline 21 & rs7766070 & 6 & 20686573 & rs1561927 & 8 & 129568078 & rs17025867 & 2 & 40578559 \\
\hline 22 & rs7756992 & 6 & 20679709 & rs10991043 & 9 & 106797388 & rs6726292 & 2 & 55156630 \\
\hline 23 & rs13234407 & 7 & 130438214 & rs2417487 & 9 & 106887581 & rs6731302 & 2 & 58833493 \\
\hline 24 & rs1635852 & 7 & 28189411 & rs687289 & 9 & 136137106 & rs887912 & 2 & 59302877 \\
\hline 25 & rs2191348 & 7 & 15064255 & chr9_136149229 & 9 & 136149229 & rs7581710 & 2 & 121195181 \\
\hline 26 & rs 4607517 & 7 & 44235668 & rs7310409 & 12 & 121424861 & rs16867321 & 2 & 181362379 \\
\hline 27 & rs13266634 & 8 & 118184783 & chr12_121454622 & 12 & 121454622 & rs7603514 & 2 & 206836612 \\
\hline 28 & rs3802177 & 8 & 118185025 & rs9554197 & 13 & 28476978 & rs2943650 & 2 & 227105921 \\
\hline 29 & rs896854 & 8 & 95960511 & rs9581943 & 13 & 28493997 & rs11680012 & 2 & 238672425 \\
\hline 30 & rs2383208 & 9 & 22132076 & rs9543325 & 13 & 73916628 & rs12635698 & 3 & 16408489 \\
\hline 31 & rs10811661 & 9 & 22134094 & chr16_75263661 & 16 & 75263661 & rs 1435703 & 3 & 25560231 \\
\hline 32 & rs10512085 & 9 & 81924713 & rs7200646 & 16 & 86335351 & rs13078807 & 3 & 85884150 \\
\hline 33 & rs7903146 & 10 & 114758349 & rs4795218 & 17 & 36078510 & rs7638110 & 3 & 138903985 \\
\hline 34 & rs5015480 & 10 & 94465559 & rs77038344 & 17 & 38644214 & rs1516725 & 3 & 185824004 \\
\hline 35 & rs1111875 & 10 & 94462882 & chr17_70400166 & 17 & 70400166 & rs9816226 & 3 & 185834499 \\
\hline 36 & rs7901695 & 10 & 114754088 & rs7214041 & 17 & 70401476 & rs13130484 & 4 & 45175691 \\
\hline 37 & rs11257655 & 10 & 12307894 & rs1517037 & 18 & 56878274 & rs10938397 & 4 & 45182527 \\
\hline 38 & rs11603334 & 11 & 72432985 & rs6073450 & 20 & 43086648 & rs4833407 & 4 & 113311790 \\
\hline 39 & rs1552224 & 11 & 72433098 & rs450960 & 22 & 18316304 & rs10433903 & 4 & 118093137 \\
\hline 40 & rs5215 & 11 & 17408630 & rs16986825 & 22 & 29300306 & rs 4864201 & 4 & 130731284 \\
\hline 41 & rs5219 & 11 & 17409572 & & & & rs925642 & 4 & 1876788666 \\
\hline 42 & rs10830963 & 11 & 92708710 & & & & rs2307111 & 5 & 75003678 \\
\hline 43 & rs2237892 & 11 & 2839751 & & & & rs2112347 & 5 & 75015242 \\
\hline
\end{tabular}




\begin{tabular}{|c|c|c|c|c|c|}
\hline 44 & rs1387153 & 92673828 & rs374748 & 5 & 127699375 \\
\hline 45 & rs2334499 & 1696849 & rs9328321 & 6 & 5600438 \\
\hline 46 & rs231362 & 2691471 & rs4712652 & 6 & 22078615 \\
\hline 47 & rs1353362 & 71613276 & rs999943 & 6 & 33624733 \\
\hline 48 & rs2612067 & 66170163 & rs2274459 & 6 & 33762242 \\
\hline 49 & rs7965349 & 121471931 & rs2206277 & 6 & 50798526 \\
\hline 50 & rs1359790 & 80717156 & rs987237 & 6 & 50803050 \\
\hline 51 & rs2028299 & 90374257 & rs734597 & 6 & 50836279 \\
\hline 52 & rs7172432 & 62396389 & rs2207139 & 6 & 50845490 \\
\hline 53 & rs4778582 & 80420966 & rs2807278 & 6 & 131809920 \\
\hline 54 & rs 8042680 & 91521337 & rs 10953454 & 7 & 104503813 \\
\hline 55 & rs8050136 & $16 \quad 53816275$ & rs545854 & 8 & 10002570 \\
\hline 56 & rs9939609 & $16 \quad 53820527$ & rs 17150703 & 8 & 9745798 \\
\hline 57 & rs4430796 & 36098040 & rs 17126232 & 8 & 17977650 \\
\hline 58 & & & rs4735692 & 8 & 76615663 \\
\hline 59 & & & rs10968576 & 9 & 28414339 \\
\hline 60 & & & rs1412239 & 9 & 28425515 \\
\hline 61 & & & rs16933812 & 9 & 36969205 \\
\hline 62 & & & rs2275848 & 9 & 95887320 \\
\hline 63 & & & rs 10508503 & 10 & 16299951 \\
\hline 64 & & & rs 16923476 & 10 & 23858211 \\
\hline 65 & & & rs7474896 & 10 & 37982097 \\
\hline 66 & & & rs10999409 & 10 & 72332440 \\
\hline 67 & & & rs2116830 & 10 & 78646536 \\
\hline 68 & & & rs 11042023 & 11 & 8662516 \\
\hline 69 & & & rs297325 & 11 & 16389594 \\
\hline 70 & & & rs4756846 & 11 & 16403511 \\
\hline 71 & & & rs12295638 & 11 & 26605331 \\
\hline 72 & & & rs988712 & 11 & 27563382 \\
\hline 73 & & & rs2030323 & 11 & 27728539 \\
\hline 74 & & & rs564343 & 11 & 65895166 \\
\hline 75 & & & rs1048466 & 12 & 551550 \\
\hline 76 & & & rs3782724 & 12 & 6466081 \\
\hline 77 & & & rs 10875976 & 12 & 50226467 \\
\hline 78 & & & rs7138803 & 12 & 50247468 \\
\hline 79 & & & rs 11109072 & 12 & 97901270 \\
\hline 80 & & & rs9568856 & 13 & 54064981 \\
\hline 81 & & & rs9568867 & 13 & 54107352 \\
\hline 82 & & & rs 17081231 & 13 & 66967622 \\
\hline 83 & & & rs534870 & 13 & 80959207 \\
\hline 84 & & & rs7989336 & 13 & 97017548 \\
\hline 85 & & & rs1957894 & 14 & 61908111 \\
\hline 86 & & & rs699363 & 14 & 72692493 \\
\hline 87 & & & rs11624704 & 14 & 78786077 \\
\hline 88 & & & rs7141420 & 14 & 79899454 \\
\hline 89 & & & rs2370983 & 14 & 79903376 \\
\hline
\end{tabular}




\begin{tabular}{|c|c|c|}
\hline rs8028313 & 15 & 68043057 \\
\hline rs 970843 & 15 & 98876029 \\
\hline rs2531995 & 16 & 4013467 \\
\hline rs12446554 & 16 & 19935073 \\
\hline rs12446632 & 16 & 19935389 \\
\hline rs11639988 & 16 & 19944363 \\
\hline rs7498665 & 16 & 28883241 \\
\hline rs7184597 & 16 & 28921809 \\
\hline rs1421085 & 16 & 53800954 \\
\hline rs1558902 & 16 & 53803574 \\
\hline rs1121980 & 16 & 53809247 \\
\hline rs17817449 & 16 & 53813367 \\
\hline rs8043757 & 16 & 53813450 \\
\hline rs8050136 & 16 & 53816275 \\
\hline rs7185735 & 16 & 53822651 \\
\hline rs9941349 & 16 & 53825488 \\
\hline rs9923451 & 16 & 78952439 \\
\hline rs1424233 & 16 & 79682751 \\
\hline rs7187365 & 16 & 86511915 \\
\hline rs9299 & 17 & 46669430 \\
\hline rs7503807 & 17 & 78591111 \\
\hline rs1805081 & 18 & 21140432 \\
\hline rs17697518 & 18 & 38765659 \\
\hline rs1631486 & 18 & 53026357 \\
\hline rs 17700144 & 18 & 57811982 \\
\hline rs538656 & 18 & 57850422 \\
\hline rs 17782313 & 18 & 57851097 \\
\hline rs10871777 & 18 & 57851763 \\
\hline rs 476828 & 18 & 57852587 \\
\hline rs 11152213 & 18 & 57852948 \\
\hline rs 17773430 & 18 & 57963117 \\
\hline rs1800437 & 19 & 46181392 \\
\hline rs10423928 & 19 & 46182304 \\
\hline rs6110577 & 20 & 15335754 \\
\hline rs 13041126 & 20 & 51092996 \\
\hline rs11088859 & 21 & 22689344 \\
\hline rs5762430 & 22 & 28378472 \\
\hline
\end{tabular}

SNPs in LD (>0.8) for T2DM-related variants: rs4712523, rs10946398, rs7754840, rs7756992, rs9939609, rs8050136, rs5215, rs1552224, rs11603334, rs5015480, rs7903146, rs10811661, rs3802177, rs1801282, rs2877716, rs 1470579 SNPs in LD (>0.8) for PC-related variants: rs31490, rs9554197

SNPs in LD (>0.8) for Obesity-related variants: rs2568958, rs7531118, rs1514174, rs12463617, rs11127485, rs10189761, rs10938397, rs2112347, rs987237, rs734597, rs2207139, rs1412239, rs7184597, rs1558902, rs1121980, rs17817449, rs8043757, rs8050136, rs7185735, rs9941349, rs9923451, rs12446554, rs12446632, rs11639988, rs538656, rs17782313, rs10871777, rs476828, rs11152213, rs10423928 
Supplemental Table 2: Evaluation of the performance of the missing data imputation.

\begin{tabular}{|c|c|c|c|c|c|}
\hline Variable & $\begin{array}{l}\text { Proportion of } \\
\text { missings (\%) }\end{array}$ & $\begin{array}{l}\text { OOB Error Test }{ }^{1} \\
\text { in test set }\end{array}$ & $\begin{array}{l}\text { Imputed } \\
\text { values }\end{array}$ & $\begin{array}{l}\text { Proportion of } \\
\text { concordance () }\end{array}$ & $\begin{array}{l}\text { OOB Error Test }{ }^{1} \\
\text { in full set }\end{array}$ \\
\hline status & 0.00 & 0.0000 & 0 & NA & 0.0000 \\
\hline country & 0.00 & 0.0000 & 0 & NA & 0.0000 \\
\hline gender & 0.11 & 0.1315 & 2 & 50 & 0.1320 \\
\hline smoking status & 3.29 & 0.0103 & 30 & 96.67 & 0.0015 \\
\hline alcohol status & 1.83 & 0.4893 & 21 & 57.14 & 0.4117 \\
\hline chronic pancreatitis status & 3.71 & 0.0052 & 37 & 100 & 0.0053 \\
\hline diabetes by type & 2.67 & 0.0031 & 26 & 100 & 0.0003 \\
\hline educational level & 2.22 & 0.6254 & 21 & 47.62 & 0.5677 \\
\hline FH of pancreatic cancer & 3.57 & 0.0576 & 26 & 100 & 0.0498 \\
\hline FH of diabetes ${ }^{2}$ & 20.15 & 0.4210 & 226 & 100 & 0.3537 \\
\hline periodontitis & 26.39 & 0.1903 & 257 & 81.71 & 0.1745 \\
\hline recession & 37.16 & 0.4041 & 362 & 67.96 & 0.2862 \\
\hline diabetes diet control & 3.99 & 0.0031 & 41 & 100 & 0.0000 \\
\hline diabetes oral medication & 3.23 & 0.0021 & 42 & 97.62 & 0.0000 \\
\hline diabetes insulin control & 3.65 & 0.0021 & 29 & 100 & 0.0000 \\
\hline Pancreatitis type & 3.71 & 0.0294 & 46 & 93.48 & 0.0330 \\
\hline asthma status & 9.33 & 0.0215 & 113 & 100 & 0.0015 \\
\hline nasal allergies & 8.63 & 0.0088 & 94 & 98.94 & 0.0018 \\
\hline cancer & 8.12 & 0.1393 & 86 & 90.70 & 0.1367 \\
\hline diabetes status & 1.60 & 0.0000 & 15 & 100.00 & 0.0000 \\
\hline metabolic syndrome & 18.27 & 0.0061 & 182 & 97.25 & 0.0007 \\
\hline center & 0.00 & 0.0000 & 0 & NA & 0.0000 \\
\hline weighton body site & 8.68 & 0.0621 & 96 & 91.67 & 0.0160 \\
\hline BMI 2 years before & 4.86 & 0.0000 & 42 & 100 & 0.0000 \\
\hline $\mathrm{BMl}$ at age 20 & 19.93 & 0.0447 & 192 & 95.31 & 0.0074 \\
\hline BMl at age 50 & 27.18 & 0.0351 & 257 & 94.55 & 0.0108 \\
\hline pack-years in tertiles & 10.20 & 0.0055 & 90 & 96.67 & 0.0006 \\
\hline age in categories & 0.37 & 0.0643 & 2 & 100 & 0.0220 \\
\hline place fat deposition & 8.68 & 0.0132 & 92 & 97.83 & 0.0031 \\
\hline weight gain $5 \mathrm{~kg}$ & 32.66 & 0.0029 & 309 & 95.15 & 0.0008 \\
\hline weight gain $10 \mathrm{~kg}$ & 32.66 & 0.0000 & 324 & 94.75 & 0.0004 \\
\hline weight at age 20 in tertiles & 18.94 & 0.0109 & 173 & 98.27 & 0.0010 \\
\hline weight at age 50 in tertiles & 25.74 & 0.0202 & 257 & 94.55 & 0.0019 \\
\hline Weight since age 50 & 26.45 & 0.0000 & 250 & 98.00 & 0.0000 \\
\hline hypertension & 9.19 & 0.0044 & 96 & 94.79 & 0.0009 \\
\hline cholesterol & 10.85 & 0.0000 & 116 & 98.28 & 0.0022 \\
\hline height in tertiles & 2.22 & 0.0206 & 27 & 100 & 0.0040 \\
\hline smoking duration in tertiles & 9.47 & 0.0143 & 90 & 97.78 & 0.0053 \\
\hline smoking intensity in tertiles & 3.20 & 0.0145 & 31 & 100 & 0.0044 \\
\hline
\end{tabular}

NA=not applicable

$\mathrm{FH}=$ family history

Covariates used to improve imputation were case-control status, country, center, medical history (cancer, asthma, allergies, chronic pancreatitis), smoking variables (intensity and duration) and weight and height.

1 Out of bag (OOB) error rates: normalized squared error for continuous variables (e.g. age) and proportion of falsely classified entries for categorical variables. Values close to zero indicated good performance and values close to one indicated bad performance.

${ }^{2}$ Concordance test applied to the study population without Ireland since this country did not collect information on family history of the disease. 
Supplemental Table 3: Genetic variants associated individually at $p$-value level $<0.05$ with T2DM and PC, as well as with selected covariates in the study population (752 controls).

\begin{tabular}{|c|c|c|c|c|}
\hline \multicolumn{5}{|l|}{ T2DM-SNPs } \\
\hline NODM & LSDM & PC & smoking & obesity \\
\hline any & $\begin{array}{l}r s 2943641 \\
(p=0.018) \\
r s 1801282 \\
(p=0.051) \\
r s 7901695 \\
(p=0.045) \\
r s 7903146 \\
(p=0.016)\end{array}$ & $\begin{array}{l}r s 2191348 \\
(p=0.015) \\
r s 13266634 \\
(p=0.006) \\
r s 3802177 \\
(p=0.005) \\
r s 7965349 \\
(p=0.011)\end{array}$ & $\begin{array}{l}r s 2641348 \\
(p=0.006) \\
r s 13234407 \\
(p=0.011) \\
r s 1111875 \\
(p=0.018) \\
r s 5015480 \\
(p=0.020) \\
r s 2334499 \\
(p=0.043)\end{array}$ & $\begin{array}{l}\text { rs10830963 } \\
(p=0.044) \\
\text { rs4430796 } \\
(p=0.031)\end{array}$ \\
\hline \multicolumn{5}{|l|}{ PC-SNPs } \\
\hline NODM & LSDM & $P C$ & smoking & obesity \\
\hline $\begin{array}{l}\text { rs2816938.199985368.T.A } \\
(p=0.006) \\
\text { rs7310409 } \\
(p=0.016) \\
\text { chr12_121454622_C_T } \\
(p=0.005)\end{array}$ & any & $\begin{array}{l}\text { rs351365.113046395 } \\
(p=0.002) \\
\text { rs2816938.199985368 } \\
(p=0.001) \\
\text { rs1486134.67639769 } \\
(p=0.049) \\
\text { rs31490 } \\
(p=0.029) \\
\text { rs73328514.47488569 } \\
(p=0.024) \\
\text { rs6971499 } \\
(p=0.007) \\
\text { rs2941471.76470404 } \\
(p=0.031) \\
\text { rs9543325 } \\
(p=0.003) \\
\text { chr16_75263661 } \\
(p=0.001) \\
\text { chr17_70400166 } \\
(p=0.005) \\
\text { rs7214041.70401476 } \\
(p=0.005)\end{array}$ & $\begin{array}{l}\text { rs6537481.148396094 } \\
(p=0.001)\end{array}$ & $\begin{array}{l}\text { rs1747924.64538961 } \\
(p=0.011) \\
\text { rs2816938.199985368 } \\
(p=0.012) \\
\text { rs2736098.1294086 } \\
(p=0.005) \\
r s 17688601.40866663 \\
(p=0.026)\end{array}$ \\
\hline
\end{tabular}

NA: not applicable 
Supplemental Table 4: General characteristics of the study population. PanGenEU study (2,018 cases and 1,540 controls). Imputed data.

\begin{tabular}{|c|c|c|c|c|c|c|c|}
\hline & $\begin{array}{c}\text { Cases } \\
\mathrm{N}=2018 \\
\mathrm{~N}\end{array}$ & $\%$ & $\begin{array}{c}\text { Controls } \\
\mathrm{N}=1540 \\
\mathrm{~N}\end{array}$ & $\%$ & p-value & OR & {$[95 \% \mathrm{Cl}]$} \\
\hline Country & & & & & $<0.001$ & & \\
\hline Spain & 884 & 43.80 & 770 & 50.00 & & & \\
\hline England & 126 & 6.24 & 22 & 1.43 & & & \\
\hline Germany & 131 & 6.49 & 111 & 7.21 & & & \\
\hline Ireland & 173 & 8.57 & 290 & 18.80 & & & \\
\hline Italy & 533 & 26.40 & 0 & 0.00 & & & \\
\hline Sweden & 171 & 8.47 & 347 & 22.50 & & & \\
\hline Gender & & & & & 0.143 & & \\
\hline females & 873 & 43.30 & 705 & 45.80 & & Ref. & \\
\hline males & 1145 & 56.70 & 835 & 54.20 & & 1.11 & {$[0.97 ; 1.27]$} \\
\hline Age (years) & 64.3 & 12.10 & 66.8 & 12.50 & $<0.001$ & 0.98 & {$[0.98 ; 0.99]$} \\
\hline Age in categories & & & & & $<0.001$ & & \\
\hline$<55 y$ & 409 & 20.30 & 261 & 16.90 & & Ref. & \\
\hline $55-65$ y & 500 & 24.80 & 323 & 21.00 & & 0.99 & {$[0.80 ; 1.22]$} \\
\hline $65-75 y$ & 708 & 35.10 & 500 & 32.50 & & 0.90 & {$[0.74 ; 1.10]$} \\
\hline$\geq 75 y$ & 401 & 19.90 & 456 & 29.60 & & 0.56 & {$[0.46 ; 0.69]$} \\
\hline BMI 2 years before & & & & & 0.971 & & \\
\hline$<25$ & 761 & 37.70 & 575 & 37.30 & & Ref. & \\
\hline $25-29.99$ & 868 & 43.00 & 668 & 43.40 & & 0.98 & {$[0.85 ; 1.14]$} \\
\hline$\geq 30$ & 389 & 19.30 & 297 & 19.30 & & 0.99 & {$[0.82 ; 1.19]$} \\
\hline BMl at age 20 & & & & & 0.263 & & \\
\hline$<25$ & 1750 & 86.70 & 1330 & 86.40 & & Ref. & \\
\hline $25-29.99$ & 228 & 11.30 & 189 & 12.30 & & 0.92 & {$[0.75 ; 1.13]$} \\
\hline$\geq 30$ & 40 & 1.98 & 21 & 1.36 & & 1.44 & {$[0.85 ; 2.51]$} \\
\hline BMl at age 50 & & & & & $<0.001$ & & \\
\hline$<25$ & 620 & 30.70 & 612 & 39.70 & & Ref. & \\
\hline $25-29.99$ & 929 & 46.10 & 604 & 39.20 & & 1.52 & {$[1.30 ; 1.77]$} \\
\hline$\geq 30$ & 468 & 23.20 & 324 & 21.00 & & 1.43 & {$[1.19 ; 1.71]$} \\
\hline Weight gain $>5 \mathrm{~kg}$ (age 20-50) & & & & & 0.343 & & \\
\hline no & 391 & 19.40 & 319 & 20.70 & & Ref. & \\
\hline yes & 1627 & 80.60 & 1221 & 79.30 & & 1.09 & {$[0.92 ; 1.28]$} \\
\hline Weight gain >10kg (age 20-50) & & & & & $<0.001$ & & \\
\hline no & 742 & 36.80 & 676 & 43.90 & & Ref. & \\
\hline yes & 1276 & 63.20 & 864 & 56.10 & & 1.35 & {$[1.18 ; 1.54]$} \\
\hline Weight loss since age 50 & & & & & 0.012 & & \\
\hline no & 1346 & 66.70 & 1089 & 70.70 & & Ref. & \\
\hline yes & 672 & 33.30 & 451 & 29.30 & & 1.21 & {$[1.04 ; 1.39]$} \\
\hline Smoking status & & & & & $<0.001$ & & \\
\hline never & 760 & 37.70 & 691 & 44.90 & & Ref. & \\
\hline former & 683 & 33.80 & 563 & 36.60 & & 1.10 & {$[0.95 ; 1.28]$} \\
\hline current & 575 & 28.50 & 286 & 18.60 & & 1.83 & {$[1.53 ; 2.18]$} \\
\hline Pack-years in tertiles & & & & & $<0.001$ & & \\
\hline never smokers & 760 & 37.70 & 691 & 44.90 & & Ref. & \\
\hline$[0.05,12.95]$ & 259 & 12.80 & 269 & 17.50 & & 0.88 & {$[0.72 ; 1.07]$} \\
\hline$[13,36]$ & 583 & 28.90 & 327 & 21.20 & & 1.62 & {$[1.37 ; 1.92]$} \\
\hline$[36.3,240]$ & 416 & 20.60 & 253 & 16.40 & & 1.49 & {$[1.24 ; 1.80]$} \\
\hline Alcohol status & & & & & $<0.001$ & & \\
\hline
\end{tabular}




\section{Family history of PC}

$\begin{array}{ll}\text { never } & 599 \\ \text { former } & 508 \\ \text { current } & 911\end{array}$

Pancreatitis type

\begin{tabular}{|c|c|c|c|c|c|c|}
\hline \multicolumn{3}{|l|}{ lype } & \multicolumn{4}{|c|}{$<.001$} \\
\hline no & 1918 & 95.00 & 1523 & 98.90 & Ref. & \\
\hline acute & 81 & 4.01 & 15 & 0.97 & 4.25 & {$[2.51 ; 7.71]$} \\
\hline \multirow{2}{*}{\multicolumn{3}{|c|}{ level (years of education) }} & 2 & 0.13 & 7.06 & {$[2.03 ; 48.0]$} \\
\hline & & & & & & \\
\hline
\end{tabular}

Educational level (years of education)

$\begin{array}{ll}<5 y & 343 \\ 6 \text { to } 9 y & 486 \\ 10 \text { to } 13 y & 698\end{array}$$$
\geq 14 \text { y }
$$

491

\section{no}

$$
\text { yes }
$$

Periodontitis

$$
\begin{array}{ll} 
& \text { no } \\
\text { Recession } &
\end{array}
$$$$
\text { no }
$$

Asthma

$$
\text { yes }
$$

no

$$
\text { yes }
$$

Nasal allergies

no
yes
Hypertension

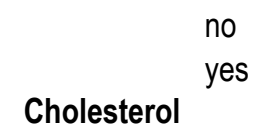

no

$$
\text { yes }
$$

\subsection{0}

24.10

177

399

11.50

25.90

33.00

29.60

24.30

508

456

1889

129

93.60

6.39

1499

41

97.30

2.66

1744

86.40

274

13.60

1340

200

87.00

13.00

$1481 \quad 73.40$

1197

343

77.70

22.30

26.60

1381

1887

93.50

1381
159

89.70

10.30

6.49

1236

304

80.30

19.70

247

12.20

$1324 \quad 65.60$

34.40

913

627

59.30

40.70

$1459 \quad 72.30$

559 27.70

1000

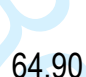

Ref.

$0.63 \quad[0.50 ; 0.79]$

$0.71 \quad[0.57 ; 0.88]$

$0.56 \quad[0.44 ; 0.69]$

$<0.001$

Ref.

2.49

[1.76;3.60]

0.643

Ref.

$1.05 \quad$ [0.87;1.28]

0.003

Ref.

[1.27 [1.08;1.48]

$<0.001$

Ref.

$0.60 \quad[0.47 ; 0.77]$

$<0.001$

Ref.

$0.57 \quad[0.47 ; 0.68]$

$<0.001$

Ref.

$0.76 \quad[0.67 ; 0.88]$

$<0.001$

Ref.

35.10

Differences between cases and controls evaluated via Chi-squared test (categprocal variables) and Student's t-test or Mann-Whitney (continuous variables).

Odds Ratios (OR) derived from unadjusted unconditional logistic resgression models.

Data of all variables was self-reported. 
Supplemental Table 5: Baseline characteristics of NODM and LSDM in the PanGenEU study (538 cases and 198 controls). Imputed data.

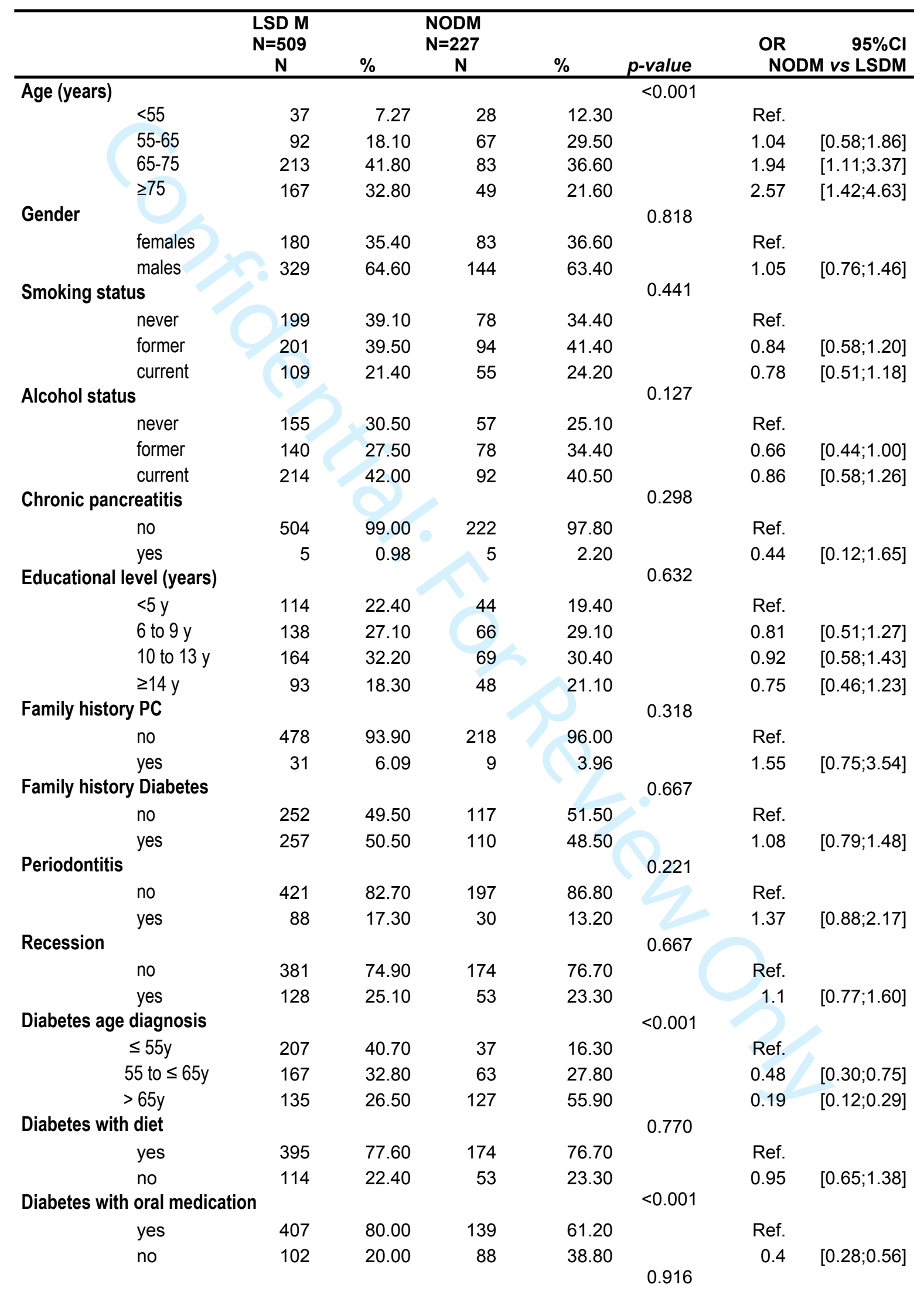


Diabetes with insulin

\begin{tabular}{|c|c|c|c|c|c|c|c|c|}
\hline & yes & 293 & 57.60 & 129 & 56.80 & & Ref. & \\
\hline & no & 216 & 42.40 & 98 & 43.20 & & 0.97 & {$[0.71 ; 1.33]$} \\
\hline \multirow[t]{3}{*}{ Asthma } & & & & & & 0.135 & & \\
\hline & no & 467 & 91.70 & 216 & 95.20 & & Ref. & \\
\hline & yes & 42 & 8.25 & 11 & 4.85 & & 1.75 & {$[0.91 ; 3.65]$} \\
\hline \multicolumn{2}{|c|}{ Nasal allergies } & & & & & 0.46 & & \\
\hline & no & 453 & 89.00 & 197 & 86.80 & & Ref. & \\
\hline & yes & 56 & 11.00 & 30 & 13.20 & & 0.81 & {$[0.51 ; 1.32]$} \\
\hline \multicolumn{4}{|c|}{ Metabolic syndrome } & & & 0.116 & & \\
\hline & Any one & 146 & 28.70 & 58 & 25.60 & & Ref. & \\
\hline & Any two & 170 & 33.40 & 96 & 42.30 & & 0.7 & {$[0.47 ; 1.04]$} \\
\hline & Any three & 151 & 29.70 & 60 & 26.40 & & 1 & {$[0.65 ; 1.53]$} \\
\hline & All four & 42 & 8.25 & 13 & 5.73 & & 1.27 & {$[0.65 ; 2.64]$} \\
\hline \multicolumn{2}{|c|}{ BMI 2 years before } & & & & & 0.172 & & \\
\hline & $<25$ & 128 & 25.10 & 47 & 20.70 & & Ref. & \\
\hline & $25-29.99$ & 245 & 48.10 & 126 & 55.50 & & 0.72 & {$[0.48 ; 1.06]$} \\
\hline & $\geq 30$ & 136 & 26.70 & 54 & 23.80 & & 0.93 & {$[0.58 ; 1.47]$} \\
\hline \multicolumn{2}{|c|}{ BMI at age 20} & & & & & 0.713 & & \\
\hline & $<25$ & 421 & 82.70 & 184 & 81.10 & & Ref. & \\
\hline & $25-29.99$ & 72 & 14.10 & 37 & 16.30 & & 0.85 & {$[0.55 ; 1.32]$} \\
\hline & $\geq 30$ & 16 & 3.14 & 6 & 2.64 & & 1.15 & {$[0.46 ; 3.29]$} \\
\hline \multicolumn{2}{|c|}{$\mathrm{BMI}$ at age 50} & & & & & 0.99 & & \\
\hline & $<25$ & 110 & 21.60 & 48 & 21.10 & & Ref. & \\
\hline & $25-29.99$ & 241 & 47.30 & 108 & 47.60 & & 0.97 & {$[0.64 ; 1.46]$} \\
\hline & $\geq 30$ & 158 & 31.00 & 71 & 31.30 & & 0.97 & {$[0.62 ; 1.51]$} \\
\hline \multicolumn{2}{|c|}{ Pack-years in tertiles } & & & & & 0.585 & & \\
\hline & never & & & & & & & \\
\hline & smokers & 199 & 39.10 & 78 & 34.40 & & Ref. & \\
\hline & {$[0.05,12.95]$} & 51 & 10.00 & 27 & 11.90 & & 0.74 & {$[0.43 ; 1.28]$} \\
\hline & {$[13,36]$} & 129 & 25.30 & 64 & 28.20 & & 0.79 & {$[0.53 ; 1.18]$} \\
\hline & {$[36.3,240]$} & 130 & 25.50 & 58 & 25.60 & & 0.88 & {$[0.59 ; 1.32]$} \\
\hline \multicolumn{3}{|c|}{ Weightgain >5kg (age 20-50) } & & & & 0.943 & & \\
\hline & no & 58 & 11.40 & 27 & 11.90 & & Ref. & \\
\hline & yes & 451 & 88.60 & 200 & 88.10 & & 1.05 & {$[0.64 ; 1.70]$} \\
\hline \multicolumn{3}{|c|}{ Weightgain >10kg (age 20-50) } & & & & 0.797 & & \\
\hline & no & 155 & 30.50 & 72 & 31.70 & & Ref. & \\
\hline & yes & 354 & 69.50 & 155 & 68.30 & & 1.06 & {$[0.75 ; 1.48]$} \\
\hline \multicolumn{2}{|l|}{ Hypertension } & & & & & 0.596 & & \\
\hline & no & 241 & 47.30 & 113 & 49.80 & & Ref. & \\
\hline & yes & 268 & 52.70 & 114 & 50.20 & & 1.1 & {$[0.81 ; 1.51]$} \\
\hline \multirow[t]{3}{*}{ Cholesterol } & & & & & & 0.981 & & \\
\hline & no & 316 & 62.10 & 140 & 61.70 & & Ref. & \\
\hline & yes & 193 & 37.90 & 87 & 38.30 & & 0.98 & {$[0.71 ; 1.36]$} \\
\hline \multicolumn{3}{|c|}{ Weight loss since age $\mathbf{5 0}$} & & & & 0.429 & & \\
\hline & no & 333 & 65.4 & 156 & 68.7 & & Ref. & \\
\hline & yes & 176 & 34.6 & 71 & 31.3 & & 1.16 & {$[0.83 ; 1.63]$} \\
\hline
\end{tabular}

Differences between cases and controls evaluated via Chi-squared test (categprocal variables) and Student's t-test (continuous variables). Odds Ratios (OR) derived from unadjusted unconditional logistic resgression models. 
Supplemental Table 6: Association between diabetes-related variables and PC risk in the PanGenEU study (2,018 cases and 1,540 controls) when adjusting for T2DM treatment and duration of the disease.

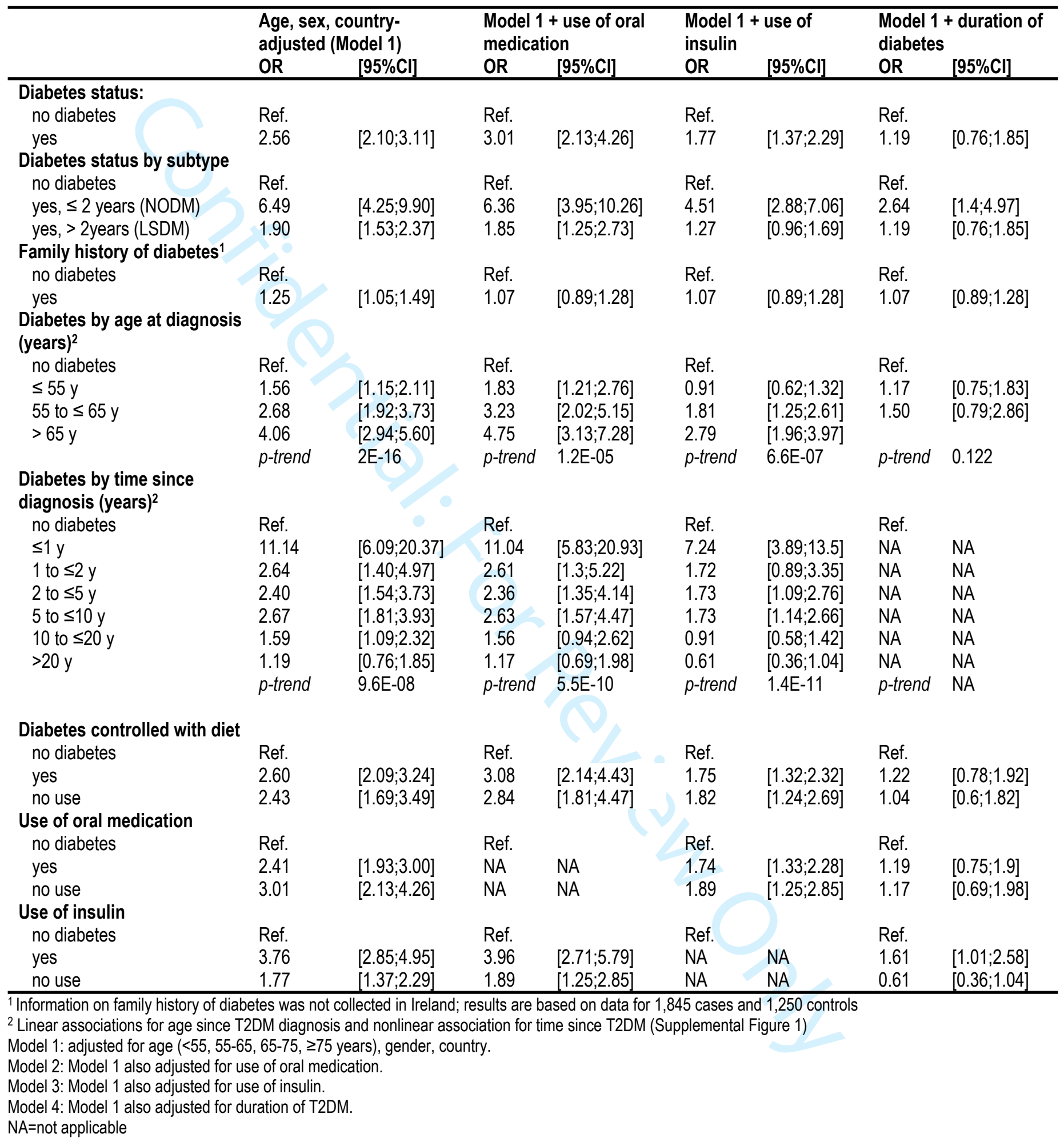


Supplemental Table 7: Association between T2DM status based on Hb1Ac levels and questionnaire data and PC risk in the PanGenEU study.

\begin{tabular}{|c|c|c|c|c|c|c|c|c|c|c|c|}
\hline & \multicolumn{2}{|l|}{ Cases } & \multicolumn{2}{|c|}{ Controls } & \multicolumn{3}{|c|}{ Crude Model } & \multirow{2}{*}{$\begin{array}{c}\text { Model1 } \\
\text { OR }\end{array}$} & \multicolumn{3}{|c|}{ Model2 } \\
\hline & P50 & IQR & P50 & IQR & $p$-value ${ }^{1}$ & OR & {$[95 \% \mathrm{Cl}]$} & & {$[95 \% \mathrm{Cl}]$} & OR & {$[95 \% \mathrm{Cl}]$} \\
\hline $\mathrm{HbA1c}(\%)^{2,3}$ per 1 unit increase & 6.1 & $5.6 ; 6.9$ & 5.6 & $5.4 ; 6.0$ & $<0.001$ & 1.48 & {$[1.30 ; 1.69]$} & 1.50 & {$[1.31 ; 1.71]$} & 1.49 & {$[1.30 ; 1.70]$} \\
\hline C-Peptide ${ }^{2,3}$ per log2 increase & 2.3 & $1.4 ; 3.7$ & 4.2 & $2.5 ; 6.4$ & $<0.001$ & 0.45 & {$[0.38 ; 0.56]$} & 0.46 & {$[0.39 ; 0.54]$} & 0.46 & {$[0.39 ; 0.53]$} \\
\hline 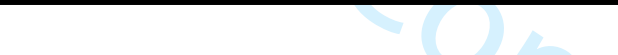 & $\mathrm{N}$ & $\%$ & $\mathrm{~N}$ & $\%$ & & & & & & & \\
\hline Diabetogenic status by HbA1c levels ${ }^{3}$ & & & & & $<0.001$ & & & & & & \\
\hline $\mathrm{HbA} 1 \mathrm{c}<6.5 \%$ & 336 & 66 & 354 & 85.7 & & Ref. & & Ref. & & Ref. & \\
\hline $\mathrm{HbA} 1 \mathrm{c} \geq 6.5 \%$ & 173 & 34 & 59 & 14.3 & & 3.08 & {$[2.22 ; 4.32]$} & 3.29 & {$[2.34 ; 4.62]$} & 3.27 & {$[2.32 ; 4.60]$} \\
\hline Biomarker and self-reported diabetes status & & & & & $<0.001$ & & & & & & \\
\hline no diabetes & 286 & 56.2 & 322 & 78 & & Ref. & & Ref. & & Ref. & \\
\hline self-reported but normal Hb1Ac levels & 50 & 9.8 & 32 & 7.7 & & 1.76 & {$[1.10 ; 2.84]$} & 1.9 & {$[1.18 ; 3.10]$} & 1.92 & {$[1.19 ; 3.13]$} \\
\hline self-reported and $\mathrm{HbA} 1 \mathrm{c} \geq 6.5 \%$ & 173 & 34 & 59 & 14.3 & & 3.3 & {$[2.37 ; 4.65]$} & 3.59 & {$[2.55 ; 5.11]$} & 3.58 & {$[2.53 ; 5.11]$} \\
\hline Diabetes status ${ }^{3}$ & & & & & $<0.001$ & & & & & & \\
\hline no diabetes & 350 & 68.7 & 341 & 82.6 & & Ref. & & Ref. & & Ref. & \\
\hline yes & 159 & 31.3 & 72 & 17.40 & & 2.15 & {$[1.57 ; 2.96]$} & 2.26 & {$[1.64 ; 3.15]$} & 2.26 & {$[1.64 ; 3.15]$} \\
\hline Reclassified diabetes status ${ }^{3}$ & & & & & $<0.00$ & & & & & & \\
\hline no diabetes & 286 & 56.2 & 322 & 78 & & Ref. & & Ref. & & Ref. & \\
\hline self-reported and/or $\mathrm{HbA} 1 \mathrm{c} \geq 6.5 \%$ & 223 & 43.8 & 91 & 22 & & 2.76 & {$[2.07 ; 3.70]$} & 2.99 & {$[2.21 ; 4.06]$} & 2.99 & {$[2.21 ; 4.07]$} \\
\hline Diabetes status by subtype ${ }^{3}$ & & & & & $<0.001$ & & & & & & \\
\hline no diabetes & 350 & 68.7 & 341 & 82.6 & & Ref. & & Ref. & & Ref. & \\
\hline NODM & 66 & 13 & 15 & 3.6 & & 4.29 & {$[2.47 ; 7.93]$} & 4.53 & {$[2.59 ; 8.42]$} & 4.58 & {$[2.61 ; 8.55]$} \\
\hline LSDM & 93 & 18.3 & 57 & 13.8 & & 1.59 & {$[1.11 ; 2.29]$} & 1.65 & {$[1.14 ; 2.41]$} & 1.64 & {$[1.13 ; 2.40]$} \\
\hline Reclassified diabetes status by subtypes ${ }^{3}$ & & & & & $<0.001$ & & & & & & \\
\hline no diabetes & 286 & 56.2 & 322 & 78 & & Ref. & & Ref. & & Ref. & \\
\hline NODM & 130 & 25.5 & 34 & 8.2 & & 4.3 & {$[2.89 ; 6.57]$} & 4.63 & {$[3.08 ; 7.12]$} & 4.63 & {$[3.07 ; 7.15]$} \\
\hline LSDM & 93 & 18.3 & 57 & 13.8 & & 1.84 & {$[1.28 ; 2.66]$} & 1.98 & {$[1.35 ; 2.90]$} & 1.97 & {$[1.35 ; 2.90]$} \\
\hline Biomarker Hb1Ac levels ${ }^{3}$ & & & & & $<0.001$ & & & & & & \\
\hline$<5.5$ & 100 & 19.6 & 129 & 31.2 & & Ref. & & Ref. & & Ref. & \\
\hline $5.5-5.8$ & 72 & 14.1 & 121 & 29.3 & & 0.77 & {$[0.52 ; 1.14]$} & 0.71 & {$[0.47 ; 1.06]$} & 0.71 & {$[0.47 ; 1.06]$} \\
\hline $5.8-6.0$ & 50 & 9.9 & 51 & 12.5 & & 1.26 & {$[0.79 ; 2.03]$} & 1.26 & {$[0.78 ; 2.04]$} & 1.23 & {$[0.76 ; 1.99]$} \\
\hline $6.0-6.5$ & 114 & 22.4 & 53 & 13 & & 2.76 & {$[1.83 ; 4.22]$} & 2.75 & {$[1.80 ; 4.24]$} & 2.72 & {$[1.77 ; 4.17]$} \\
\hline
\end{tabular}


Reclassified NODM into type 3c-like diabetes ${ }^{3}$

p-trend $2.70 \mathrm{E}-10$

p-trend $2.00 \mathrm{E}-16$

p-trend $2.00 \mathrm{E}-16$

$$
\text { no diabetes }
$$

NODM and C-Peptide $>4.2 \mu \mathrm{g} / \mathrm{L}$

NODM and C-Peptide $<4.2 \mu \mathrm{g} / \mathrm{L}$ (T3c)

$\begin{array}{lllll}286 & 56.20 & 322 & 77.97 & \text { Ref. }\end{array}$

$\begin{array}{llll}37 & 7.20 & 21 & 5.08\end{array}$

$\begin{array}{llll}93 & 18.30 & 13 & 3.15\end{array}$

$\begin{array}{llll}93 & 18.30 & 57 & 13.80\end{array}$

\section{$\frac{\text { LSDM }}{\text { Diabetes status }^{4}}$}

no diabetes

yes

Reclassified diabetes status ${ }^{4}$

no diabetes

self-reported and/or $\mathrm{HbA} 1 \mathrm{c} \geq 6.5 \%$

Diabetes status by subtype PanGenEU 4

no diabetes

NODM

LSDM

Reclassified diabetes status by subtypes ${ }^{4}$

$$
\text { no diabetes }
$$

NODM

LSDM

Reclassified NODM into type 3c-like diabetes ${ }^{4}$

no diabetes

NODM and C-Peptide $>4.2 \mu \mathrm{g} / \mathrm{L}$

NODM and C-Peptide $<4.2 \mu \mathrm{g} / \mathrm{L}$ (T3C)

LSDM

diabetes status ${ }^{5}$

no diabetes

yes

Reclassified diabetes status ${ }^{5}$

no diabetes

self-reported and/or $\mathrm{HbA} 1 \mathrm{c} \geq 6.5 \%$

Diabetes status by subtype ${ }^{5}$

$\begin{array}{llllll}1480 & 73.3 & 1342 & 87.1 & <0.001\end{array}$

$\begin{array}{rrrr}1480 & 73.3 & 1342 & 87.1 \\ 538 & 26.7 & 198 & 12.9\end{array}$

$\begin{array}{llll}1416 & 70.2 & 1323 & 85.9\end{array}$

$\begin{array}{llll}602 & 29.8 & 217 & 14.1\end{array}$

$<0.001$

$\begin{array}{llll}1480 & 73.3 & 1342 & 87.1\end{array}$

$\begin{array}{llll}200 & 9.91 & 27 & 1.75\end{array}$

$\begin{array}{llll}338 & 16.7 & 171 & 11.1\end{array}$

$\begin{array}{llll}1416 & 70.2 & 1323 & 85.9\end{array}$

$\begin{array}{llll}264 & 13.1 & 46 & 3\end{array}$

$\begin{array}{llll}338 & 16.7 & 171 & 11.1\end{array}$

$\begin{array}{llll}1416 & 70.2 & 1323 & 85.9\end{array}$

$\begin{array}{rrrr}171 & 8.5 & 33 & 2.2\end{array}$

$\begin{array}{llll}93 & 4.6 & 13 & 0.8\end{array}$

$\begin{array}{llll}338 & 16.7 & 171 & 11.1\end{array}$

$\begin{array}{llll}596 & 67.4 & 628 & 81.6\end{array}$

$\begin{array}{llll}596 & 67.4 & 628 & 81.6 \\ 288 & 32.6 & 142 & 18.4\end{array}$

$\begin{array}{llll}532 & 60.2 & 609 & 19.1\end{array}$

$\begin{array}{llll}352 & 39.8 & 161 & 80.9\end{array}$
$<0.001$

Ref.

Ref.

$6.68 \quad[4.52 ; 10.3]$

$$
1.79 \quad[1.47 ; 2.19]
$$

$<0.001$

$$
\text { Ref. }
$$

\section{Ref.}

$3.93 ; 7.49]$

$<0.001$

[1.52;2.26]

Ref.

$4.84 \quad[3.36 ; 7.20]$

$6.68 \quad[3.86 ; 12.58]$

$<0.001$

Ref.

Ref.

$2.14 \quad[1.70 ; 2.70]$

$<0.001$

Ref.

$<0.001$
$1.85[1.52 ; 2.26]$ $\begin{array}{ccccc}\text { Ref. } & & \text { Ref. } & & \text { Ref. } \\ 2.5 & {[2.01 ; 3.12]} & 2.57 & {[2.04 ; 3.24]} & 2.54\end{array}$

$2.54 \quad[2.01 ; 3.22]$
Ref.

$2.28 \quad[1.30 ; 4.10]$

$8.38 \quad[4.71 ; 16.11]$

$1.98 \quad[1.35 ; 2.92]$

$1.99 \quad[1.36,2.92]$

Ref. Ref.

$2.56 \quad[2.10 ; 3.11] \quad 2.5 \quad[2.05 ; 3.05]$

Ref. Ref.

$2.85 \quad[2.36 ; 3.45] \quad 2.79 \quad[2.31 ; 3.39]$

Ref. Ref.

$6.49 \quad[4.25 ; 9.90] \quad 6.39 \quad[4.18 ; 9.78]$

$1.9 \quad[1.53 ; 2.37] \quad 1.86 \quad[1.49 ; 2.32]$

Ref. Ref.

$5.74 \quad[4.14 ; 8.11] \quad 5.67 \quad[4.09 ; 8.03]$

$2.03 \quad[1.62 ; 2.53] \quad 1.98 \quad[1.59 ; 2.48]$

Ref. Ref.

$4.65 \quad[3.16 ; 7.02] \quad 4.51 \quad[3.06 ; 6.83]$

$8.83 \quad[5.06 ; 1.67] \quad 8.86 \quad[5.07 ; 1.68]$

$2.06 \quad[1.65 ; 2.56] \quad 2.00 \quad[1.61 ; 2.51]$

18 


\begin{tabular}{|c|c|c|c|c|c|c|c|c|c|c|}
\hline no diabetes & 596 & 67.4 & 628 & 81.6 & Ref. & & Ref. & & Ref. & \\
\hline NODM & 109 & 12.2 & 20 & 2.6 & 5.74 & {$[3.60 ; 9.63]$} & 5.7 & [3.54;9.62] & 5.67 & {$[3.52 ; 9.60]$} \\
\hline LSDM & 179 & 20.3 & 122 & 15.8 & 1.55 & {$[1.20 ; 2.00]$} & 1.47 & {$[1.12 ; 1.93]$} & 1.45 & {$[1.11 ; 1.91]$} \\
\hline Reclassified diabetes status by subtypes 5 & & & & & $<0.001$ & & & & & \\
\hline no diabetes & 532 & 60.2 & 609 & 79.1 & Ref. & & Ref. & & Ref. & \\
\hline NODM & 173 & 19.6 & 39 & 5.1 & 5.08 & {$[3.56 ; 7.42]$} & 5.4 & {$[3.75 ; 7.94]$} & 5.35 & {$[3.71 ; 7.88]$} \\
\hline LSDM & 179 & 20.2 & 122 & 15.8 & 1.68 & {$[1.30 ; 2.18]$} & 1.63 & {$[1.24 ; 2.15]$} & 1.62 & {$[1.23 ; 2.14]$} \\
\hline \multicolumn{11}{|c|}{ Reclassified NODM into type 3c-like diabetes ${ }^{5}$} \\
\hline no diabetes & 532 & 60.2 & 609 & 79.1 & Ref. & & Ref. & & Ref. & \\
\hline NODM and C-Peptide $>4.2 \mu \mathrm{g} / \mathrm{L}$ & 80 & 9.1 & 26 & 3.4 & 3.52 & {$[2.26 ; 5.66]$} & 3.49 & {$[2.21 ; 5.68]$} & 3.41 & {$[2.15 ; 5.57]$} \\
\hline NODM and C-Peptide <4.2 $\mu \mathrm{g} / \mathrm{L}$ (T3c) & 93 & 10.5 & 13 & 1.7 & 8.19 & {$[4.70 ; 15.50]$} & 9.46 & {$[5.40 ; 17.96]$} & 9.47 & {$[5.40 ; 18.02]$} \\
\hline LSDM & 179 & 20.2 & 122 & 15.8 & 1.68 & {$[1.30 ; 2.18]$} & 1.65 & {$[1.26 ; 2.18]$} & 1.63 & {$[1.24 ; 2.16]$} \\
\hline
\end{tabular}

1 Differences between groups evaluated by the Chi-square test (categorical variables) and Mann-Whitney test (continuous variables).

2 Linear association for $\mathrm{Hb} 1 \mathrm{Ac}$ levels and non-linear for C-Peptide (Supplemental Figure 1).

${ }^{3}$ NODM and LSDM was classified with questionnaire and biomarker data in the biomarker study population (509 cases and 413 controls).

${ }^{4}$ NODM and LSDM was classified with questionnaire and biomarker data in the entire study population (2,018 cases and 1,540 controls).

${ }^{5}$ NODM and LSDM was classified with questionnaire and biomarker data in the PanGenEU-Spain study population (884 cases and 770 controls).

Crude Model: unadjusted.

Model 1: adjusted for age ( $<55,55-65,65-75, \geq 75$ years), sex and center (Spain) or country.

Model 2: Model 1 also adjusted for pack years (never-smokers and tertiles of pack-years) and BMI (<25, 25-30, $\geq 30 \mathrm{~kg} / \mathrm{m} 2$ ). 
Supplemental Table 8: Association between T2DM and PC risk by T2MD subtypes and other covariates in the PanGenEU study (2,018 cases and 1,540 controls).

\begin{tabular}{|c|c|c|c|c|c|}
\hline & No diabetes (Ref.) & NODM & & LSDM & \\
\hline & Cases;Controls & Cases;Controls & $\mathrm{OR}^{1}[95 \% \mathrm{Cl}]$ & Cases;Controls & $\mathrm{OR}^{1}[95 \% \mathrm{Cl}]$ \\
\hline \multicolumn{6}{|l|}{ Alcohol status } \\
\hline never & $451 ; 326$ & $47 ; 10$ & $3.62[1.81 ; 7.90]$ & $101 ; 54$ & $1.43[0.95 ; 2.16]$ \\
\hline former & $329 ; 195$ & $71 ; 7$ & $6.59[3.09 ; 16.33]$ & $108 ; 32$ & $2.61[1.66 ; 4.20]$ \\
\hline \multirow[t]{2}{*}{ current } & $700 ; 821$ & $82 ; 10$ & $8.21[4.30 ; 17.34]$ & $129 ; 85$ & $1.71[1.24 ; 2.37]$ \\
\hline & $\mathrm{p}$-value for interaction & 0.3530 & & 0.3914 & \\
\hline \multicolumn{6}{|c|}{ Chronic pancreatitis } \\
\hline no & $1469 ; 1342$ & $195 ; 27$ & $6.31[4.2 ; 9.83]$ & $335 ; 169$ & $1.92[1.55 ; 2.40]$ \\
\hline \multirow[t]{2}{*}{ yes } & $11 ; 0$ & $5 ; 0$ & NA & $3 ; 2$ & NA \\
\hline & $\mathrm{p}$-value for interaction & NA & & NA & \\
\hline \multicolumn{6}{|c|}{ Family history PC } \\
\hline no & $1378 ; 1305$ & $191 ; 27$ & $6.26[4.16 ; 9.77]$ & $311 ; 167$ & $1.88[1.50 ; 2.35]$ \\
\hline \multirow[t]{2}{*}{ yes } & $93 ; 37$ & $9 ; 0$ & NA & $27 ; 4$ & $\begin{array}{r}2.79 \\
{[0.90 ; 10.72]}\end{array}$ \\
\hline & $\mathrm{p}$-value for interaction & 0.2209 & & 0.4220 & \\
\hline \multicolumn{6}{|l|}{ Asthma } \\
\hline no & $1378 ; 1207$ & $192 ; 24$ & $6.83[4.46 ; 10.9]$ & $317 ; 150$ & $2[1.59 ; 2.52]$ \\
\hline \multirow[t]{2}{*}{ yes } & $102 ; 135$ & $8 ; 3$ & $2.56[0.6 ; 13.26]$ & $21 ; 21$ & $1.34[0.61 ; 2.9]$ \\
\hline & $\mathrm{p}$-value for interaction & 0.1853 & & 0.1832 & \\
\hline \multicolumn{6}{|l|}{ Nasal allergies } \\
\hline no & $1292 ; 1065$ & $172 ; 25$ & $5.5[3.59 ; 8.75]$ & $307 ; 146$ & $1.84[1.46 ; 2.34]$ \\
\hline \multirow[t]{2}{*}{ yes } & $188 ; 277$ & $28 ; 2$ & $17.39[4.92 ; 110.72]$ & $31 ; 25$ & $2.1[1.14 ; 3.88]$ \\
\hline & $\mathrm{p}$-value for interaction & 0.1131 & & 0.8289 & \\
\hline \multicolumn{6}{|c|}{ BMI 2 years before } \\
\hline$<25$ & $635 ; 524$ & $45 ; 2$ & $20.35[6.11 ; 126.34]$ & $79 ; 49$ & $1.22[0.79 ; 1.87]$ \\
\hline $25-29.99$ & $593 ; 570$ & $109 ; 17$ & $5.41[3.2 ; 9.65]$ & $165 ; 80$ & $2.16[1.57 ; 2.99]$ \\
\hline \multirow[t]{2}{*}{$\geq 30$} & $252 ; 248$ & $46 ; 8$ & $5.01[2.34 ; 12.04]$ & $94 ; 42$ & $2.37[1.53 ; 3.71]$ \\
\hline & $\mathrm{p}$-value for interaction & 0.1222 & & 0.0496 & \\
\hline \multicolumn{6}{|l|}{ BMl at age 20} \\
\hline$<25$ & $1311 ; 1162$ & $163 ; 21$ & $6.72[4.26 ; 11.12]$ & $271 ; 147$ & $1.78[1.40 ; 2.26]$ \\
\hline $25-29.99$ & $143 ; 161$ & $31 ; 6$ & $5.06[2.08 ; 14.28]$ & $53 ; 19$ & $3.11[1.69 ; 5.93]$ \\
\hline \multirow[t]{2}{*}{$\geq 30$} & $26 ; 19$ & $6 ; 0$ & NA & $11 ; 5$ & $\begin{array}{r}2.69 \\
{[0.63 ; 13.71]}\end{array}$ \\
\hline & $\mathrm{p}$-value for interaction & 0.5767 & & 0.3708 & \\
\hline \multicolumn{6}{|l|}{$\mathrm{BMI}$ at age 50} \\
\hline$<25$ & $516 ; 562$ & $39 ; 9$ & $4.21[2.04 ; 9.57]$ & $66 ; 44$ & $1.58[1.02 ; 2.44]$ \\
\hline $25-29.99$ & $665 ; 517$ & $100 ; 8$ & $11.03[5.55 ; 25.21]$ & $164 ; 77$ & $1.93[1.39 ; 2.70]$ \\
\hline \multirow[t]{2}{*}{$\geq 30$} & $299 ; 263$ & $61 ; 10$ & $4.98[2.48 ; 10.92]$ & $108 ; 50$ & $2.14[1.40 ; 3.28]$ \\
\hline & $p$-value for interaction & 0.1333 & & 0.635 & \\
\hline \multicolumn{6}{|c|}{ Age categorized: } \\
\hline$<55$ & $356 ; 249$ & $24 ; 4$ & $4.73[1.69 ; 16.79]$ & $29 ; 8$ & $3.17[1.42 ; 7.78]$ \\
\hline $55-65$ & $369 ; 295$ & $61 ; 6$ & $7.94[3.56 ; 21.15]$ & $70 ; 22$ & $2.20[1.28 ; 3.86]$ \\
\hline $65-75$ & $482 ; 430$ & $75 ; 8$ & $7.54[3.72 ; 17.45]$ & $151 ; 62$ & $2.18[1.54 ; 3.11]$ \\
\hline \multirow[t]{2}{*}{$\geq 75$} & $273 ; 368$ & $40 ; 9$ & $4.74[2.27 ; 10.89]$ & $88 ; 79$ & $1.34[0.93 ; 1.94]$ \\
\hline & $p$-value for interaction & 0.7985 & & 0.2534 & \\
\hline
\end{tabular}




\section{Place fat deposition}

\begin{tabular}{|c|c|c|c|c|c|}
\hline $\begin{array}{l}\text { Never carried } \\
\text { any extra weight } \\
\text { Abdominal }\end{array}$ & $966 ; 927$ & $140 ; 20$ & $4.95[0.59 ; 111.11]$ & $239 ; 134$ & $\begin{array}{r}2.71 \\
{[0.77 ; 11.19]} \\
1.78[1.38 ; 2.30]\end{array}$ \\
\hline Hips & $127 ; 120$ & $10 ; 2$ & $7.52[1.66 ; 53.69]$ & $12 ; 5$ & $\begin{array}{r}4.94 \\
{[1.55 ; 18.11]}\end{array}$ \\
\hline \multirow[t]{2}{*}{ All over equally } & $297 ; 223$ & $46 ; 4$ & $8.9[3.43 ; 30.4]$ & $77 ; 28$ & $2.05[1.24 ; 3.47]$ \\
\hline & interaction & 0.8896 & & 0.5682 & \\
\hline \multicolumn{6}{|c|}{ ght gain $>5 \mathrm{~kg}$ between age $20-50$} \\
\hline no & $326 ; 299$ & $26 ; 1$ & $19.9[4.08 ; 359.30]$ & $39 ; 19$ & $1.64[0.89 ; 3.10]$ \\
\hline \multirow[t]{2}{*}{ yes } & $1154 ; 1043$ & $174 ; 26$ & $6.12[4.02 ; 9.67]$ & $299 ; 152$ & $2.04[1.61 ; 2.59]$ \\
\hline & interaction & 0.1841 & & 0.4969 & \\
\hline \multicolumn{6}{|c|}{ ght gain >10kg between age 20-50 } \\
\hline no & $578 ; 613$ & $62 ; 10$ & $6.08[3.17 ; 12.90]$ & $102 ; 53$ & $2.06[1.42 ; 3.01]$ \\
\hline \multirow[t]{2}{*}{ yes } & $902 ; 729$ & $138 ; 17$ & $6.62[3.98 ; 11.66]$ & $236 ; 118$ & $1.87[1.42 ; 2.46]$ \\
\hline & interaction & 0.8334 & & 0.7456 & \\
\hline
\end{tabular}

\footnotetext{
1 Odds ratios (ORs) adjusted for age ( $<55,55-65,65-75, \geq 75$ years), gender, country, pack years (never-smokers and tertiles of pack-years) and BMI $\left(<25,25-30, \geq 30 \mathrm{~kg} / \mathrm{m}^{2}\right)$, except: sex in analyses stratified by sex, BMl in analyses stratified by obesity and pack-years in analyses stratified by smoking status.

2 Obesity status defined based on BMI 2 years before recruitment.
} 
Supplemental Table 9: Factors associated with PC risk among patients with NODM and LSDM in the PanGenEU study (2,018 cases and 1,540 controls).

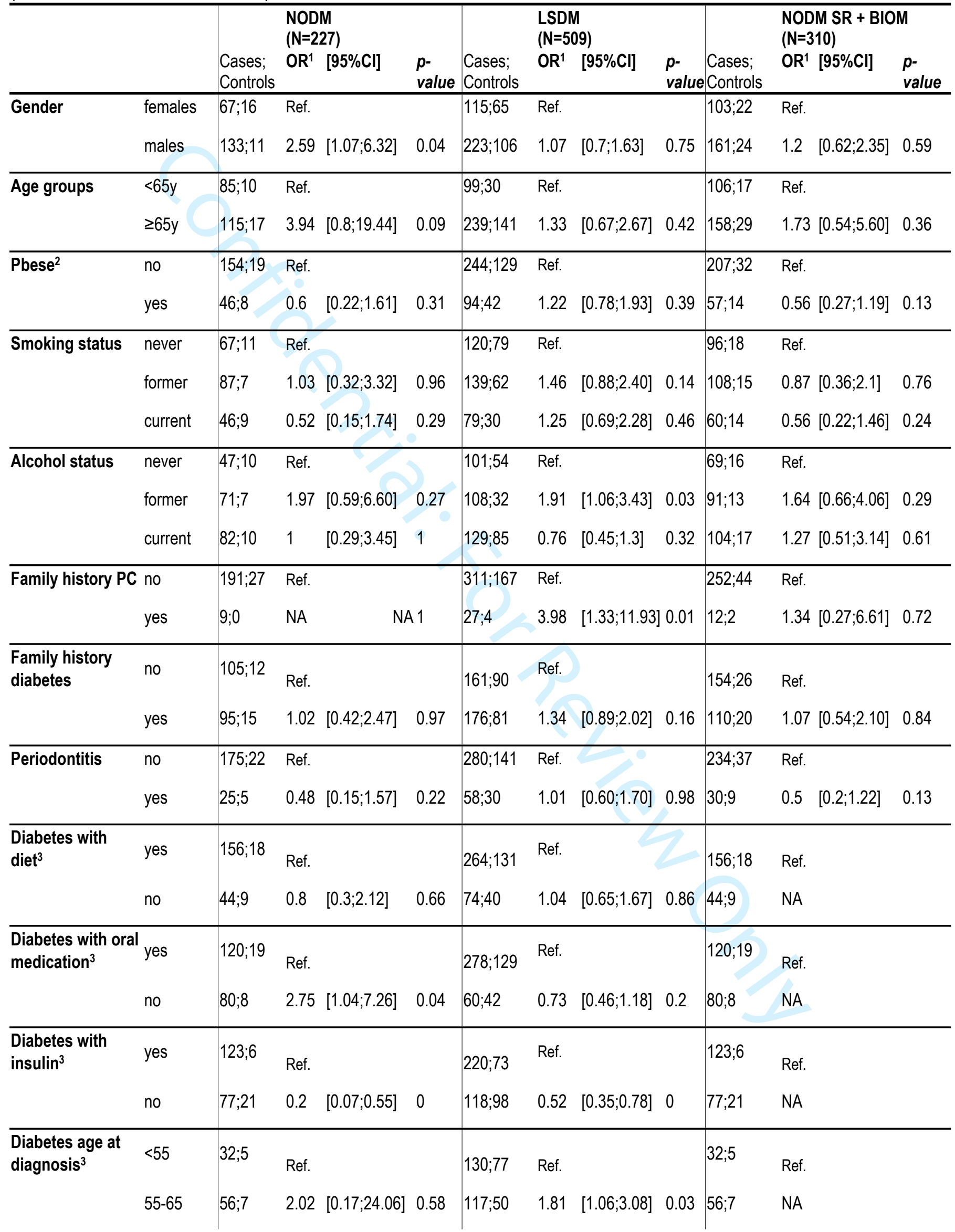




\begin{tabular}{|c|c|c|c|c|c|c|c|c|c|c|c|}
\hline & $>65$ & 112;15 & $10.48[0.41 ; 270.43]$ & 0.16 & $91 ; 44$ & 3.15 & {$[1.74 ; 5.69]$} & 0 & $112 ; 15$ & NA & \\
\hline \multirow[t]{4}{*}{ Educational level } & $<5 y$ & $61 ; 9$ & Ref. & & $74 ; 40$ & Ref. & & & $61 ; 9$ & Ref. & \\
\hline & 6 to $9 y$ & $70 ; 16$ & $0.39[0.11 ; 1.4]$ & 0.15 & $78 ; 60$ & 0.57 & {$[0.32 ; 1.01]$} & 0.06 & $70 ; 16$ & $0.49[0.19 ; 1.28]$ & 0.15 \\
\hline & 10 to $13 y$ & $70 ; 13$ & $0.78[0.18 ; 3.34]$ & 0.74 & $120 ; 44$ & 0.97 & {$[0.51 ; 1.84]$} & 0.93 & $70 ; 13$ & $0.65[0.23 ; 1.85]$ & 0.42 \\
\hline & $\geq 14 y$ & $63 ; 8$ & $1.52[0.29 ; 7.96]$ & 0.62 & $66 ; 27$ & 1.17 & {$[0.59 ; 2.30]$} & 0.65 & $63 ; 4$ & $0.92[0.29 ; 2.87]$ & \\
\hline \multirow[t]{3}{*}{$\begin{array}{l}\text { BMI } 2 \text { years } \\
\text { before }^{2}\end{array}$} & normal & $45 ; 2$ & Ref. & & $79 ; 49$ & Ref. & & & $66 ; 8$ & Ref. & \\
\hline & over & $109 ; 17$ & $0.2 \quad[0.04 ; 0.99]$ & 0.05 & $165 ; 80$ & 1.59 & {$[0.97 ; 2.62]$} & 0.07 & $141 ; 24$ & $0.57[0.24 ; 1.4]$ & 0.22 \\
\hline & obese & $46 ; 8$ & $0.17[0.03 ; 0.94]$ & 0.04 & $94 ; 42$ & 1.62 & {$[0.93 ; 2.84]$} & 0.09 & $57 ; 14$ & $0.38[0.14 ; 1.03]$ & 0.06 \\
\hline \multirow[t]{3}{*}{ BMl at age 20} & normal & $163 ; 21$ & Ref. & & $274 ; 147$ & Ref. & & & $218 ; 37$ & Ref. & \\
\hline & over & $31 ; 6$ & $0.64[0.22 ; 1.88]$ & 0.42 & $53 ; 19$ & 1.48 & {$[0.81 ; 2.69]$} & 0.2 & $38 ; 7$ & $0.79[0.33 ; 1.92]$ & 0.61 \\
\hline & obese & $6 ; 0$ & NA & $A 1$ & $11 ; 5$ & 1.22 & {$[0.38 ; 3.89]$} & 0.74 & $8 ; 2$ & $0.94[0.10 ; 8.55]$ & 0.96 \\
\hline \multirow[t]{3}{*}{$\mathrm{BMI}$ at age 50} & normal & $39 ; 9$ & Ref. & & $66 ; 44$ & Ref. & & & $60 ; 17$ & Ref. & \\
\hline & over & $100 ; 8$ & $3.62[1.12 ; 11.75]$ & 0.03 & $164 ; 77$ & 1.29 & {$[0.78 ; 2.13]$} & 0.33 & $129 ; 13$ & $2.48[1.07 ; 5.74]$ & 0.03 \\
\hline & obese & $61 ; 10$ & $1.28[0.43 ; 3.79]$ & 0.66 & $108 ; 50$ & 1.09 & {$[0.62 ; 1.89]$} & 0.77 & $75 ; 16$ & $1 \quad[0.44 ; 2.29]$ & 0.99 \\
\hline \multirow[t]{2}{*}{ Weight gain $>5 \mathrm{~kg}$} & no & $26 ; 1$ & Ref. & & $39 ; 19$ & Ref. & & & $39 ; 7$ & Ref. & \\
\hline & yes & $174 ; 26$ & $0.24 \quad[0.03 ; 1.95]$ & 0.18 & $299 ; 152$ & 0.9 & {$[0.48 ; 1.68]$} & 0.74 & $225 ; 39$ & $0.97[0.39 ; 2.39]$ & 0.94 \\
\hline \multirow[t]{2}{*}{$\begin{array}{l}\text { Weight gain } \\
>10 \mathrm{~kg}\end{array}$} & no & $62 ; 10$ & Ref. & & $102 ; 53$ & Ref. & & & $90 ; 20$ & Ref. & \\
\hline & yes & $138 ; 17$ & $1.17[0.47 ; 2.89]$ & 0.74 & $236 ; 118$ & 0.81 & {$[0.53 ; 1.25]$} & 0.35 & $174 ; 26$ & $1.27[0.65 ; 2.47]$ & 0.49 \\
\hline \multirow[t]{2}{*}{$\begin{array}{l}\text { Weight loss since } \\
\text { age } 50\end{array}$} & yes & $135 ; 21$ & Ref. & & $217 ; 116$ & Ref. & & & $175 ; 36$ & Ref. & \\
\hline & no & $65 ; 6$ & $0.4 \quad[0.13 ; 1.21]$ & 0.1 & $121 ; 55$ & 0.72 & {$[0.45 ; 1.15]$} & 0.17 & $89 ; 10$ & $0.43[0.2 ; 0.96]$ & 0.04 \\
\hline
\end{tabular}

${ }^{1}$ Odds ratios (ORs) adjusted for age ( $<55,55-65,65-75, \geq 75$ years), gender, country, pack years (never-smokers and tertiles of pack-years) and BMI (<25, 25$30, \geq 30 \mathrm{~kg} / \mathrm{m}^{2}$ ), except: sex in analyses stratified by sex, BMl in analyses stratified by obesity and pack-years in analyses stratified by smoking status.

${ }^{2}$ Obesity status defined based on BMI 2 years before recruitment.

${ }^{3}$ The association with PC risk could not be evaluated in reclassified NODM for diabetes-related variables due to lack of information on these variables. 
Supplemental Table 10: Estimates for the observational and causal association between T2DM and PC and viceversa, applying different MRA methods, conducted among 1,162 cases and 752 controls with epidemiological and genetic data. T2DM status based on self-reported (SR) data.

\begin{tabular}{|c|c|c|c|c|c|c|c|c|c|}
\hline \multirow[b]{3}{*}{ Diabetes-->PC } & \multicolumn{4}{|c|}{ SR-based classification of T2DM status } & \multicolumn{5}{|c|}{ SR-based classification of T2DM status } \\
\hline & \multicolumn{2}{|l|}{$\operatorname{LSDM}(\mathrm{N}=289)^{1}$} & \multicolumn{2}{|l|}{$\operatorname{NODM}(\mathrm{N}=136)^{1}$} & \multirow[b]{2}{*}{ PC-->Diabetes } & \multicolumn{2}{|l|}{ LSDM $(\mathrm{N}=289)^{1}$} & \multicolumn{2}{|l|}{ NODM $(\mathrm{N}=136)^{1}$} \\
\hline & OR $[95 \% \mathrm{Cl}]^{2}$ & p-value & OR $[95 \% \mathrm{Cl}]^{2}$ & p-value & & OR $[95 \% \mathrm{Cl}]^{2}$ & p-value & OR $[95 \% \mathrm{Cl}]^{2}$ & p-value \\
\hline Observational association study & & & & & Observational association study & & & & \\
\hline T2DM and PC & $1.43[1.09 ; 1.88]$ & 0.011 & $6.10[3.45 ; 10.8]$ & $5.40 \mathrm{E}-13$ & PC and T2DM & $1.45[1.10 ; 1.91]$ & 0.008 & $6.08[3.44 ; 10.7]$ & $4.80 \mathrm{E}-10$ \\
\hline T2DM-allele score ${ }^{3}$ and T2DM in controls & $1.15[1.09 ; 1.21]$ & $1.20 \mathrm{E}-05$ & $1.31[1.15 ; 1.47]$ & 0.0007 & PC-allele score ${ }^{4}$ and PC (without T2DM) & $1.10[1.06 ; 1.13]$ & $9.30 \mathrm{E}-09$ & $1.10[1.06 ; 1.14]$ & 4.10E-09 \\
\hline T2DM-allele score ${ }^{3}$ and PC & $1.01[0.98 ; 1.04]$ & 0.5 & $1.02[0.98 ; 1.05]$ & 0.315 & PC-allele score ${ }^{4}$ and T2DM & $1.03[0.99 ; 1.06]$ & 0.121 & $1.09[1.04 ; 1.14]$ & 0.0002 \\
\hline Causal estimates: MR study & & & & & Causal estimates: MR study & & & & \\
\hline MRA_Wald & $1.08[0.86 ; 1.29]$ & 0.5 & $1.06[0.95 ; 1.17]$ & 0.315 & MRA_Wald & $1.32[0.97 ; 1.67]$ & 0.121 & $2.52[2.07 ; 3.03]$ & 0.0002 \\
\hline TSLS Estimates & $1.08[0,87 ; 1.33]$ & 0.5 & $1.07[0.96 ; 1.20]$ & 0.239 & TSLS Estimates & $1.31[0.97 ; 1.66]$ & 0.123 & $2.52[2.18 ; 2.88]$ & 0.0002 \\
\hline Inverse-variance weighted method (IVW) & $0.90[0.77 ; 1.07]$ & 0.238 & $0.98[0.96 ; 1.02]$ & 0.692 & Inverse-variance weighted method (IVW) & $1.12[0.89 ; 1.41]$ & 0.326 & $1.57[1.13 ; 2.12]$ & 0.007 \\
\hline Mr-Egger regression & $0.98[0.74 ; 1.30]$ & 0.918 & $0.98[0.96 ; 1.02]$ & 0.694 & Mr-Egger regression & $1.09[0.78 ; 1.51]$ & 0.614 & $0.94[0.57 ; 1.55]$ & 0.804 \\
\hline Mr-Egger Intercept & $-0.022(0.030)$ & 0.468 & $0.006(0.018)$ & 0.964 & Mr-Egger Intercept & $0.007(0.028)$ & 0.807 & $0.090(0.042)$ & 0.027 \\
\hline Weighted median & $0.94[0.73 ; 1.22]$ & 0.649 & $0.99[0.98 ; 1.02]$ & 0.905 & Weighted median & $1.18[0.85 ; 1.65]$ & 0.323 & $1.36[0.85 ; 2.16]$ & 0.197 \\
\hline Simple median & $0.83[0.60 ; 1.06]$ & 0.117 & $1.03[0.94 ; 1.13]$ & 0.496 & Simple median & $1.50[1.00 ; 2.26]$ & 0.049 & $2.37[1.78 ; 2.96]$ & $<0.001$ \\
\hline
\end{tabular}

1 LSDM and NODM was evaluated in comparison to non-diabetics (1,489 subjects: 851 PC cases and 638 controls), with subjects classified as either NODM (N=136) or LSDM (N=289) being removed, respectively.

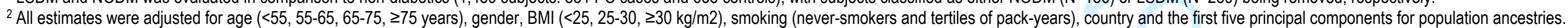

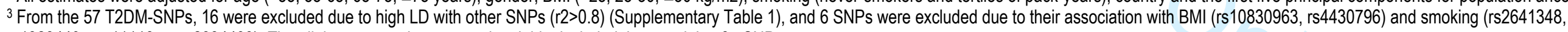
rs13234407, rs1111875, rs2334499). The allele score, as instrumental variable, included the remaining 35 SNPs.

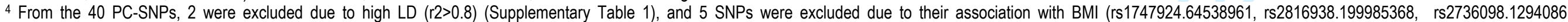
rs 17688601.40866663) and smoking (rs6537481.148396094). The allele score, as instrumental variable, included the remaining 33 SNPs. 
Supplemental Table 11: Estimates for the causal association between T2DM and PC and viceversa, applying different Multivariable MRA methods, conducted among 1,162 cases and 752 controls with epidemiological and genetic data. T2DM status based on self-reported (SR) data.

\begin{tabular}{|c|c|c|c|c|}
\hline & \multicolumn{4}{|c|}{ SR-based classification of T2DM status } \\
\hline & Single MRA & & Multivariable MRA & \\
\hline & OR $[95 \% \mathrm{Cl}]^{1}$ & OR $[95 \% \mathrm{Cl}]^{1}$ & OR $[95 \% \mathrm{Cl}]^{1}$ & OR $[95 \% \mathrm{Cl}]^{1}$ \\
\hline Diabetes-->PC & LSDM $(\mathrm{N}=289)^{2}$ & NODM $(\mathrm{N}=136)^{2}$ & $\operatorname{LSDM}^{2}(X 1)+\operatorname{BMI}(X 2)->P C$ & $\mathrm{NODM}^{2}(\mathrm{X} 1)+\mathrm{BMI}(\mathrm{X} 2)->\mathrm{PC}$ \\
\hline TSLS Estimates & $1.08[0,87 ; 1.33]$ & $1.07[0.96 ; 1.20]$ & $1.08[0.84 ; 1.41]$ & $1.06[0.95 ; 1.19]$ \\
\hline Inverse-variance weighted method (IVW) & $0.90[0.77 ; 1.07]$ & $0.98[0.96 ; 1.02]$ & $0.94[0.80 ; 1.10]$ & $1.00[0.99 ; 1.01]$ \\
\hline Mr-Egger regression & $0.98[0.74 ; 1.30]$ & $0.98[0.96 ; 1.02]$ & $1.00[0.76 ; 1.30]$ & $1.00[0.99 ; 1.01]$ \\
\hline Mr-Egger Intercept & $-0.022 ; p=0.468$ & $0.006 ; p=0.964$ & $-0.014 ; p=0.54$ & $0.001 ; p=0.93$ \\
\hline PC-->Diabetes & 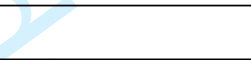 & & $P C(X 1)+B M I(X 2) \rightarrow$ NODM & PC (X1) + BMI (X2) -> LSDM \\
\hline TSLS Estimates & $1.03[0.99 ; 1.06]$ & $2.52[2.05 ; 3.03]$ & $1.05[0.90 ; 1.20]$ & $1.31[1.10 ; 1.52]$ \\
\hline Inverse-variance weighted method (IVW) & $1.12[0.89 ; 1.41]$ & $1.57[1.13 ; 2.12]$ & $1.20[0.98 ; 1.48]$ & $1.58[1.15 ; 2.17]$ \\
\hline Mr-Egger regression & $1.09[0.78 ; 1.51]$ & $0.94[0.57 ; 1.55]$ & $1.21[0.87 ; 1.69]$ & $1.19[0.72 ; 1.96]$ \\
\hline Mr-Egger Intercept & $0.007 ; p=0.81$ & $0.090 ; p=0.027$ & $-0.002 ; p=0.93$ & $0.063 ; p=0.14$ \\
\hline PC-->Diabetes (without outliers) ${ }^{3}$ & $\infty$ & & $\mathrm{PC}(\mathrm{X} 1)+\mathrm{BMI}(\mathrm{X} 2) \rightarrow \mathrm{NODM}$ & $\mathrm{PC}(\mathrm{X} 1)+\mathrm{BMI}(\mathrm{X} 2) \rightarrow \mathrm{LSDM}$ \\
\hline TSLS Estimates & $1.38[0.95 ; 1.99]$ & $2.85[2.04 ; 3.98]$ & & \\
\hline Inverse-variance weighted method (IVW) & $1.18[0.93 ; 1.51]$ & $1.52[1.08 ; 2.13]$ & $1.19[0.97 ; 1.42]$ & $1.77[1.46 ; 2.08]$ \\
\hline Mr-Egger regression & $1.18[0.84 ; 1.66]$ & $1.36[0.80 ; 2.32]$ & $1.28[0.87 ; 1.87]$ & $1.65[0.98 ; 2.77]$ \\
\hline Mr-Egger Intercept & $0.001 ; p=0.96$ & $0.023 ; p=0.6$ & $-0.01 ; p=0.645$ & $0.01 ; p=0.73$ \\
\hline
\end{tabular}

From the 57 T2DM-SNPs, 16 were excluded due to high LD with other SNPs (r2>0.8) (Supplementary Table 1), and 4 SNPs was excluded due to its association with smoking (rs2641348, rs13234407, rs1111875, rs2334499). The allele score, as instrumental variable, included the remaining 37 SNPs. SNPs associated with obesity were not excluded.

From the 40 PC-SNPs, 2 were excluded due to high LD ( $r 2>0.8)$ (Supplementary Table 1), and 1 SNPs was excluded due to its association with smoking (rs6537481.148396094). The allele score, as instrumental variable, included the remaining 37 SNPs. SNPs associated with obesity were not excluded.

${ }^{1}$ All estimates were adjusted for age ( $<55,55-65,65-75, \geq 75$ years), gender, BMI ( $\left.<25,25-30, \geq 30 \mathrm{~kg} / \mathrm{m} 2\right)$, smoking (never-smokers and tertiles of pack-years), country and the first five principal components for population ancestries.

${ }^{2}$ LSDM and NODM was evaluated in comparison to non-diabetics (1,489 subjects: 851 PC cases and 638 controls), with subjects classified as either NODM $(\mathrm{N}=136)$ or LSDM $(\mathrm{N}=289)$ being removed, respectively. BMI to define obesity (yes, no) two years before recruitment.

${ }^{3}$ Outliers removed: "rs1747924:64538961:C:A", "rs1486134:67639769:G:T", "rs17688601:40866663:C:A" for LDSM and "rs6971499" and "rs7310409" for NODM 
Supplemental Table 12: Estimates for the observational and causal association between obesity measures and PC, applying different MRA methods, conducted among 1,162 cases and 752 controls with epidemiological and genetic data.

\begin{tabular}{|c|c|c|c|c|}
\hline \multirow[b]{3}{*}{ BMI-->PC } & \multicolumn{4}{|c|}{ SR-based classification of obesity status } \\
\hline & \multicolumn{2}{|c|}{ BMI 2 years ( $\mathrm{N}=343$ obese) } & \multicolumn{2}{|c|}{ BMI 50 years ( $N=401$ obese) } \\
\hline & OR $[95 \% \mathrm{Cl}]^{1}$ & $p$-value & OR $[95 \% \mathrm{Cl}]^{1}$ & $p$-value \\
\hline \multicolumn{5}{|l|}{ Observational association study } \\
\hline $\mathrm{BMI}$ and $\mathrm{PC}$ & $0.89[0.69 ; 1.14]$ & 0.356 & $0.83[0.64 ; 1.07]$ & $1.41 \mathrm{E}-01$ \\
\hline BMI-allele score ${ }^{2}$ and BMI in controls & $1.11[1.08 ; 1.15]$ & $3.06 \mathrm{E}-09$ & $1.16[1.12 ; 1.21]$ & $1.71 \mathrm{E}-11$ \\
\hline BMI-allele score ${ }^{2}$ and $P C$ & $1.01[0.98 ; 1.02]$ & 0.927 & $1.01[0.99 ; 1.03]$ & 0.311 \\
\hline \multicolumn{5}{|l|}{ Causal estimates: MR study } \\
\hline MRA_Wald & $1.01[0.98 ; 1.03]$ & 0.927 & $1.07[0.94 ; 1.21]$ & 0.311 \\
\hline TSLS Estimates & $1.01[0,85 ; 1.20]$ & 0.927 & $1.09[0.95 ; 1.25]$ & 0.293 \\
\hline $\begin{array}{l}\text { Inverse-variance weighted method } \\
\text { (IVW) }\end{array}$ & & 0.828 & $1.03[0.93 ; 1.14]$ & 0.542 \\
\hline Mr-Egger regression & $0.98[0.74 ; 1.30]$ & 0.794 & $0.97[0.82 ; 1.15]$ & 0.705 \\
\hline Mr-Egger Intercept & $0.009(0.015)$ & 0.573 & $0.016(0.017)$ & 0.343 \\
\hline Weighted median & $0.96[0.80 ; 1.32]$ & 0.688 & $1.03[0.88 ; 1.20]$ & 0.728 \\
\hline Simple median & $1.10[0.92 ; 1.32]$ & 0.278 & $1.05[0.90 ; 1.22]$ & 0.554 \\
\hline
\end{tabular}

${ }^{1}$ All estimates were adjusted for age ( $<55,55-65,65-75, \geq 75$ years), gender, smoking (never-smokers and tertiles of pack-years), country and the first five principal components for population ancestries.

${ }^{4}$ From the 126 obesity-SNPs, 30 were excluded due to high LD ( $\left.r 2>0.8\right)$ (Supplementary Table 1), and 11 SNPs were excluded due to their association with T2DM and smoking. The allele score, as instrumental variable, included the remaining 85 SNPs.

There were few obese subjects at age 20 years; $\mathrm{BMl}$ at this age was therefore not considered. 
Supplemental Table 13: Results of causal mediation analyses evaluating mediator effects of T2DM on the obesity and PC association considering different obesity measures, and mediator effects of obesity on the T2DM and PC association. Estimates are derived from counterfactual models (2,018 cases and 1,540 controls) and MRA (1,162 cases and 752 controls with epidemiological and genetic data).

\begin{tabular}{|c|c|c|c|c|c|c|c|c|c|c|c|c|}
\hline & $\mathrm{OR}^{1}$ & {$[95 \% \mathrm{Cl}]$} & $\mathrm{OR}^{1}$ & {$[95 \% \mathrm{Cl}]$} & $\mathrm{OR}^{1}$ & {$[95 \% \mathrm{Cl}]$} & $O^{1}$ & {$[095 \% \mathrm{Cl}]$} & $\mathrm{OR}^{1}$ & {$[95 \% \mathrm{Cl}]$} & $\mathrm{OR}^{1}$ & {$[95 \% \mathrm{Cl}]$} \\
\hline Counterfactual model & NDE & & NIE & & TE & & NDE & & NIE & & TE & \\
\hline NODM mediator & & & & & & & LSDM & mediator & & & & \\
\hline Obese $^{2}$ & 0.90 & {$[0.73 ; 1.10]$} & 1.04 & {$[1.01 ; 1,11]$} & 0.94 & {$[0.77 ; 1.17]$} & 0.95 & {$[0.80 ; 1.15]$} & 1.05 & {$[1.02 ; 1.10]$} & 1.00 & {$[0.84 ; 1.22]$} \\
\hline Overweight/obese $^{2}$ & 0.83 & {$[0.71 ; 0.98]$} & 1.09 & {$[1.08 ; 1,13]$} & 0.91 & {$[0.79 ; 1.11]$} & 0.92 & {$[0.80 ; 1.08]$} & 1.03 & {$[1.01 ; 1.06]$} & 0.95 & {$[0.82 ; 1.11]$} \\
\hline Weight gain $>5 \mathrm{~kg}^{3}$ & 0.82 & {$[0.66 ; 0.97]$} & 1.08 & {$[1.07 ; 1.10]$} & 0.89 & {$[0.72 ; 1.07]$} & 0.86 & {$[0.70 ; 1.03]$} & 1.05 & {$[1.03 ; 1.08]$} & 0.89 & {$[0.74 ; 1.08]$} \\
\hline Weight loss ${ }^{3}$ & 1.04 & {$[0.85 ; 1.38]$} & 0.95 & {$[0.73 ; 1.02]$} & 1.00 & {$[0.83 ; 1.19]$} & 0.98 & {$[0.82 ; 1.15]$} & 1.02 & {$[1.00 ; 1.04]$} & 1.00 & {$[0.84 ; 1.17]$} \\
\hline Obese at age $50^{3}$ & 0.83 & {$[0.67 ; 1.01]$} & 1.07 & {$[1.04 ; 1,13]$} & 0.89 & {$[0.73 ; 1.08]$} & 0.88 & {$[0.72 ; 1.07]$} & 1.07 & {$[1.04 ; 1.15]$} & 0.94 & {$[0.78 ; 1.14]$} \\
\hline Overweight/obese at age $50^{3}$ & 1.21 & {$[1.01 ; 1.44]$} & 1.03 & {$[0.98 ; 1.08]$} & 1.25 & {$[1.07 ; 1.51]$} & 1.18 & {$[1.01 ; 1.37]$} & 1.04 & {$[1.03 ; 1.07]$} & 1.23 & {$[1.06 ; 1.43]$} \\
\hline Obese $^{2}$ mediator & & & & & & & \multicolumn{6}{|c|}{ Overweight/obese ${ }^{2}$ mediator } \\
\hline NODM & 5.92 & {$[3.69 ; 9.14]$} & 0.97 & {$[0.78 ; 1.01]$} & 5.72 & {$[3.76 ; 9.11]$} & 10.14 & {$[5.48 ; 22.69]$} & 0.55 & {$[0.23 ; 0.92]$} & 5.58 & {$[3.65 ; 8.92]$} \\
\hline LSDM & 1.65 & {$[1.34 ; 2.03]$} & 1.02 & {$[0.99 ; 1.07]$} & 1.68 & {$[1.37 ; 2.06]$} & 1.61 & {$[1.31 ; 2.00]$} & 1.03 & {$[1.01 ; 1.08]$} & 1.67 & {$[1.35 ; 2.06]$} \\
\hline Obese at age $50^{3}$ mediator & & & & . & & & \multicolumn{6}{|c|}{ Overweight/obese at age $50^{3}$ mediator } \\
\hline NODM & 4.99 & {$[2.54 ; 10.87]$} & 0.87 & {$[0.43 ; 1.04]$} & 4.35 & {$[2.35 ; 9.65]$} & 4.27 & {$[2.14 ; 8.08]$} & 1.08 & {$[1.03 ; 1.12]$} & 4.63 & {$[2.66 ; 10.82]$} \\
\hline LSDM & 1.53 & {$[1.13 ; 2.09]$} & 0.99 & {$[0.87 ; 1.07]$} & 1.50 & {$[1.14 ; 2.17]$} & 1.38 & {$[1.08 ; 1.94]$} & 1.09 & {$[1.03 ; 1.15]$} & 1.49 & {$[1.17 ; 2.02]$} \\
\hline Counterfactual IV & NDE & & NIE & & TE & & NDE & & NIE & & TE & \\
\hline NODM mediator & & & & & & 28 & LSDM & mediator & & & & \\
\hline Obese $^{2}$ & 0.83 & [0.63;1.15] & 1.03 & {$[1.00 ; 1.11]$} & 0.85 & {$[0.68 ; 1.24]$} & 0.88 & {$[0.63 ; 1.27]$} & 1.02 & {$[0.99 ; 1.04]$} & 0.89 & {$[0.68 ; 1.27]$} \\
\hline Overweight/obese ${ }^{2}$ & 0.93 & [0.72;1.12] & 1.05 & {$[1.00 ; 1.08]$} & 0.97 & {$[0.81 ; 1.26]$} & 0.98 & {$[0.81 ; 1.27]$} & 1.01 & {$[0.99 ; 1.02]$} & 0.98 & {$[0.79 ; 1.27]$} \\
\hline Weight gain $>5 \mathrm{~kg}^{3}$ & 1.15 & {$[0.68 ; 1.53]$} & 1.03 & {$[1.00 ; 1.07]$} & 1.19 & {$[0.68 ; 1.56]$} & 1.16 & {$[0.94 ; 1.58]$} & 1.02 & {$[1.00 ; 1.03]$} & 1.18 & {$[0.95 ; 1.78]$} \\
\hline Weight loss ${ }^{3}$ & 1.20 & {$[0.96 ; 1.69]$} & 0.94 & {$[0.90 ; 0.98]$} & 1.13 & {$[0.92 ; 1.48]$} & 1.13 & {$[0.88 ; 1.35]$} & 1.01 & {$[0.99 ; 1.02]$} & 1.14 & {$[0.88 ; 1.39]$} \\
\hline Obese at age $50^{3}$ & 0.82 & {$[0.66 ; 1.22]$} & 1.06 & {$[1.00 ; 1.12]$} & 0.87 & {$[0.70 ; 1.31]$} & 0.84 & {$[0.66 ; 1.12]$} & 1.02 & {$[1.00 ; 1.06]$} & 0.86 & {$[0.68 ; 1.13]$} \\
\hline Overweight/obese at age $50^{3}$ & 1.44 & {$[1.18 ; 1.89]$} & 1.03 & {$[1.00 ; 1.06]$} & 1.49 & {$[1.23 ; 1.96]$} & 1.47 & {$[1.17 ; 1.88]$} & 1.02 & {$[1.01 ; 1.03]$} & 1.49 & {$[1.19 ; 1.90]$} \\
\hline Obese $^{2}$ mediator & & & & & & & \multicolumn{6}{|c|}{ Overweight/obese ${ }^{2}$ mediator } \\
\hline NODM & 5.06 & {$[3.15 ; 13.19]$} & 0.92 & {$[0.40 ; 1.01]$} & 4.67 & {$[2.97 ; 9.77]$} & 8.21 & {$[6.6$} & 0.53 & {$[0.38 ; 0.75]$} & 4.37 & {$[3.02 ; 7.75]$} \\
\hline LSDM & 1.46 & {$[1.02 ; 1.91]$} & 1.02 & {$[0.97 ; 1.07]$} & 1.47 & {$[1.07 ; 2.01]$} & 1.45 & {$[1.12 ; 2.18]$} & 1.01 & {$[0.94 ; 1.04]$} & 1.46 & {$[1.22 ; 2.29]$} \\
\hline Obese at age $50^{3}$ mediator & & & & & & & \multicolumn{6}{|c|}{ Overweight/obese at age $50^{3}$ mediator } \\
\hline NODM & 5.01 & {$[3.02 ; 12.20]$} & 0.86 & {$[0.37 ; 1.06]$} & 4.32 & {$[2.78 ; 8.77]$} & 4.28 & {$[2.72 ; 9.79]$} & 1.09 & {$[1.05 ; 1.20]$} & 4.68 & {$[3.04 ; 11.49]$} \\
\hline LSDM & 1.51 & {$[1.24 ; 2.20]$} & 0.98 & {$[0.87 ; 1.04]$} & 1.49 & {$[1.25 ; 2.32]$} & 1.37 & {$[0.88 ; 1.81]$} & 1.08 & {$[1.03 ; 1.16]$} & 1.48 & {$[1.07 ; 2.15]$} \\
\hline
\end{tabular}

$\mathrm{Cl}$, confidence interval; TE, marginal total effect; NDE, natural direct effect; NIE, natural indirect effect;

${ }^{1}$ All estimates were adjusted for age ( $<55,55-65,65-75, \geq 75$ years), gender, smoking (never-smokers and tertiles of pack-years), country, and the first five principal components for population ancestries in network MRA

2 Obesity status defined based on BMI 2 years before recruitment

${ }^{3}$ Obesity-related variables based on information collected at age 50 years, such as weight gain from age 20 to 50 and weight loss since age 50 years

Significant estimates are marked in bold. 
Supplemental Table 14: Association between diabetes-related variables and PC risk in the PanGenEU study $(2,018$ cases and 1,540 controls). Unimputed data.

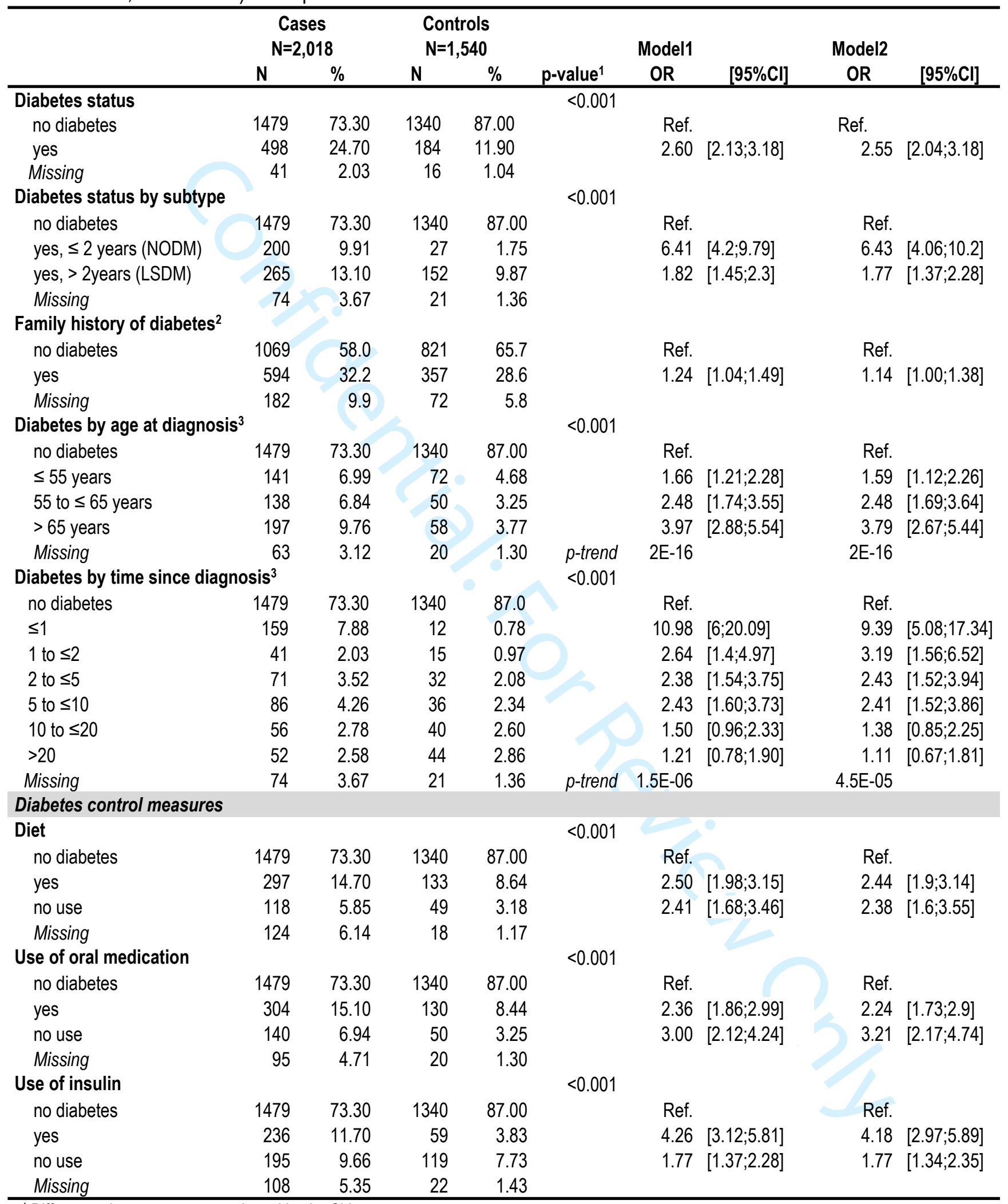

${ }^{1}$ Differences between groups evaluated by the Chi-square test

2 Information on family history of diabetes was not collected in Ireland; results are based on data for 1,845 cases and 1,250 controls

${ }^{3}$ Linear association for age since T2DM diagnosis and nonlinear association for time since T2DM (Supplemental Figure 1)

Model 1: adjusted for age ( $<55,55-65,65-75, \geq 75$ years), gender, country.

Model 2: Model 1 also adjusted for pack years (never-smokers and tertiles of pack-years) and BMI $\left(<25,25-30, \geq 30 \mathrm{~kg} / \mathrm{m}^{2}\right)$ 
Supplemental Table 15: Estimates for the observational and causal association between T2DM and PC and vice versa, applying different MRA methods, conducted among 1,162 cases and 752 controls with epidemiological and genetic data. T2DM status based on self-reported (SR) and biomarker data.

\begin{tabular}{|c|c|c|c|c|c|c|c|c|c|}
\hline \multirow[b]{3}{*}{ Diabetes-->PC } & \multicolumn{4}{|c|}{ SR + biomarker-based classification of T2DM status } & \multirow[b]{3}{*}{ PC-->Diabetes } & \multicolumn{4}{|c|}{ SR + biomarker -based classification of T2DM status } \\
\hline & \multicolumn{2}{|l|}{ LSDM $(\mathrm{N}=289)^{1}$} & \multicolumn{2}{|l|}{ NODM $(\mathrm{N}=190)^{1}$} & & \multicolumn{2}{|l|}{ LSDM $(\mathrm{N}=289)^{1}$} & \multicolumn{2}{|l|}{ NODM $(\mathrm{N}=190)^{1}$} \\
\hline & OR $[95 \% \mathrm{Cl}]^{2}$ & p-value & $\mathrm{OR}[95 \% \mathrm{Cl}]^{2}$ & $p$-value & & $\mathrm{OR}[95 \% \mathrm{Cl}]^{2}$ & $p$-value & OR $[95 \% \mathrm{Cl}]^{2}$ & $p$-value \\
\hline Observational association study & & & & & Observational associatic & & & & \\
\hline T2DM and PC & $1.50[1.14 ; 1.98]$ & 0.003 & $5.08[3.27 ; 7.90]$ & 4.40E-13 & PC and T2DM & $1.51[1.15 ; 2.00]$ & 0.003 & $5.15[3.31 ; 8.00]$ & $3.22 \mathrm{E}-13$ \\
\hline T2DM-allele score ${ }^{3}$ and T2DM in controls & $1.11[1.05 ; 1.16]$ & 3.73E-04 & $1.23[1.13 ; 1.33]$ & 4.74E-05 & PC-allele score 4 and PC (without T2DM) & $1.10[0.75 ; 1.45]$ & $1.54 \mathrm{E}-08$ & $1.09[1.07 ; 1.13]$ & $1.54 \mathrm{E}-08$ \\
\hline T2DM-allele score ${ }^{3}$ and PC & $1.02[0.99 ; 1.05]$ & 0.146 & $0.99[0.96 ; 1.02]$ & 0.461 & PC-allele score ${ }^{4}$ and T2DM & $1.03[0.99 ; 1.06]$ & 0.119 & $1.07[1.03 ; 1.11]$ & 0.0014 \\
\hline Causal estimates: MR study & & & & & Causal estimates: MR study & & & & \\
\hline MRA_Wald & $1.21[0.95 ; 1.47]$ & 0.146 & $0.95[0.96 ; 1.02]$ & 0.461 & MRA_Wald & $1.32[0.97 ; 1.67]$ & 0.12 & $2.01[1.58 ; 2.43]$ & 0.0014 \\
\hline T2LS Estimates & $1.19[0.92 ; 1.54]$ & 0.194 & $0.95[0.84 ; 1.08]$ & 0.461 & T2LS Estimates & $1.03[0.99 ; 1.06]$ & 0.12 & $2.86[2.07 ; 3.97]$ & $2.37 \mathrm{E}-10$ \\
\hline Inverse-variance weighted method (IVW) & $1.06[0.79 ; 1.42]$ & 0.708 & $0.99[0.93 ; 1.05]$ & 0.725 & Inverse-variance weighted method (IVW) & $1.12[0.89 ; 1.41]$ & 0.316 & $1.29[0.98 ; 1.70]$ & 0.078 \\
\hline Mr-Egger regression & $1.31[0.80 ; 2.15]$ & 0.278 & $1.00[0.94 ; 1.06]$ & 0.921 & Mr-Egger regression & $1.05[0.76 ; 1.47]$ & 0.756 & $0.83[0.55 ; 1.26]$ & 0.382 \\
\hline Mr-Egger Intercept & $-0.049(0.045)$ & 0.283 & $-0.019(0.029)$ & 0.538 & Mr-Egger Intercept & $0.015(0.028)$ & 0.604 & $0.095(0.034)$ & 0.005 \\
\hline Weighted median & $0.97[0.72 ; 1.30]$ & 0.823 & $1.00[0.96 ; 1.04]$ & 0.812 & Weighted median & $1.22\left[0.88 ; 1.17^{*}\right.$ & 0.238 & $1.16[0.78 ; 1.75]$ & 0.446 \\
\hline Simple median & $1.20[0.86 ; 1.70]$ & 0.284 & $1.00[0.85 ; 1.17]$ & 0.95 & Simple median & $1.55[1.00 ; 2.32]$ & 0.05 & $1.56[0.96 ; 2.54]$ & 0.075 \\
\hline
\end{tabular}

${ }^{1}$ LSDM and NODM was evaluated in comparison to non-diabetics after reclassifying T2DM status with the biomarker data (obtained for 654 subjects with epidemiological and genetic data), with subjects reclassified as either NODM $(\mathrm{N}=190)$ or LSDM ( $\mathrm{N}=289)$ being removed, respectively.

${ }^{2}$ All estimates were adjusted for age ( $<55,55-65,65-75, \geq 75$ years), gender, BMI $(<25,25-30, \geq 30 \mathrm{~kg} / \mathrm{m} 2)$, smoking (never-smokers and tertiles of pack-years), country and the first five principal components for population ancestries. ${ }^{3}$ From the 57 T2DM-SNPs, 16 were excluded due to high LD with other SNPs (r2>0.8) (Supplementary Table 1), and 6 SNPs were excluded due to their association with BMI (rs10830963, rs4430796) and smoking (rs2641348, rs13234407, rs1111875, rs2334499). The allele score, as instrumental variable, included the remaining 35 SNPs.

${ }_{4}^{4}$ From the 40 PC-SNPs, 2 were excluded due to high LD (r2>0.8), and 5 SNPs were excluded due to their association with BMI (rs1747924.64538961, rs2816938.199985368, rs2736098.1294086, rs17688601.40866663) and smoking (rs6537481.148396094). The allele score, as instrumental variable, included the remaining 33 SNPs.

Removal of SNPs potentially associated with other traits (at p-value 10-8) according to PhenoScanner database led to similar results. 
Supplemental Table 16: Estimates for the observational and causal association between T2DM and PC and vice versa, after removing other potential pleiotropic variants and outliers (based on Cook's distances) and applying different MRA methods, conducted among 1,162 cases and 752 controls with epidemiological and genetic data. T2DM status based on self-reported (SR) data.

\begin{tabular}{|c|c|c|c|c|c|c|c|c|c|}
\hline \multirow[b]{3}{*}{ Diabetes-->PC } & \multicolumn{4}{|c|}{ SR-based classification of T2DM status } & \multicolumn{5}{|c|}{ SR-based classification of T2DM status } \\
\hline & \multicolumn{2}{|l|}{ LSDM $(\mathrm{N}=289)^{1}$} & \multicolumn{2}{|l|}{ NODM $(\mathrm{N}=136)^{1}$} & \multirow[b]{2}{*}{ PC-->Diabetes } & \multicolumn{2}{|l|}{ LSDM $(\mathrm{N}=289)^{1}$} & \multicolumn{2}{|l|}{ NODM $(\mathrm{N}=136)^{1}$} \\
\hline & $\mathrm{OR}[95 \% \mathrm{Cl}]^{2}$ & $p$-value & OR $[95 \% \mathrm{Cl}]^{2}$ & p-value & & $\mathrm{OR}[95 \% \mathrm{Cl}]^{2}$ & $p$-value & OR $[95 \% \mathrm{Cl}]^{2}$ & $p$-value \\
\hline Observational association study & & & & & Observational association study & & & & \\
\hline T2DM and PC & $1.43[1.09 ; 1.88]$ & 0.011 & $6.10[3.45 ; 10.8]$ & $<0.001$ & PC and T2DM & $1.45[1.10 ; 1.91]$ & 0.008 & $6.08[3.44 ; 10.7]$ & $4.80 \mathrm{E}-10$ \\
\hline T2DM-allele score $^{3}$ and T2DM in controls & $1.16[1.09 ; 1.22]$ & $1.42 \mathrm{E}-05$ & $1.32[1.15 ; 1.48]$ & 0.001 & PC-allele score ${ }^{4}$ and PC (without T2DM) & $1.10[1.06 ; 1.13]$ & 4.10E-08 & $1.10[1.06 ; 1.13]$ & $3.10 \mathrm{E}-08$ \\
\hline T2DM-allele score ${ }^{3}$ and PC & $1.00[0.97 ; 1.03]$ & $9.93 \mathrm{E}-01$ & $1.01[0.98 ; 1.05]$ & 0.389 & PC-allele score 4 and T2DM & $1.03[1.00 ; 1.06]$ & 0.09 & $1.08[1.03 ; 1.13]$ & 0.0023 \\
\hline Causal estimates: MR study & & & & & Causal estimates: MR study & & & & \\
\hline MRA_Wald & $1.00[0.79 ; 1.22]$ & 0.273 & $1.05[0.99 ; 1.09]$ & 0.389 & MRA_Wald & $1.38[0.99 ; 1.74]$ & 0.09 & $2.47[1.71 ; 2.74]$ & 0.00053 \\
\hline TSLS Estimates & $0.98[0.79 ; 1.22]$ & 0.864 & $1.05[0.93 ; 1.19]$ & 0.39 & TSLS Estimates & $1.38[0.95 ; 1.99]$ & 0.09 & $2.85[2.04 ; 3.98]$ & $2.80 \mathrm{E}-09$ \\
\hline Inverse-variance weighted method (IVW) & $0.92[0.79 ; 1.08]$ & 0.315 & $1.00[0.96 ; 1.02]$ & 0.538 & Inverse-variance weighted method (IVW) & $1.18[0.93 ; 1.51]$ & 0.16 & $1.52[1.08 ; 2.13]$ & 0.016 \\
\hline Mr-Egger regression & $1.00[0.77 ; 1.20]$ & 0.992 & $0.98[0.96 ; 1.02]$ & 0.534 & Mr-Egger regression & $1.18[0.84 ; 1.66]$ & 0.348 & $1.36[0.80 ; 2.32]$ & 0.251 \\
\hline Mr-Egger Intercept & $0.019(0.025)$ & 0.448 & $0.001(0.018)$ & 0.936 & Mr-Egger Intercept & $0.001(0.028)$ & 0.963 & $0.023(0.043)$ & 0.06 \\
\hline Weighted median & $0.96[0.74 ; 1.24]$ & 0.481 & $1.01[0.95 ; 1.04]$ & 0.966 & Weighted median & $1.18[0.84 ; 1.67]$ & 0.321 & $1.43[0.88 ; 2.33]$ & 0.15 \\
\hline Simple median & $0.86[0.69 ; 1.07]$ & 0.174 & $1.02[0.92 ; 1.11]$ & 0.735 & Simple median & $1.51[1.00 ; 2.27]$ & 0.052 & $2.84[2.27 ; 3.41]$ & $<0.001$ \\
\hline
\end{tabular}

${ }^{2}$ All estimates were adjusted for age $(<55,55-65,65-75, \geq 75$ years), gender, BMI $(<25,25-30, \geq 30 \mathrm{~kg} / \mathrm{m} 2)$, smoking (never-smokers and tertiles of pack-years), country and the first five principal components for population ancestries. ${ }^{3}$ From the 57 T2DM-SNPs, 16 were excluded due to high LD with other SNPs (r2>0.8) (Supplementary Table 1), and 6 SNPs were excluded due to their association with BMI (rs10830963, rs4430796) and smoking (rs2641348, rs 13234407, rs 1111875, rs2334499). In addition, 3 SNPs potentially being outliers were removed (rs2191348, rs13266634, rs7965349). The allele score, as instrumental variable, included the remaining 32 SNPs.

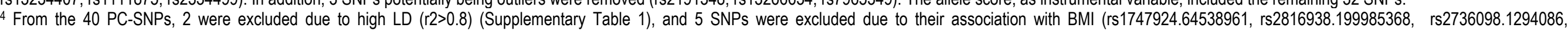

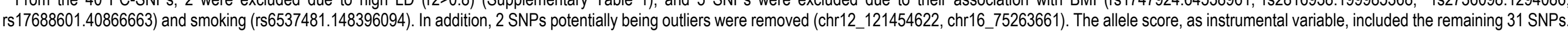


Supplemental Table 17: Magnitudes of the E-value for different combinations of the Exposure-Confounder Association RREU and the Confounder-Outcome Association RRUD for the estimation of the causal effect of NODM on PC (OR=6.39 (4.18;9.78)) and of LSDM on PC (OR=1.86 (1.49;2.32)).

\section{NODM}

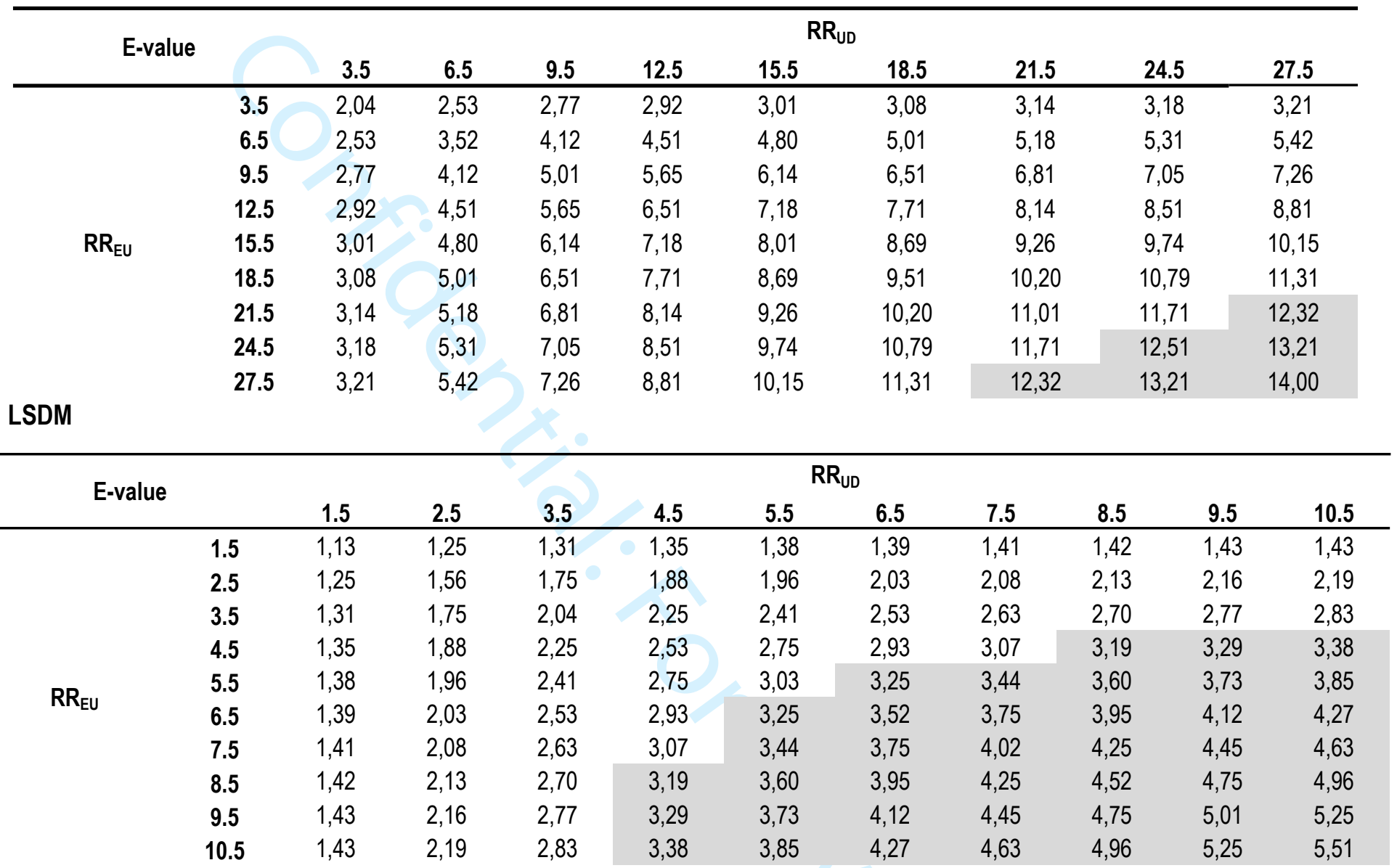


Supplemental Figure 1: Directed acyclic graphs illustrating the single MR and multivariable and network MR approaches used to explore causal associations and mediation in the causal pathways between T2DM, obesity and PC.

A: Observational association between T2DM (Exposure) and PC (Outcome)

B: Single Mendelian Randomization (MR) between T2DM (Exposure) and PC (Outcome)

C: Single Mendelian Randomization (MR) between PC (Exposure) and T2DM (Outcome) - bidirectional MR

D: Multivariable Mendelian Randomization (MR) between T2DM (Exposure) and PC (Outcome)

E: Multivariable Mendelian Randomization (MR) between PC (Exposure) and T2DM (Outcome) - bidirectional MR

F: Network Mendelian Randomization (MR) between T2DM (Exposure), Obesity (Mediator) and PC (Outcome)

G: Network Mendelian Randomization (MR) between Obesity (Exposure), T2DM (Mediator) and PC (Outcome)
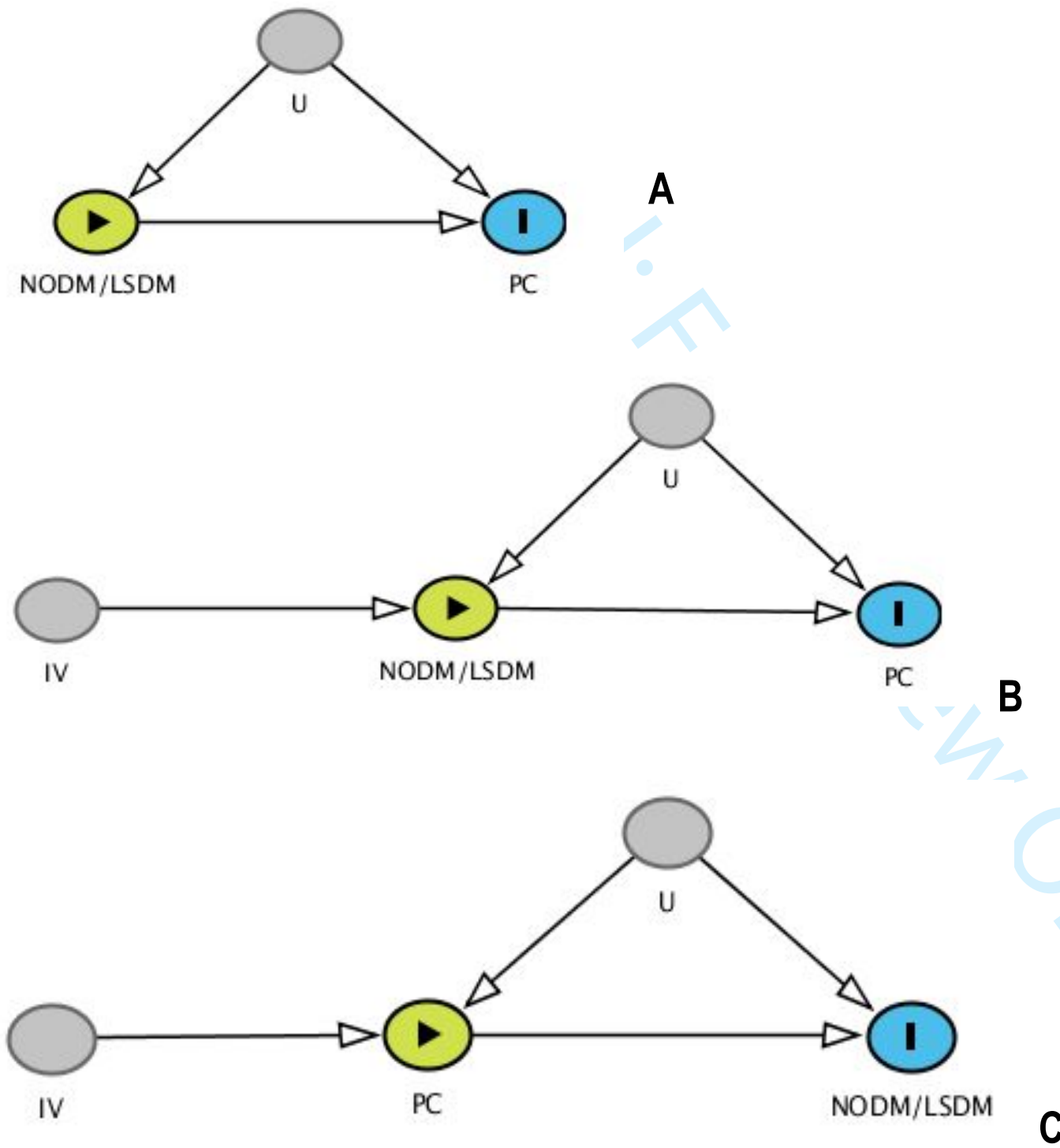

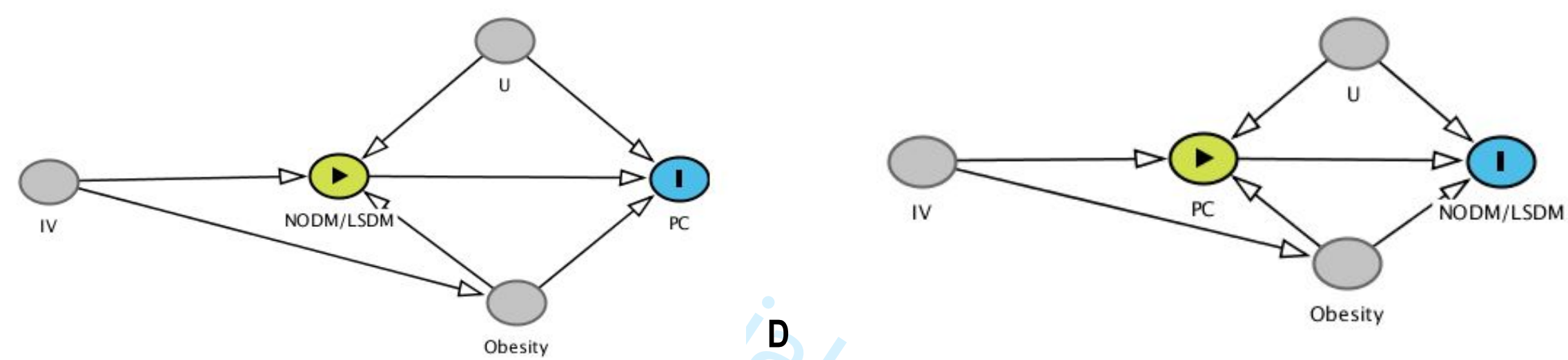

D

E
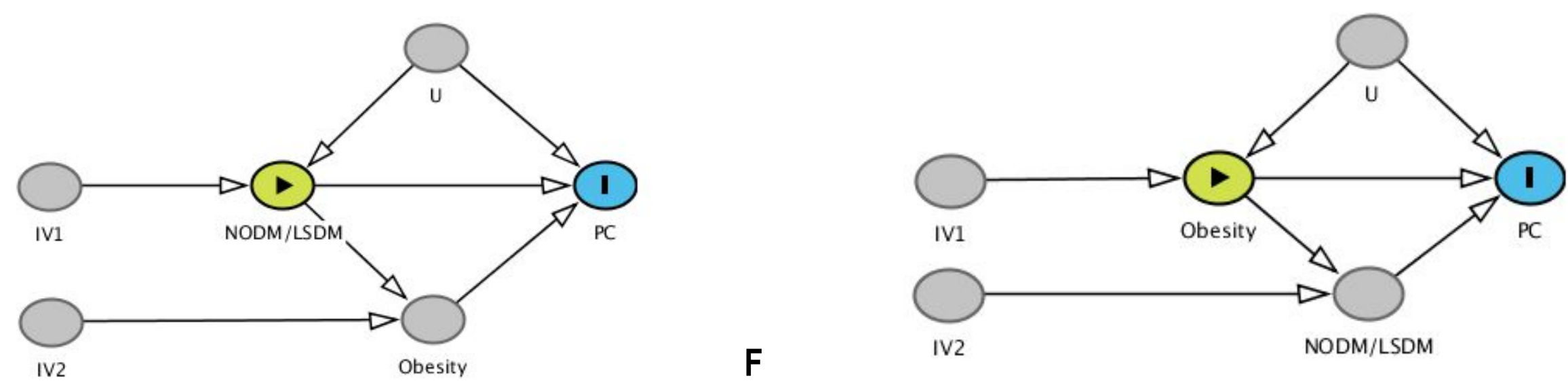

$\mathbf{F}$ 
Supplemental Figure 2: Linear and Non-linear association between T2DM-related continuous variables and pancreatic cancer risk, with non-diabetics as a reference group: (A) time since T2DM diagnosis; (B) age at T2DM diagnosis; (C) Hb1Ac levels and (D) C-Peptide levels with the minimum value (Hb1 Ac=4; C-Peptide=0.05) as the reference group.

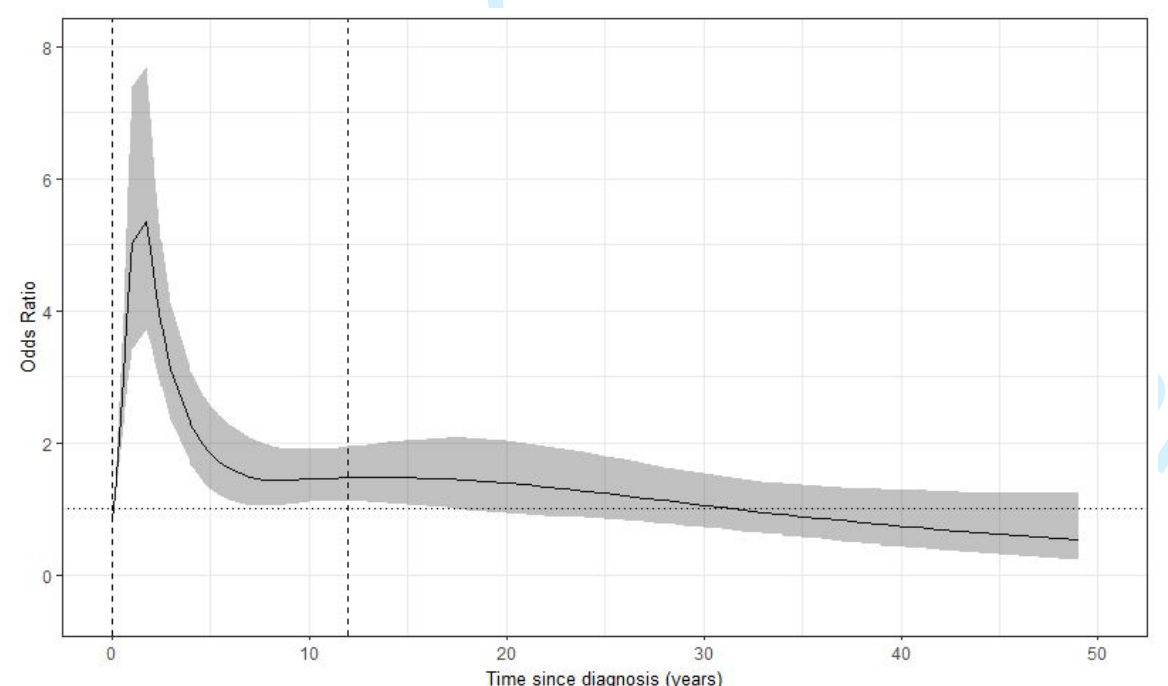

A

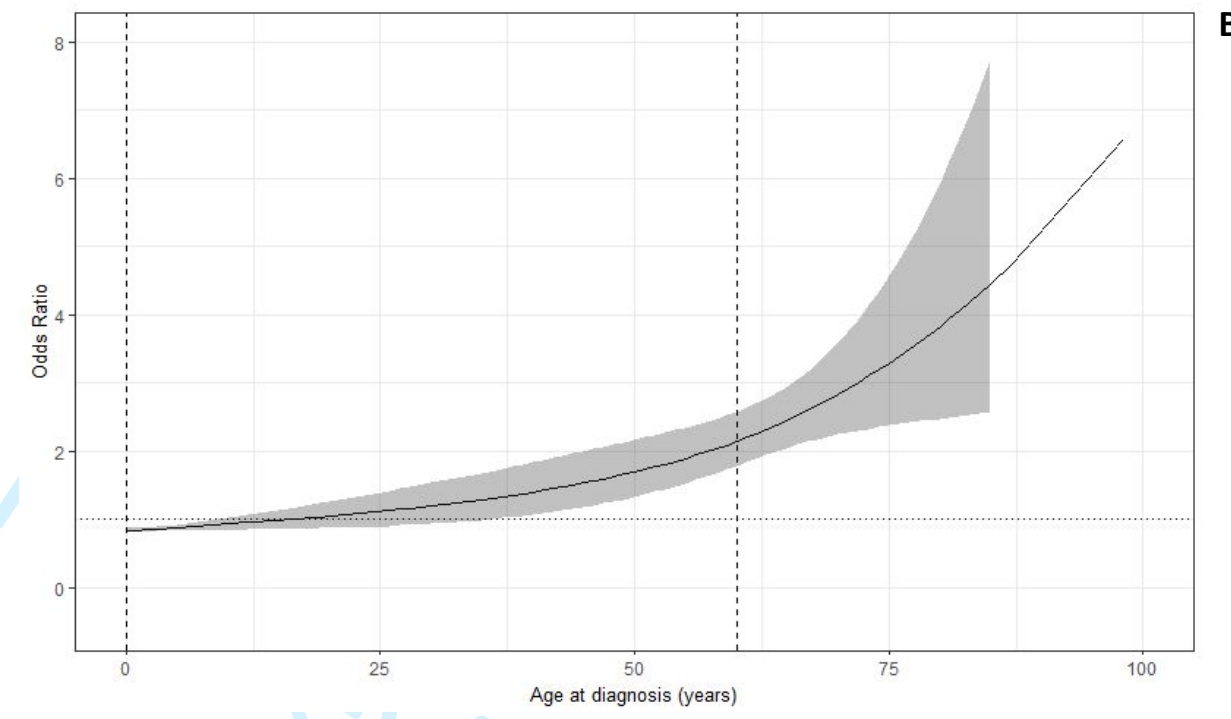

C

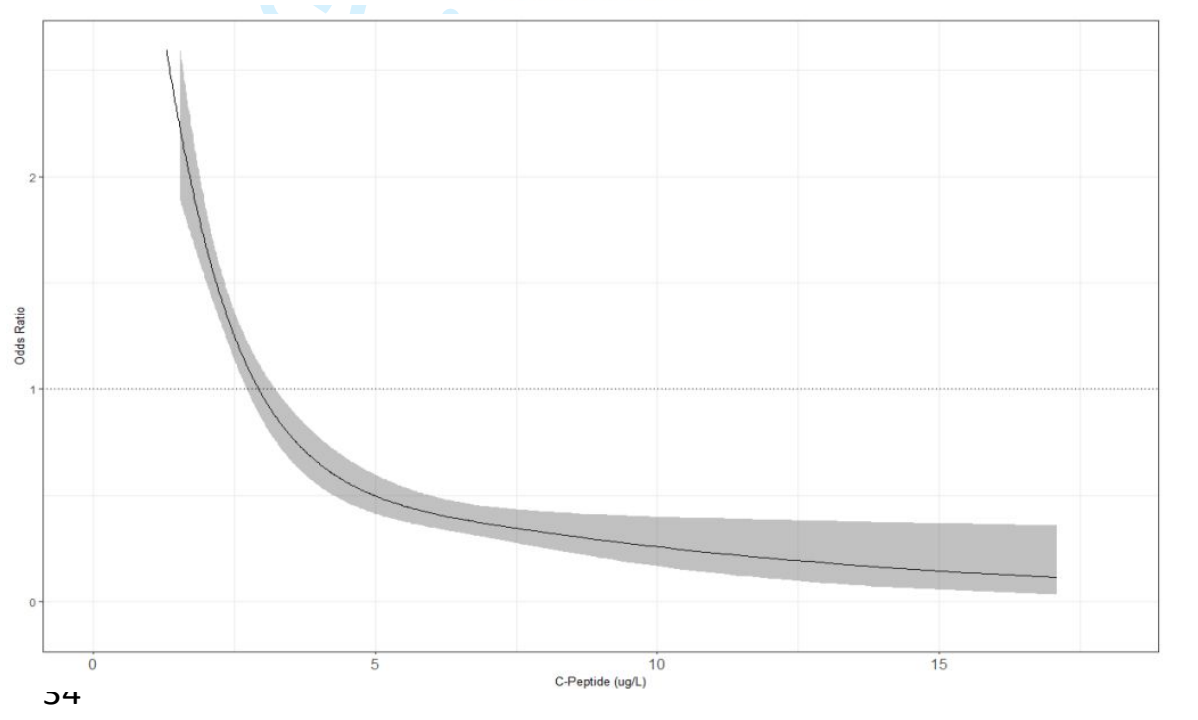

B

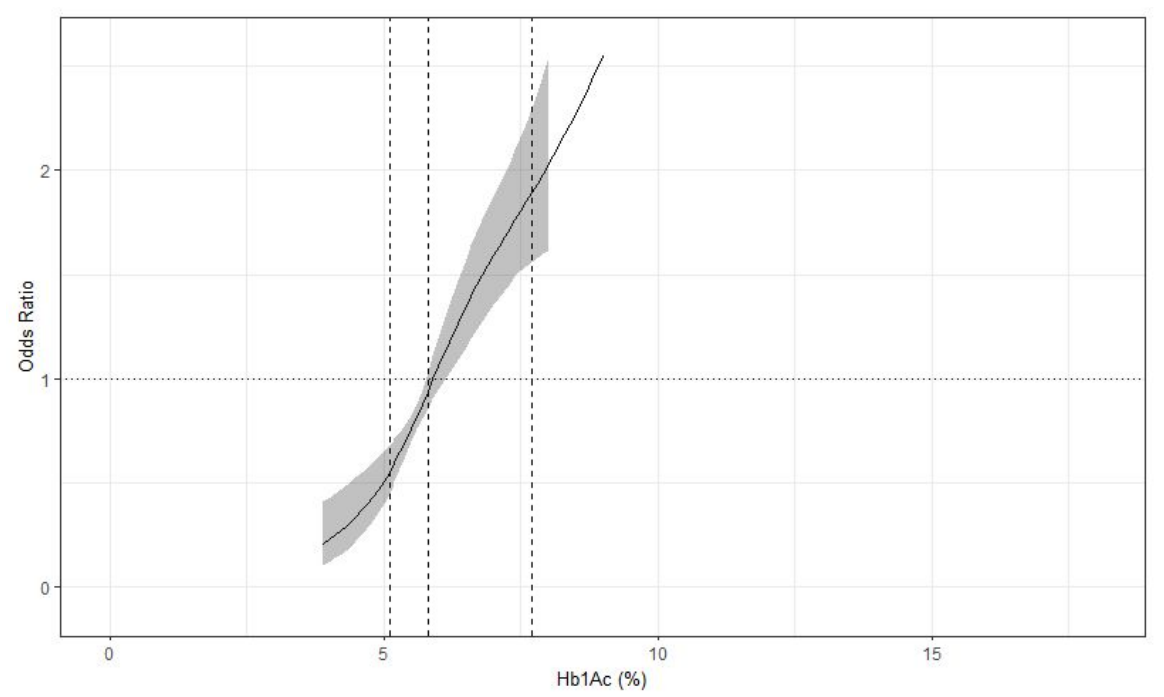

https://mc.manuscriptcentral.com/gut 
Supplemental Figure 3: Pleiotropy visualization plots regarding the directional association between PC and NODM risk.

A: funnel plot for IV made up of SNPs without SNPs in LD and SNPs associated with obesity and smoking. B: funnel plot for IV excluding further SNPs that were outliers (based on Cooks distances). Y-axes represent SNP to outcome effect corrected by SNP to exposure standard error of the effect. X-axes (SNP to exposure effect) are in logarithmic scale. C: Correlation plot of per-allele associations (genetic score of the IV) with the outcome and exposure. D: Forest plot of per-allele MR effect size for exposure on outcome and E: leave-one-out analyses.

A

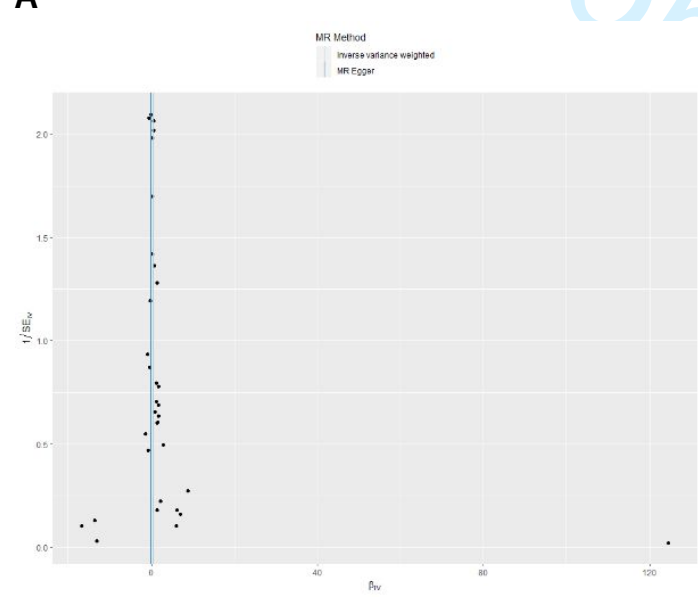

D

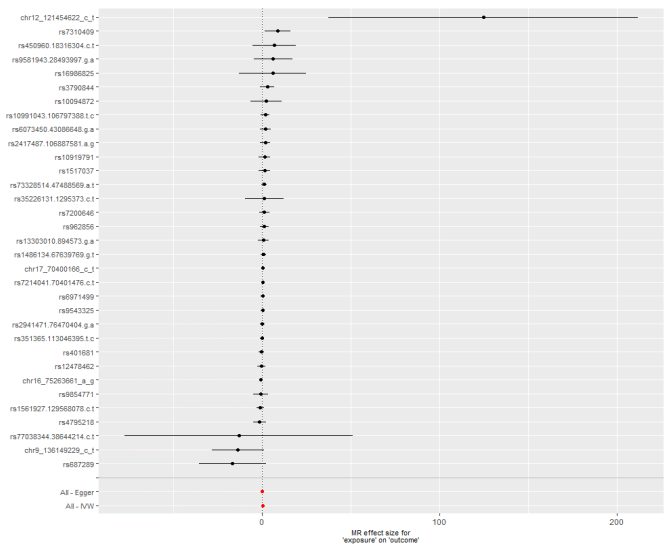

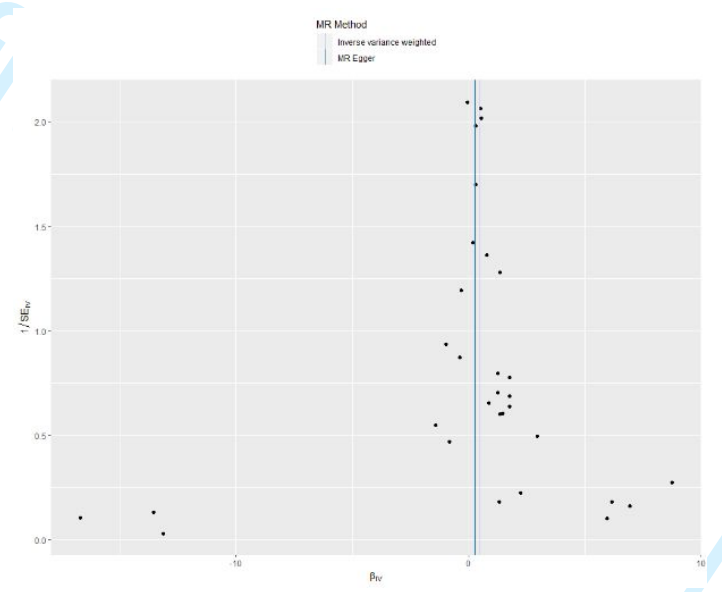

$E$

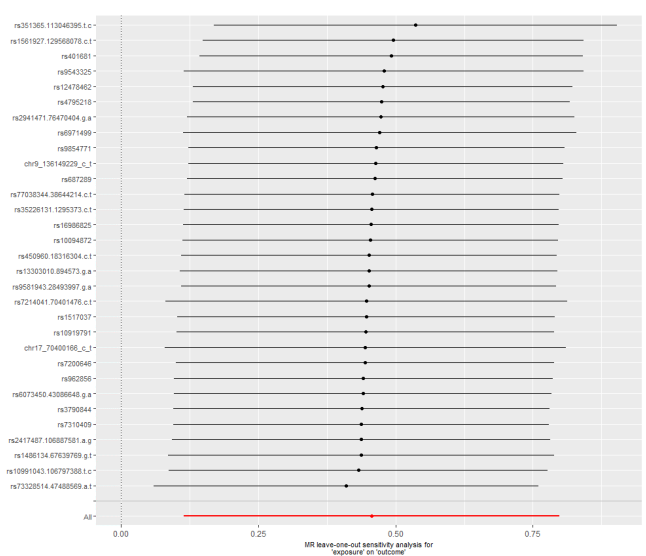

C

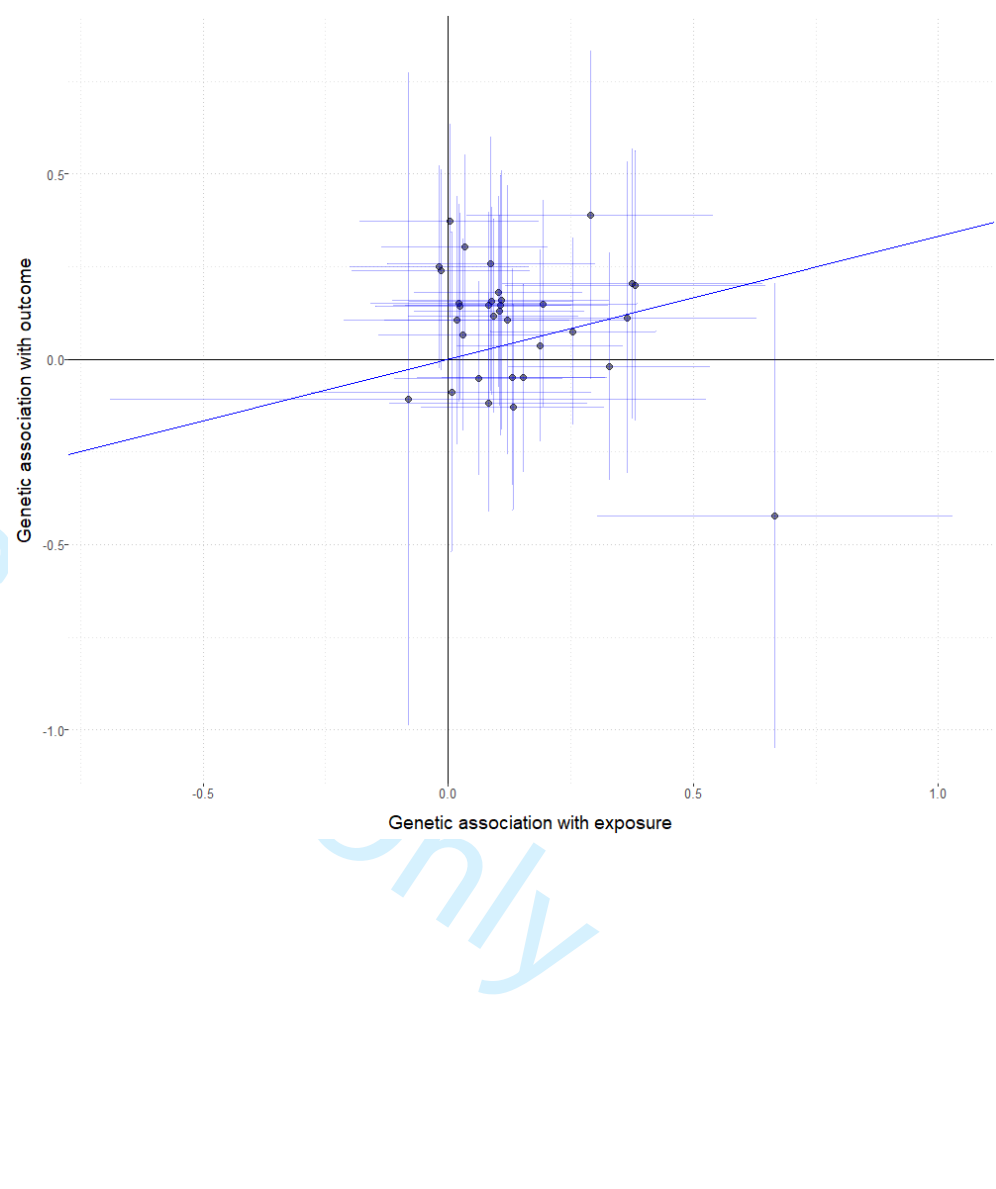

